University of Rhode Island

DigitalCommons@URI

Open Access Dissertations

1980

\title{
The Effects of Hue and Lightness Upon Color Preference and Their Relationship to Five Manifest Needs
}

Elaine Puntch Gelineau

University of Rhode Island

Follow this and additional works at: https://digitalcommons.uri.edu/oa_diss

\section{Recommended Citation}

Gelineau, Elaine Puntch, "The Effects of Hue and Lightness Upon Color Preference and Their Relationship to Five Manifest Needs" (1980). Open Access Dissertations. Paper 1118.

https://digitalcommons.uri.edu/oa_diss/1118

This Dissertation is brought to you for free and open access by DigitalCommons@URI. It has been accepted for inclusion in Open Access Dissertations by an authorized administrator of DigitalCommons@URI. For more information, please contact digitalcommons-group@uri.edu. 
THE EFFECTS OF HUE AND LIGHTNESS

UPON COLOR PREFERENCE

AND THEIR RELATIONSHIP TO FIVE MANIFEST NEEDS

BY

ELAINE PUNTCH GELINEAU

\begin{abstract}
A DISSERTATION SUBMITTED IN
PARTIAL FULFILLMENT OF THE

REQUIREMENTS FOR THE DEGREE OF

DOCTOR OF PHILOSOPHY
\end{abstract}

IN

PSYCHOLOGY

UNIVERSITY OF RHODE ISLAND

1980 
Abstract

A three-part investigation was conducted in an effort to begin to understand the psychological meaning of color preference behavior. Phase 1 used a Q-sort technique to assess intraindividual stability of preference judgments over a five-week interval. Phase 2 used principal components analysis to discern the manner in which preference judgments were being made. Phase 3 used canonical correlation analysis to evaluate a hypothesized relationship between color preference and personality; with five scales from the Personality Research Form, purported to measure manifest needs, serving as the criterion measure. Munsell standard papers, a standard light source, and a screening test for color vision dysfunction were among important control devices used. Results suggested that there were vast differences among the 90 subjects comprising the final sample group, with respect to stability of color preferences within persons. Sex differences in intraindividual stability were also apparent. A hue and lightness interaction appeared to underlie such judgments when saturation was kept constant. An unexpected breakdown in control pointed toward the possibly powerful effect of surface finish upon color preference. No relationship to manifest needs was found. It was concluded that the beginning steps had been taken toward psychometric development of a reliable instrument for the measurement of color preference behavior. 
Acknowledgmen ts

It hardly seems sufficient to formally acknowledge the extensive support afforded me in this, my first major research effort. The vast amount of energy expended on my behalf, in theoretical discussion, technical assistance, and personal encouragement, is greatly appreciated.

I am particularly grateful to my major professor and beloved mentor, Peter Merenda, whose belief in my capabilities made graduate professional education a reality. Your extensive knowledge, scholarly activity, and personal integrity have been an inspiration to me. In providing an exceptionally high standard for excellence, you have drawn from me a deep committment to seeking truth through self-discipline.

I wish to thank the other members of my committee, as well:

Shashanka Mitra, Charles Collyer, Allan Berman, and Wayne Velicer; for your many hours of consultation have provided me with what I believe has been the best possible guidance and direction. You have challenged my thinking, offered your resources, struggled with me through the difficult moments, and have given me the confidence to explore my own ideas.

A very special thank you is extended to Edward Carney, who patiently taught me to program; to Timothy Tierney, who assisted me in putting together the slide presentation; to Roger Greenwald, who helped me to plot the color vision testing results; to Tom Comisky, who provided the setting for my hypotheses to develop; and to my dear friend, Anthony Testa, who not only helped me to edit, but who many times over tested my reality. 
To my close friends, Carolyn and Myra, and to Peter, I thank you dearly. You have each contributed in your own thoughtful way to the successful completion of this work.

Of course, to the people I am most grateful to, my family, I want you to know that I appreciate your patience, your understanding, and your willingness to obsess with me the problem of color. To Toni, who assisted me in over 100 hours of testing; to Mother, who supported me as only a mother could; to Lisa, who unselfishly allowed her mother the luxury to work; and to Bob, who truly sacrificed a wife for science, how can I ever credit your love. 
Preface

The present investigation has been undertaken in an effort to explore the psychological meaning of color preference and its relationship to personality. It was intuitively held that an individual's tendency or predisposition to evaluate a particular color in a positive or negative way (a conceptual definition of attitude toward color) was reflective of the qualities that distinguish the individual as a person; hence, has psychological meaning.

Attitude research, such as color preference, can be approached from several different directions. A cognitive approach, for example, might consist of measuring an individual's thoughts or ideas about color. (One may have a positive attitude toward the color red, in that one may believe that red is alive, warm, or inviting.) A second approach might consist of measuring an individual's emotional response to color. (Red may be associated with bodily arousal which one may label as good or bad, pleasant or unpleasant.) However, a third approach might consist of measuring an individual's tendency to avoid or to approach a color, to behave in a particular manner toward it. (One may choose to select or not select red, for example.)

An operational definition of color preference (contrasted to a purely conceptual one) has been emphasized in this investigation, one which uses a behavioral approach to the measurement of attitude toward color. Although the conceptual definition has formed the basis for 
nearly all of the previous work in the area, it is held that selectivity for color (an active behavior) may be ultimately more productive in the assessment of psychological meaning than traditional conceptual approaches. The methodology that was chosen, as a consequence, reflects such thinking.

The work reported has been organized such that the reader with little knowledge of color, as a scientifically researchable problem, should quickly gain insight into the many difficulties inherent in its study. After a brief introduction, several chapters have been devoted to theoretical and technical aspects of the problem of color, segments which the more knowledgable reader may wish to quickly review. Attention, however, is drawn to Chapter III, where the color preference literature has been summarized. The research hypotheses are specifically stated in Chapter $V$, with subsequent chapters devoted to methodology, findings, discussion, and implications. Attention might also be drawn to several subsections of Chapter II (beginning with the subtopic, A Visual Communication System), for its contents include original theorizing by this author about how visual information might possibly be communicated and experienced by the viewer. 
TABLE OF CONTENTS

PAGE

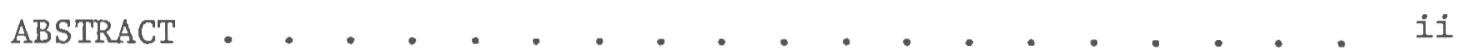

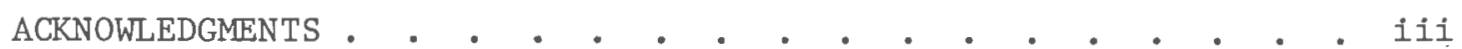

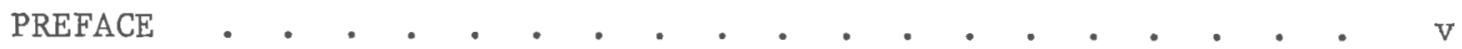

LIST OF TABLES • • • • • • • • • • • • • • • • • • • ix

LIST OF FIGURES • • • • • • • • • • • • • • • • • • • •

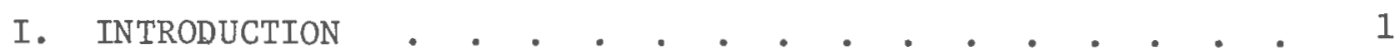

II. THE "SCIENTIFIC" INVESTIGATION OF COLOR . • • • • • . 5

The Color Problem. . . . . . . . . . . . 5

Classical Color Vision Theories . . . . . . . . . 9

Recent Developments • • • • • • • • • • • • • 19

A Visual Communication System • . . • . . . . . . 24

Characteristics of Laser Systems . . . • • • . . 27

Evidence for a Biological Laser System . . . . . . . 34

Color Vision Deficiencies . . . . . . . . . . 40

Tests for Color Blindness . . . . . . . . . . . 49

Color Theory and Measurement . . . . . . . . 53

Illumination. . . . . . . . . . . . . . 61

III. COLOR RESPONSE RESEARCH--COLOR PREFERENCE • • • • . 68

The Methods of Research . . . . . . . . . 68

Reliability--The Key Issue • . . . . . . . 76

Color Preference Reliability Studies-Within Individuals • 79 


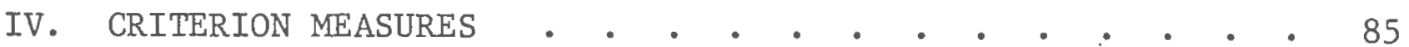

Murray's Need Theory . . . . . . . . . . . 86

Psychological Tests Based Upon Murray's Formulations • 88

V. THE RESEARCH PROBLEM • . . . • . . • . . . . 97

VI. METHODOLOGY • • . • • • . • • • • . . • . . 100

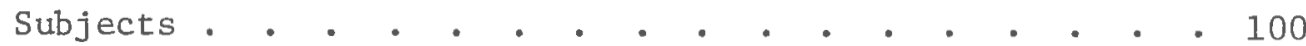

Instruments and Procedure . . . . . . . . . . 101

Experimental Conditions . • . . . . . . . . . 104

Data Processing • • . • . . . . . . . . 104

VII. RESULTS AND DISCUSSION • • • • • • • • • • • 105

Color Vision Screening . . . . . . . . . . . . 105

Phase 1. Reliability Study . . . . . . . . . . 106

Phase 2. Structural Component Study . • . . . . . 116

Phase 3. Validity Study . . . . . . . • . . 119

Additional Findings . . . . . . . . . . . . 124

VIII. SUMMARY, CONCLUSIONS, AND THEORETICAL IMPLICATIONS • • 126 APPENDIX • • • • • • • • • • • • • • • • • • •

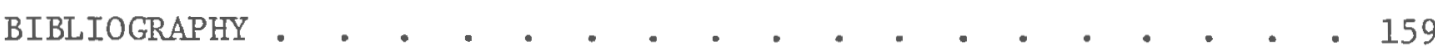




\section{LIST OF TABLES}

TABLE

PAGE

1. Percentage Frequency of Occurrence of Color Vision Defects - 42

2. Color Vision Classification and Description . . . . . 44

3. Synthesis of Color Vision Dysfunction with Hypothesized

Theoretical Explanations . . . . . . . . . . 50

4. Affective Meaning Found To Be Ascribed to Various Colors . 73

5. Murray's List of Needs . . . . . . . . . . . . 89

6. Murray's. List of Press . . . . . . . . . . . 9 92

7. Internal Consistency Analysis, First Administration of The Color Preference Test . . . . . . . . . . . . 111

8. Internal Consistency Analysis, Second Administration of The Color Preference Test . . . . . . . . . . . . . 112

9. Test-Retest Reliabilities, Subscale Scores, The Color Preference Test . . . . . . . . . . . . . . . 113

10. Test-Retest Reliabilities of The Color Preference Test Profiles, Based Upon a Time Interval of Five Weeks . . . 114

11. Pattern Analysis of Test and Retest Administration of The Color Preference Test . . . . . . . . . . . . 115

12. Principal Component Analysis, Two Administrations of The Color Preference Test . . . . . . . . . . . . . 120

13. Canonical Correlation Analysis, Ten Scales of the Color Preference Test and Five Scales of the Personality Research Form, First Administration . . . . . . . . . . . 121

14. Canonical Correlation Analysis, Ten Scales of the Color Preference Test and Five Scales of the Personality Research Form, Second Administration . . . . . . . . . . . 122 
LIST OF FIGURES

FIGURE

PAGE

1. The Problem of Color . . . . . . . . . . . . 6

2. The Original Color Circle . . . . . . . . . . . 11

3. Electromagnetic Structure of Light Waves . . . . . . . 13

4. Electromagnetic Vibrations . . . . . . . . . . . 14

5. The Young-Helmholtz Theory . . . . . . . . . . 15

6. Psychology's Primary Colors . . . • . . . . . . . 16

7. The Hering Theory . . . . . . . . . . . . . 18

8. The Ladd-Franklin Theory . . . . . . . . . . . 20

9. The Land Theory . . . . • • . • . . . . . 21

10. A Hologram • • • • • . • • • • • • • • . • 25

11. A Laser • • • • • • • • • • • • • • • • • 28

12. Optical Fibers • • • • • • • • • • . • • • 31

13. A Semiconductor-Diode Laser . • . . • . . . . . 32

14. A Tunable Laser • . • . . • • . . . • • . 33

15. An Optical Communications System . . . . • • • • • 35

16. The Scallop Eye . • . . . . . . . . . . . 37

17. Propagation of Light Waves in Mirrored Layers . . • . 38

18. The CIE System • • • • • • • • • • • • • • 55

19. Spectral Color Sequence Curve . . . . . . . . . . 56

20. The Munsell System . . . . . . . . . . . . 58

21. Spectra1 Emission Curves . • • • . • . . . . . 60 
22. Color Temperature • • • • • • • . • • • • . 62

23. Effect of Illumination on Perceived Color . . . . . . 63

24. Spectral Power Distributions of CIE Illuminants A, B, and C . 66 25. Color Pyramid Test Stimuli . . . . . . . . . . . 77

26. Q-Sort Procedure and Forced Distribution to the Normal Curve. 103 27. Frequency Distribution of Q . • • • • • . • . . 107 


\section{INTRODUCTION}

The notion that mood, affect, personality, and color are associated is a seductive one. In 1935 Hevner reported that his subjects described various colors in different terms; for example, red as happy and blue as serene and dignified. Lewinski (1938) changed the lighting in a room and found that college students described the effects of red and yellow as "most unpleasant" and green and blue as "most pleasant."

Eysneck (1941a; 1941b) found the preferences for modern paintings with bright colors correlated with extraversion, while older paintings with subdued colors were more preferred by introverts. Likewise, Barrett and Eaton (1947) found that preference for bright and pure colors was associated with introversion.

Goldstein (1942) reported a number of clinical findings concerning differential color effects. In general, he found that red was described as disagreeable, exciting, upsetting, and imposing; green as agreeable and quieting. Red and yellow had an "expansive effect upon the organism, increasing the effect of the external world, while blue and green had a decreasing effect."

Color and Affect. There is an accepted practice in the use of the Rorschach to interpret a subject's response to color as reflective of that person's emotional life. Rorschach writes, "The symptom value of color interpretation lies in the field of affectivity" (1942). The impact of these words upon interpretation of responses to the Rorschach 
can be affirmed by the fact that every systemizer of the technique has accepted this interpretation of color response in an affective manner (Frank, 1976).

On the other hand, Keehn (1945) is skeptical and writes, "... inasmuch as the Rorschach color responses are at best only indirectly affected by color, the use of the results of Rorschach studies either to support or to refute the color-emotionality hypothesis is invalid."

That no particular color on the Rorschach is consistently associated with any particular emotion (Frank, 1976), and response to color is found to be affected by hue (Cook, 1967; Hill, 1966); saturation (Dubrovner et. al., 1950); and area of visual field encompassed by color (Frank, 1976), the appropriateness of the Rorschach as the dependent measure can be seriously questioned. As Frank has concluded in his exhaustive review of the color literature, "...responses to the Rorschach plates seem to be as much, if not more, a function of the configuration of the blots, as of the color." It is not surprising, therefore, that Levy (1950) and Goodman (1950) failed to observe unique or systematic activity in galvanic skin responses when subjects were given the opportunity to view the Rorschach cards.

Several recent studies, however, have reported differential color effects, using various physiological indices (respiration rate, systolic blood pressure, heart rate, EEG measures, etc.) when pure color is presented, lending substantial support to the color-affect hypothesis (Wilson, 1966; Gerard, 1968; Jacobs \& Hustmyer, 1974). In addition, Jacobs and Suess (1975) have extended the evidence by including a psychological measure of anxiety--the state scale of the State-Trait 
Anxiety Inventory (Spielberger et al., 1970), for it was observed that various colors differentially affected scores on this test.

Color and Personality. Meanwhile, with respect to the more stable attributes of the person (the color and personality hypothesis), the waters of knowledge appear to be much more muddied; for reliability of color attitude within subjects has not been paid much attention to by researchers, as noted by Sivik (1974). Frank (1976) concludes that there appear to be strong preferences for specific colors among groups of subjects, and that these preferences appear to hold up crossculturally, but he fails to address adequately the notion that these preferences within individuals may not be particularly stable over time.

Color Attitude Research. Unfortunately, nearly all of the research concerning attitude or response to color (i.e., color and affect, color and personality) can be criticized on several additional grounds.

1. The colors used as stimuli have not always been clearly specified, making it difficult to compare results across studies.

2. Since hue has often been the only variable of interest, controls for saturation and/or lightness have of ten been completely neglected. (The asymetrical shape of the color space does not easily lend itself to control; for saturation is maximal only at moderate Iightness levels.)

3. Tests for color preference have been constructed such that they appear to be more concerned with a subject's attention to color, as opposed to selectivity for specific colors (Gotz \& Gotz, 1975).

4. A standard light source frequently has not been used.

5. Few studies have screened for possible color vision dysfunction. 
6. Very few studies have attempted to relate findings to a general model for color vision, or to some underlying model of behavior.

7. Criterion measures have not met established standards for "professionally developed psychological tests" (American Psychological Association, 1974), particularly with respect to reliability of measurement.

It is with these criticisms in mind, therefore, that the present research has been designed and undertaken. Results, although not final and conclusive, reflect a thorough and systematic effort to improve upon prior work in the area. Its findings contribute substantially to the wide body of knowledge that has captured the interest of countless numbers of researchers, and carries forth important implications for future work.

In short, the investigation has been undertaken in several phases in an effort to begin to uncover the psychological meaning of color preference, as it relates to an important dimension of personality-manifest needs (Murray, 1938). Its final emphasis is on how two psychological aspects of color perception (hue and lightness) relate to needs for achievement, order, harm avoidance, social recognition, and exhibition.

The first phase of the work was conducted for the purpose of determining whether color preference behavior is stable, within persons. The second phase was directed toward describing the underlying structural components of color preference, results of which were used to build a scoring key for a new instrument that was designed to measure color preference. The third phase was primarily aimed at assessing a general relationship between color preference and personality. 


\section{THE "SCIENTIFIC" INVESTIGATION OF COLOR}

The Color Problem

Color, as a research problem, can be looked at from various points of view. It has become apparent that a major reason why the "psychological" meaning of color is not fully understood today is because research into the psychology of color is so intimately tied to technological development in various other fields. Time, or the historical development of knowledge within each of the disciplines concerned with the problem of color, brings into focus the need for integration of knowledge. Clearly this has not been achieved for the color problem. Communication has been hampered by vast differences in the "language of color," making it difficult to share information and gain a unified understanding of the processes involved.

Kuppers (1973) sets up a mental scheme for understanding the color problem, and as a demonstration model, his is perhaps the most fitting to begin a discussion on the "scientific" pursuit (see Figure 1).

Kupper's consideration of "the problem of color" might begin with nuclear physics, the source of our understanding of all material phenomena. It is in this field that the basic structure of matter has been explored, revealing no differences between matter and energy. Here, too, the existence of light quanta (photons, the basic unit of light energy) and their motion are discussed. The neighbor to the right of nuclear physics, classical physics, has provided information on the spread of 
The Problem of Color

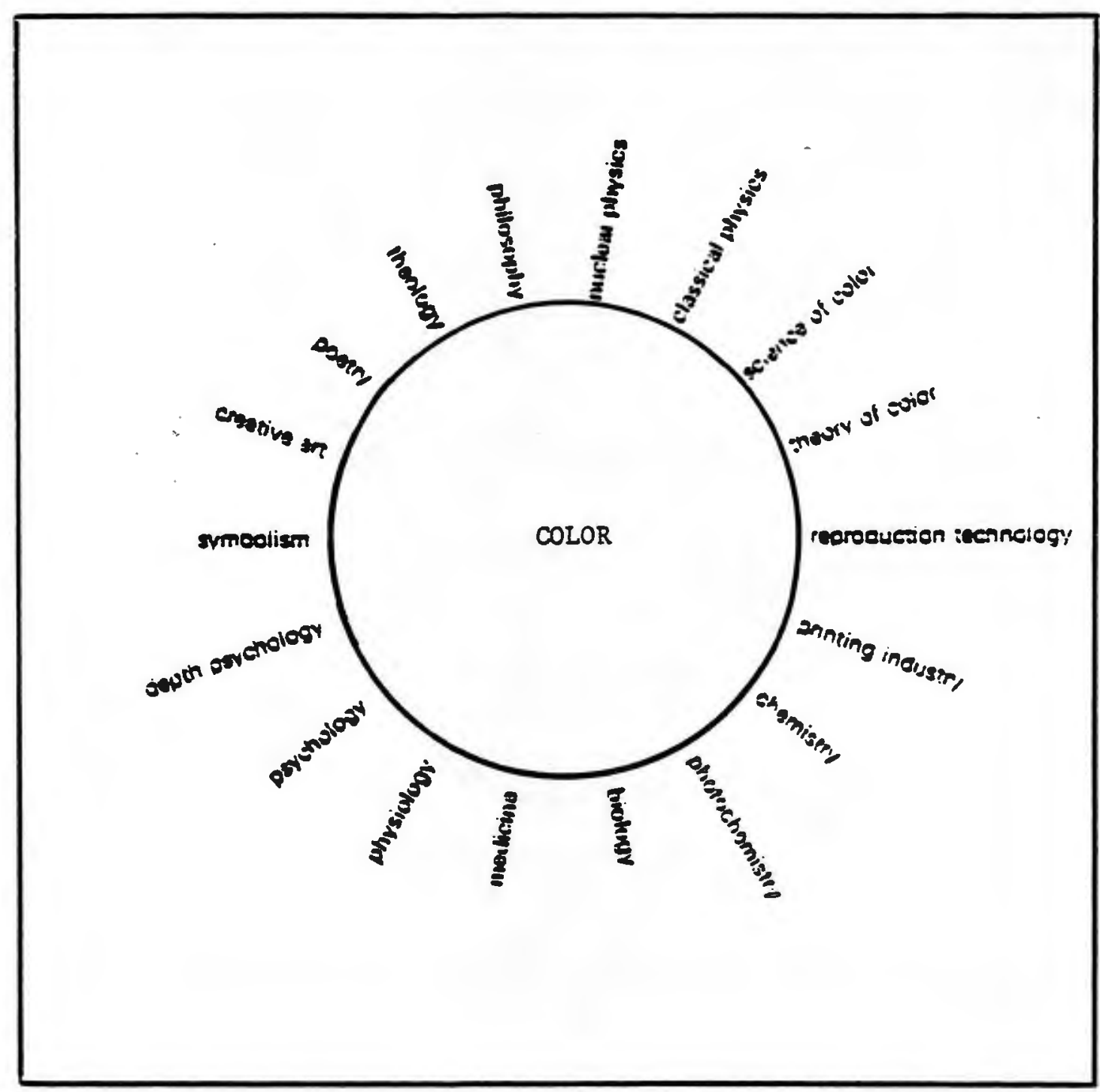

718. 1. The problem of color may be Flewed from the ridely difierent perspectives of the varlous disciplines concerned with the significance of color. (Adap ted from Ruppers, 1973) 
light into spectra, and has taught us that all visible colors are hidden in white light. The theory of color field has concerned itself with the relations existing among the various colors, and has discovered the rules governing them; for example, it has indicated the results to be expected when colored lights or pigments are mixed in certain proportions. From these additive and subtractive rules, investigators in the applied science of color have demonstrated the great variety of color phenomena of interest to the textile dye industry, for color photography, and for color television, for example; by providing the formulae upon which prototypes were first manufactured.

Setting the stage for the most varied of printing techniques available today has been reproduction technology. The reproduction process analyzes the components of a mixture representing every single hue of an original, and the printing industry makes possible the industrial production of any required quantity of prints.

Colors, which in the present context refer to dyes, pigments, and paste paints, are mainly chemically manufactured. The chemical industry provides the pigments that make the printing inks, varnish, and oil paints appear colored. Needless to say, chemistry and photochemistry are closely related, as well. The control of extremely complex reactions in photochemistry has made color photography possible, for color film consists of three layers of chemicals, each sensitive to different regions of the spectrum.

Organic chemistry constitutes the transition to biology, the science which deals with the origin, life history, and physical characteristics of organisms. Color has been identified as an important 
factor in the mating, protecting, and surviving behavior of animals. Light and heat affect the color of fruits, leaves, and man; while light enables the process of photosynthesis to take place. And since there is only a short step from biology to medicine, color is used as an aid in the diagnosis of disease. Bacteria can be made visible by staining specimens in which they are suspected, and pathology can often be detected by examination of tissue color changes. Physiology is likewise linked to color; for biological functions have been mapped through use of colored dyes, with studies being made of the paths taken by these dyes. In addition, physiologists have concerned themselves with the subject of color perception, for color impressions come to us via the organ of the eye.

Concerned with the processes of the mind and behavior, psychology has been particularly interested in the emotional effects of color. The question of what colors are suitable for particular purposes is likewise a psychological one. The color of mass transport vehicles, light signals, and color codes in electrical cables, for example, are frequently chosen on the basis of psychological considerations.

In the field of depth psychology we see the merging of psychology and symbolism. The Color Pyramid Test (Heiss \& Hiltman, 1951; Schaie \& Heiss, 1964) has utilized the symbolic significance of color to suggest that bright colors are an expression of liveliness; while white is thought to represent the embodiment of purity, radiance, and virginity. In order to appeal to a person's subconscious (the central concern for depth psychology), creative art uses color to evoke certain emotions and intended reactions, often rooted in symbolism. 
Poetry is usually thought of as an art form employing the rhythm of language, but one is reminded of how difficult it must be to relate experiences of color in words. What poet has not sung the praises of a world full of colors, and where then is the dividing line between poetry and theology? The Book of Genesis describes God's first act as the creation of light; and perhaps philosophy can be considered the ultimate link between theology and nuclear physics. The philosopher searches for the interpretations of the physical, intellectual, and spiritual worlds; and in his striving for the "light of knowledge," the philosopher also explores for the meaning of our existence. Aristotle, the father of philosophy, was the first to suggest that we need light in order to experience color.

However, it should be emphasized that the "scientist" looks at color as a problem in a fashion quite differently than does the depth psychologist, artist, or philosopher. The vast majority of writings on the psychological meaning of color reflect unscientific efforts; and as such, do not deliberately set out to test specific hypotheses. From the "scientific" point of view, psychology typically has not availed itself of knowledge from the physical and biological sciences; hence, few studies have concerned themselves with issues of repeatability and mathematical color stimulus specification. Scientific psychology's consideration of the problem of color, in its quest for a reliably measurable relationship to behavior, has only recently become a "scientific" endeavor.

\section{Classical Color Vision Theories}

Ancient man conceived of color as a spiritual property, rather 
than as a physical property. Light, he believed, was the emanation of a great deity, falling from heaven and pervading all space. Since his were the believing eyes of the mystic, and not the questioning eyes of the scientist, it was naturally more important for him to ponder the spiritual significance and not to investigate its nature as energy (Birren, 1963).

Long before the scientific age, Aristotle made sweeping deductions as to the nature of color. He was the first to hypothesize that light is necessary for one to experience color. He was the first to suggest that objects appear colorful only because they differentially absorb and reflect light.

Two thousand years passed without significant addition to, or modification of, Aristotle's notion of color. Not until the 17 th century did Newton give evidence for the spectral composition of white light. Newton was also the first to describe the visual effects of mixing different hues, constructing the original color circle (see Figure 2). Speculating at that time that color represented a barrage of particles hitting the eye, Newton set the stage for today's view of the eye as a passive sensory organ; one which, in Newton's view, contained a nerve mechanism responsive to these particles.

These fundamental ideas persisted for over a century more until Thomas Young, one of the founders of physiological optics, developed the idea that color sensation is a complex response to different vibrations of light. Young spoke of waves (vs. particles) hitting the retina and postulated the existence of three types of color receptors to account for Newton's mathematical relationships. Today we know that light rays 


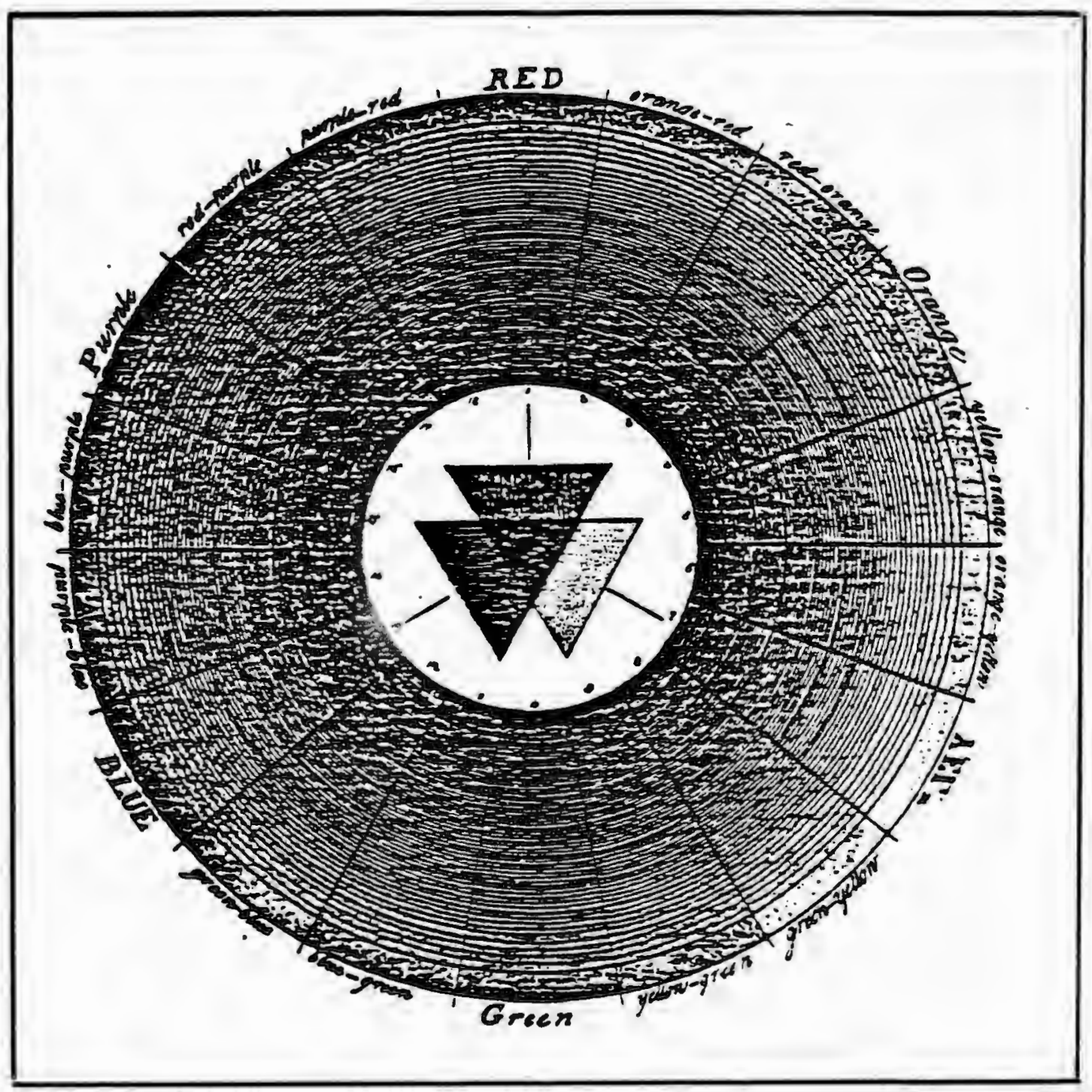

F18. 2. The color wheel represented an early attempt to 11lustrate relationships among visible colors. The three trlangles in the center suggest that all colors can be formed from red, blue, and yellow. (Adapted from Zentralbibliotek, Zurlch, appearing in Mueller and Rudolph, 1966) 
are a form of energy, comprised of minute particles called photons: and which belong to a large family of electromagnetic vibrations, differing in wavelength and intensity (see Figures 3 and 4). And since we recognize matter by its reflection of visible electromagnetic radiation into our eyes, multicolored appearance is the result of the physiological process of vision.

Still another fifty years passed before Hermann von Helmholtz gave a physiological basis to Young's three receptor theory. According to the Young-Helmholtz theory (see Figure 5) three types of color receptors in the retina absorb varying amounts of red, green, and blue wavelengths. These messages were thought to be relayed directly to the brain, where they were mixed to yield the different color sensations. Helmholtz is also credited with pointing out the difference between spectral mixtures and pigment mixtures, the foundations for what we know today as additive and subtractive properties of light and pigment (Kuppers, 1973: Optical Society of America, 1963: Birren, 1953).

The sensory aspect of color vision, however, embraces psychology as we11: for the human eye discerns not three, but four primary hues: red, green, blue, and yellow. Further, mixtures of these four primaries are medial, generally tending to work toward a neutral gray (see Figure 6). Science had been at a loss to explain this phenomenon with the fourth primary until a psychologist, Eward Hering, proposed his opponent-process theory of color vision in 1878 .

Like the Young-Helmholtz trichromatic receptor theory, Hering postulated three independent receptor types. His theory differed, however, in that the three classes of receptors were each assumed to be 
Electromagnetic Structure of Light Waves

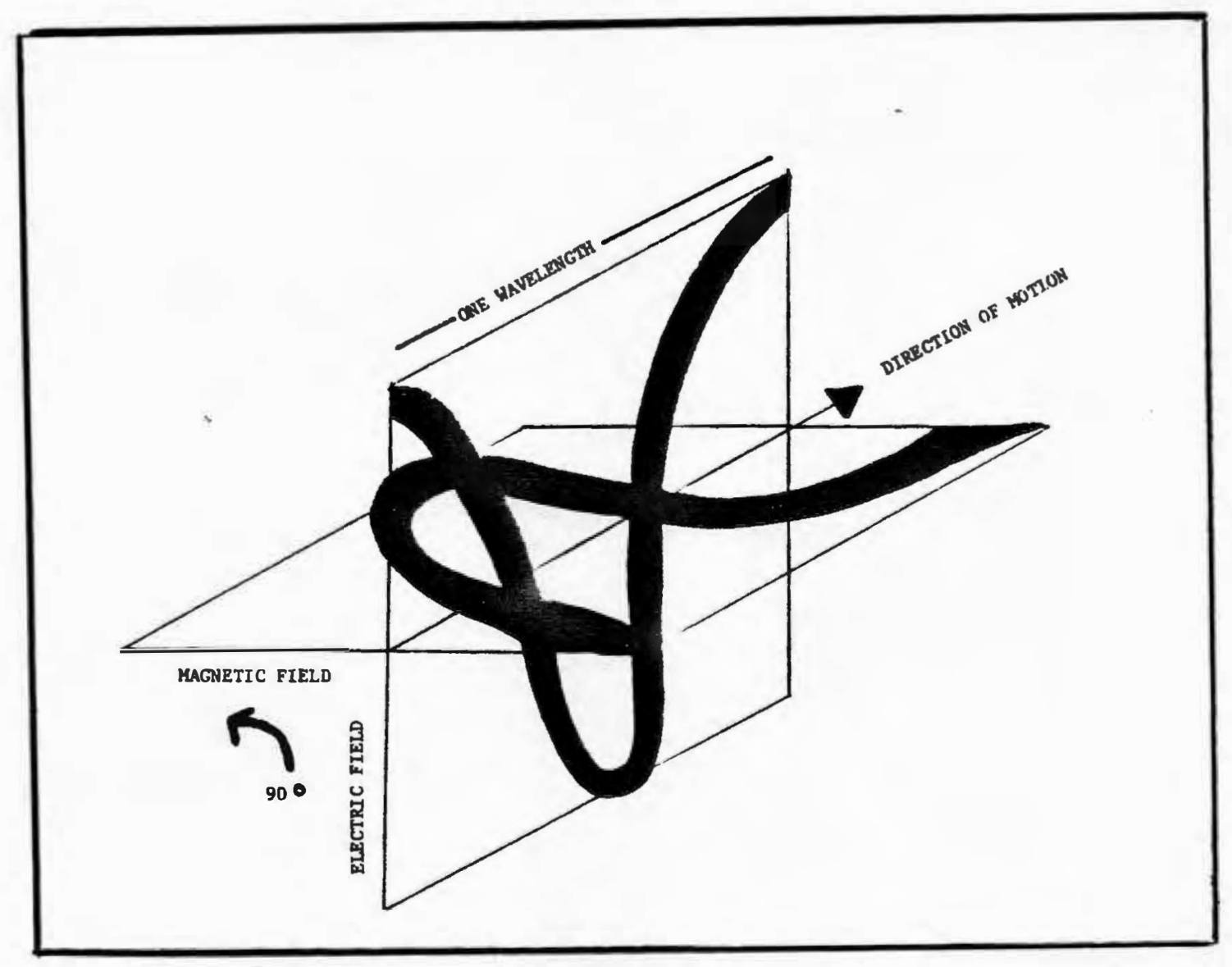

Fig. 3. Electric and magnetic fields are perpendicular to one another and to the direction of motion. (Adapted from Rainwater, 1971) 


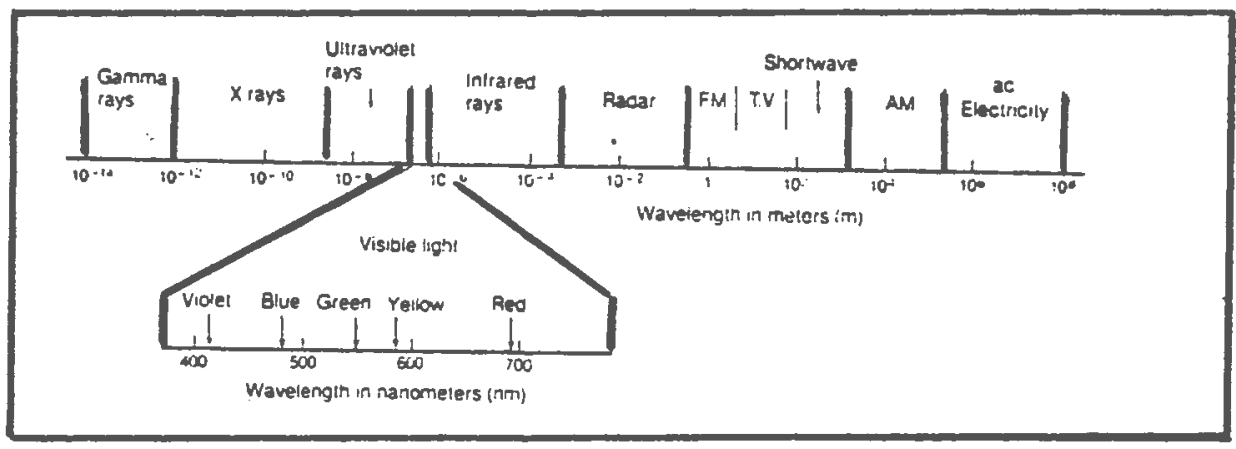

Fig. 4. That small portion of the spectrum that the human eye is sensitive to is shown expanded. Visible light is between 400 and 700 millimicrons (billionths of a meter) in wavelength. AM radio waves have a wavelength $10^{12}$ times greater, or about one meter. (Adapted from Lazerson, 1975) 
The Young-Helmholtz Theory

A Trichromatic Model

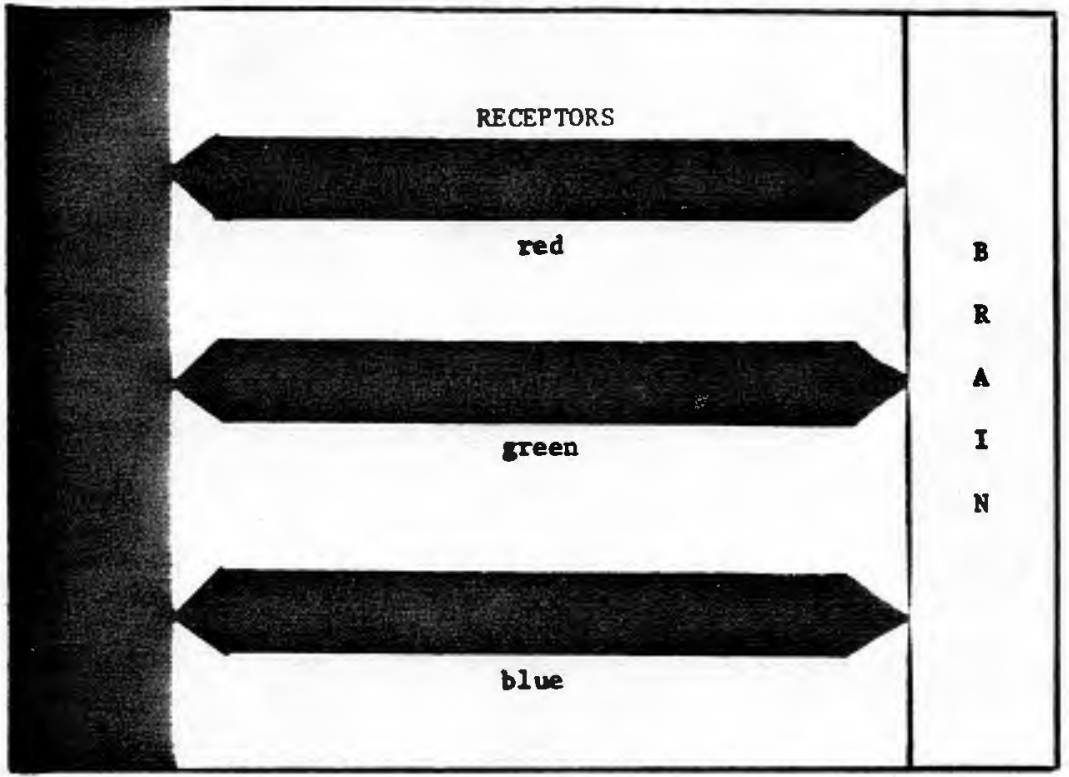

Fig. 5. According to the trichromatic model, there are three types of color receptors in the retina. Each absorbs varying amounts of red, green, and blue wavelengths, and relay respective signals to the brain, where they are mixed to yield the sensation of color. 
Psychology's Primary Colors

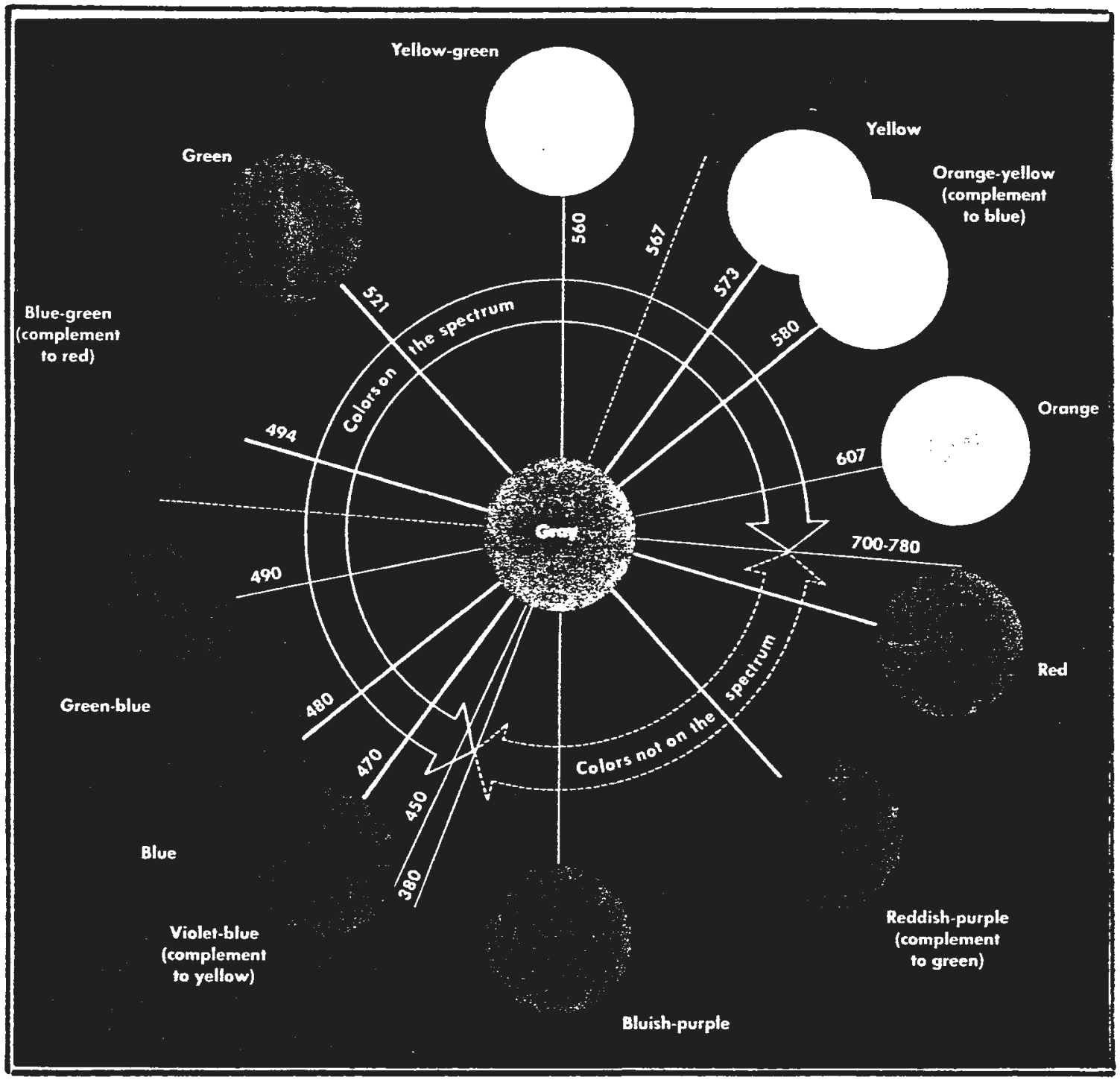

Fig. 6. The colors opposite one another $\mathrm{mix}$ to produce a neutral gray at the center. Note that the spectral colors 1ie in their natural order, but their spacing is not uniform by wavelength. (Hilgard, Atkinson, and Atkinson, 1975) 
composed of a pair of opponent color processes (or neural systems): one for blue-yellow, one for green-red, and one for black-white (see Figure 7). Further, each pair of unique sensory color receptors was thought to be associated with a corresponding pair of unique sensory qualities. Hering argued that all three types of color coders receive light from undiscriminating receptors.

For example, when orange is viewed, only the red portion of the green-red coder is stimulated. The green portion shuts down and does not send a signal to the brain. It follows that either red or green, and blue or yellow is experienced. If both members of the opponent-pair are equally stimulated, they cancel one another out and leave only gray. The Hering theory today falls short in the explanation of some types of color blindness, but has apparently explained complementaries and afterimages (Schiffman, 1976).

In an "evolutionary" theory for color vision, introduced by Christine Ladd-Franklin in 1929, the color sense is supposed to have begun with a light-sensitive substance, one which enabled the eye to distinguish light from dark. Next in evolution came a yellow-sensitive and blue-sensitive substance; and finally, the yellow component was believed to have further divided to permit the eye to see red and green (Franklin, 1929).

This somewhat composite theory, taking into account the red-greenblue primaries of the trichromatic receptor theory, as well as the redgreen-blue-yellow primaries of the opponent-process theory, has received some support among physiologists who have found evidence for chromatic zones in the retina. However, it too explains only some forms of color 
The Hering Theory

An Opponent Process Model

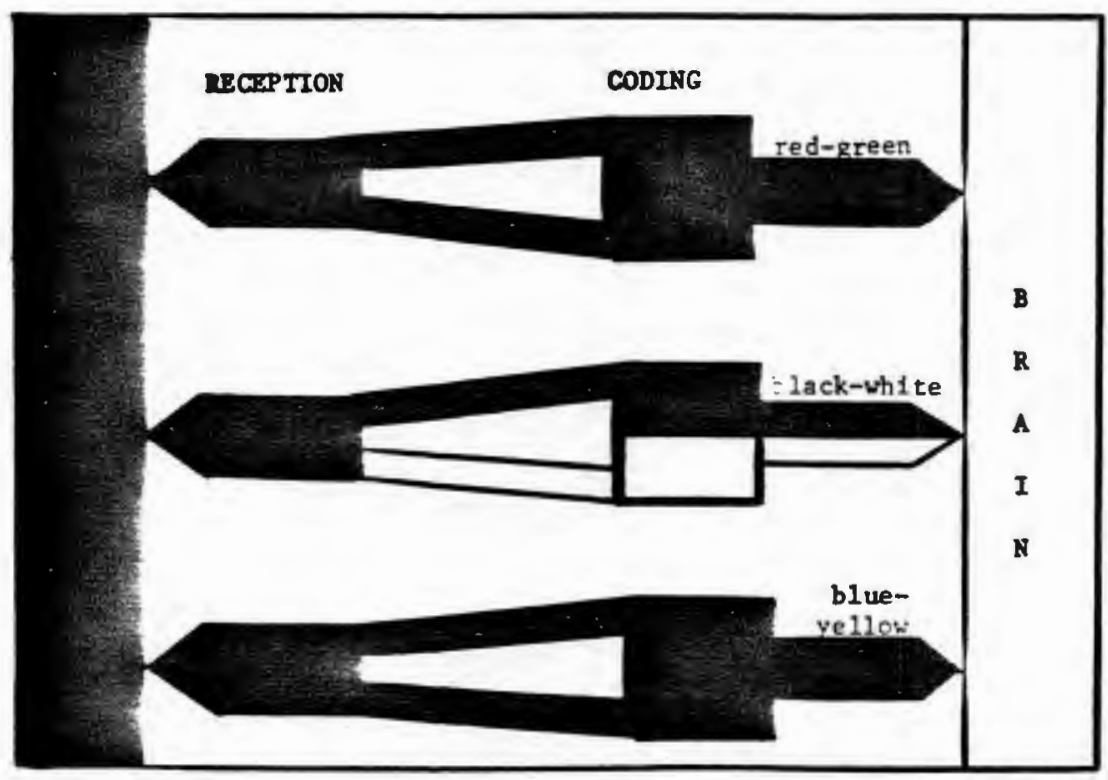

Fig. 7. Hering argued that all three types of color coders receive light from undiscriminating receptors. When orange light is viewed, for example, only the red portion of the red-green coder is active. The green portion remains off, and does not send a green signal to the brain. 
blindness, while additional assumptions about the evolutionary aspects of the theory have not held up. For example, evidence now suggests that for many forms of life lower on the phylogenetic scale than mammals, that cones do exist; according to the theory, these lower forms should be lacking them (Schiffman, 1976) (see Figure 8).

\section{Recent Developments}

Edwin Land, inventor of the Polaroid camera, has suggested a fourth major theory of color vision, a concept which he calls "The Retinex Theory" (Land, 1959; 1977). Focusing upon a retina-and-cortex system, Land sees color sensation as a "three-part code for lightness" entering the eye. This triplet of lightness information has been postulated to come from the simultaneous stimation of rods and cones, and remains independent of changes in illumination (see Figure 9).

Land was recently able to show (1977) that it is possible to stimulate only one cone system, together with the rod system, at light levels one-thousand times weaker than previously believed necessary to activate cone vision; and yet he was able to produce nearly the full range of color sensations at this very low level of illumination. This led him to conclude that lightness, a psychological function of surface reflectance, is the critical variable in the production of the infinite range of sensations we interpret as color. (Lightness is the psychophysical correlate to luminous efficiency.)

In other words, the three systems of cone cells (for red, green, and blue) are simultaneously being matched against reports from a hypersensitive rod system of cells for lightness; with the output of this combined information being relayed to the brain for further processing. 
The Ladd-Franklin Theory An Evolutionary Mode1

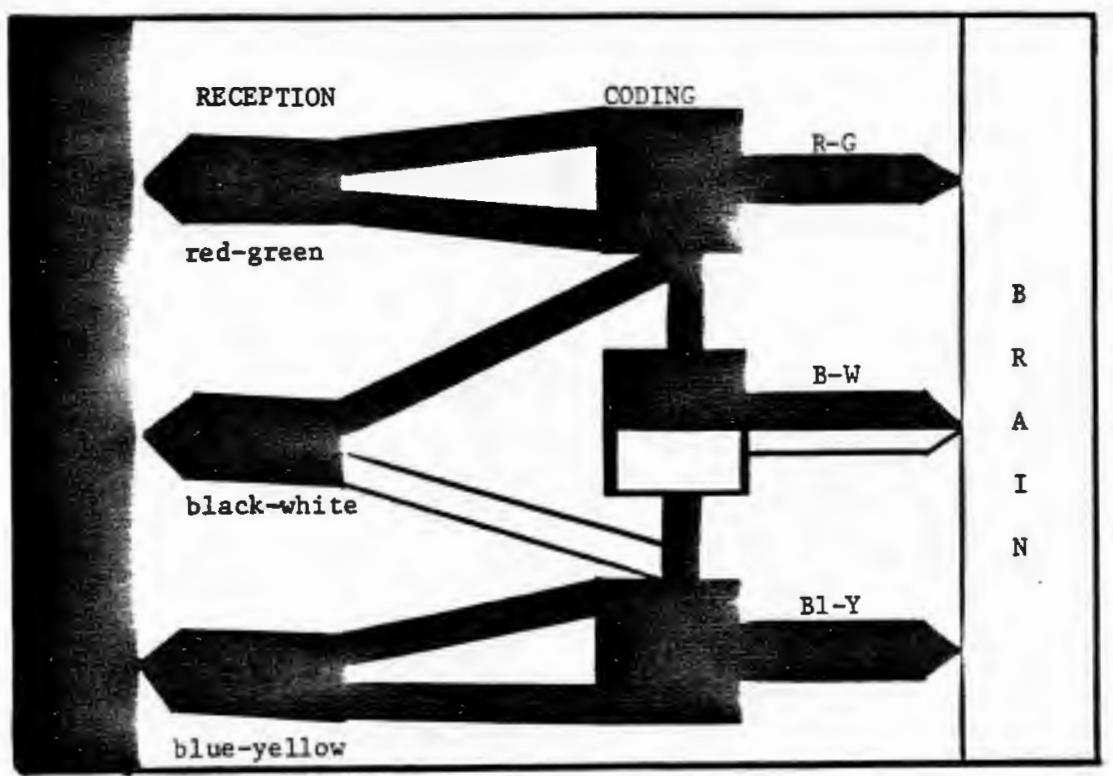

Fig. 8. Somewhat of a composite theory, orange light may draw responses from both the red and blue receptors, which then stimulate the red portion of the red-green coder and the yellow portion of the blue-yellow coder. The evoluationary aspects of the theory have not held up, however. 
The Land Theory

A Retinex Hodel

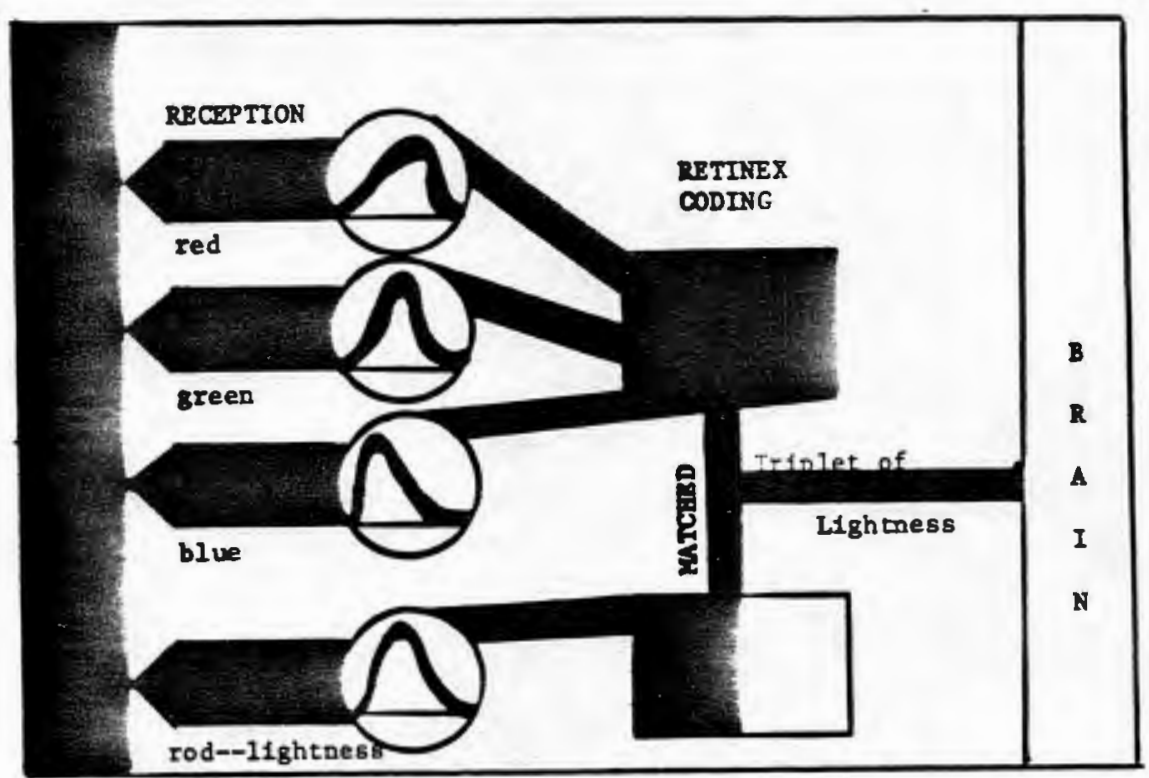

Fig. 9. Reports from the three systems of cone cells (red, green, and blue) are simultaneously matched against reports from a hypersensitive rod system of cells for lightness. This combined triplet of lightness information is transmitted (already mixed) to the brain, where it is perceived as orange. 
In direct support of Land's thinking has been Gilchrist (1979), whose experiments with the perception of surface blacks and whites affirms the critical role of lightness in visual processing. Gilchrist maintains that the intensity of light reflected from a surface is compared with its neighboring surfaces (as in Land's "scaled integrated reflectance" value); but he extends the concept further to include what he calls the "perception of illumination" in chromatic perception.

Gilchrist views the perception of surface color and the perception of illumination as parallel processes in the visual system, involving the decomposition of an image on the retina into separate patterns of surface color reflectance and illumination. He notes that most accounts of color perception have failed to consider perceived illumination, which he postulates is acquired in the same fashion as information about surface color reflection. Put another way, Gilchrist has shown that the visual system simultaneously looks at two kinds of edges: one representing surface reflectance, and the other representing surface illumination. Further, before the edges are integrated into one intensity image, they need be classified as either reflectance changes or as illumination changes.

As it turns out, therefore, Land's model works well when objects are uniformly illuminated, or when illumination is changed uniformly over the entire visual field. It is incomplete, however, when objects are not uniformly illuminated, such as when shadows occur. Under these conditions, such illumination edges are subclassified either as reflectance or as illumination, and are separately integrated into an intensity image...a process which requires not only the eye, but also the central 
nervous system.

Therefore, lightness (with its contrasting activity to wavelength) sets the stage for a major change in thinking, for up until now it has been maintained that rod activity (scotopic vision) is essentially limited to night vision. It remains to be seen what effect Land's work, in particular, will have upon the future rewriting of-textbooks concerned with models for color vision. At this point, however, the controversy continues to rage about which "classical theory" of color vision is correct; with many scientists taking the position that the YoungHelmholtz tri-receptor theory is probably more applicable at the receptor level, while the Hering opponent-process theory is more applicable at the neural level.

In the meantime, in a separate but related area of new research, investigators utilizing a mathematical process called Fourier Analysis (a form of calculus that transforms a complex pattern into its component sine-waves) have suggested that the visual system works as a frequency analyzer for patterns. Filtering these patterns into sine-waves results in wave forms organized like a hologram, with cells in the visual cortex having been reported to fire in response to the light-to-dark alterations within those patterns (Pribram, 1979). This view suggests that it is not that the cells in the visual system are detecting features alone (Hubel \& Wiesel, 1965) but the cells are also detecting and responding to patterns of light and shadow.

Light and shadow patterns, therefore, can also be thought of as the information derived from a highly sensitive daytime rod system (in the Land sense); and lightness (with its contrasting activity to wave- 
length) could be obeying the same mathematical laws that comprise the physical hologram, which is a device that stores the interference patterns of light reflected off objects and recreates a three dimensional image (see Figure 10).

Pribram uses the hologram to provide a model for how information might be distributed and stored in the brain, with visual memory postulated to be composed of wave forms organized like the hologram. The parallel between Pribram's model at the cortex level and Land's retinex model is interesting. Although the physical structures have not been specifically hypothesized in either work, the dynamics of their respective theories are quite complementary.

What would be needed to make Pribram's conceptual model physically possible is a peripheral mechanism for processing incoherent daylight, somehow rendering it into coherent laser-type light. Interestingly enough, some remarkable examples of animal eyes based upon mirror optics have only recently been reported, structures which essentially provide for the same physical properties and capabilities that characterize laser systems. The principal work in this area has been done by Michael Land (1978), whose findings will be discussed shortly.

\section{A Visual Communication System}

In the world of physical science, Yariv (1979) reports progress being made in the guided-wave optic field, in the design of devices for manipulating laser beams in "thin transparent films", in order to provide tiny and efficient components for a light wave communication system. (The reader might conceptualize such a system in terms of human vision.) 


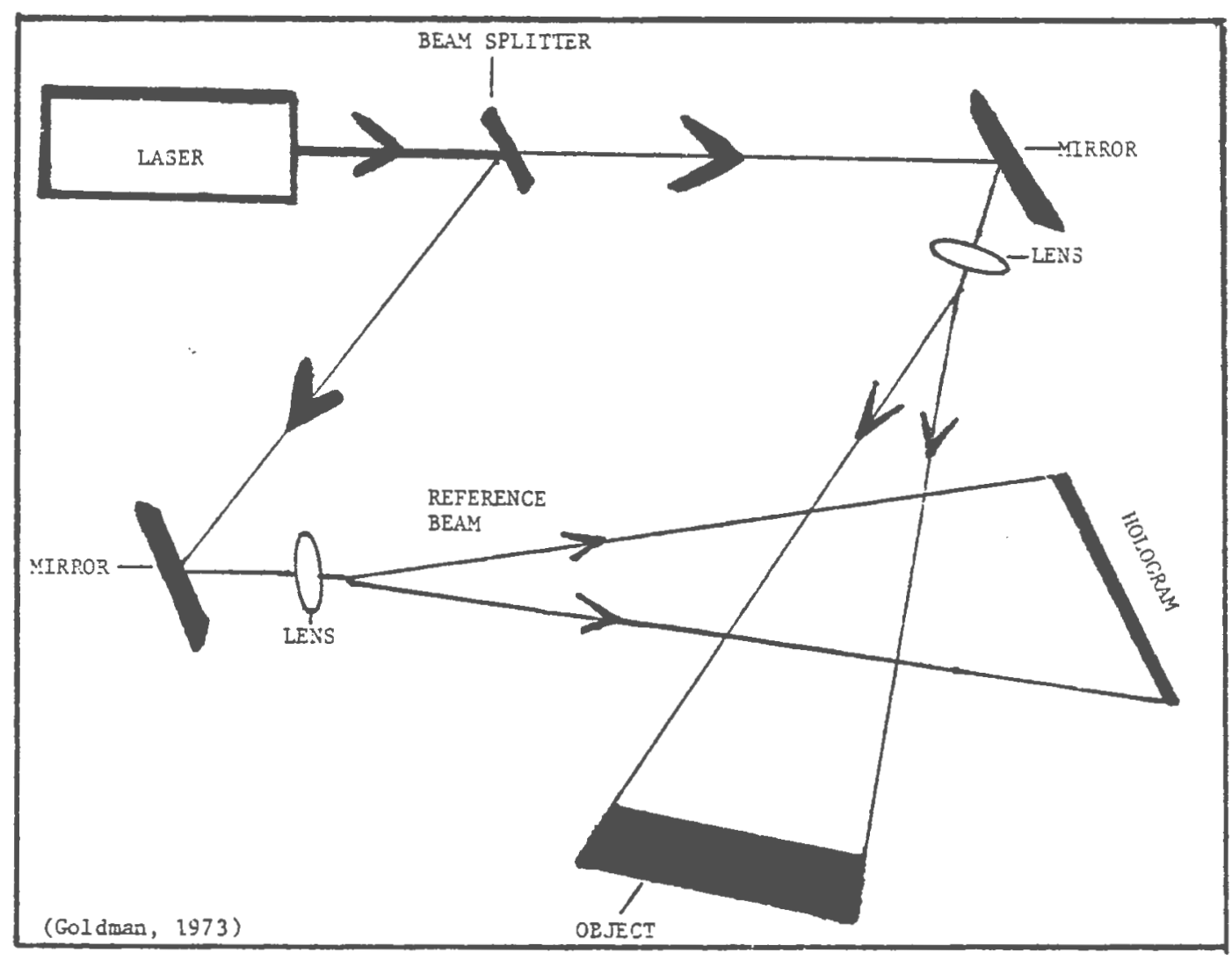

Fig. 10. After the laser's beam is split, one part is deflected toward the film plate and the other is bounced off the object. When the beams reconverge, a light interference pattern is formed and recorded. The three-dimensional appearing image is reconstructed when a second beam is reflected off the plate and diffused in the same pattern. 
Basic to Yariv's system is the semiconductor-diode laser, where the energy of a small electric current passing through a "multilayer semi-conducting crystal" is converted directly into laser light. The extremely small size of the device (less than a millimeter on a side) lends itself to use with integrated electronic microcircuits, which have the potential to drive the laser directly.

In the meantime, in the world of biological science, Michael Land (1989) describes the eyes of several kinds of animals in much the same fashion. Land talks about "multilayered stacks of very thin films"... the effect of which yields a mirror surface within the eye, providing a very high degree of reflectance.

Basic to Michael Land's findings is the physical structure of certain animal eyes, where for example, alternating layers of cytoplasm and guanine crystals provide a series of reflectors six micrometers (thousands of a millimeter) thick; and the shape of these reflectors determines the degree of brightness sensitivity.

These parallel findings in the physical and biological science worlds afford the opportunity to think about visual perception within a new paradigm; one which integrates the technical advances in two independent disciplines, but whose work share a common objective: to provide the physical components for a communication system for light. Yariv (1979), in describing a conventional microwave communication system (whose signal carrying capacity may be up to 300,000 times lower in frequency than that of light), outlines some basic constituents.

First there must be an oscillator of some kind to generate the "carrier" waves in a highly coherent form (that is, with the waves all in 
step at the same frequency). Next the waves must be modulated to carry information by varying either their frequency or their amplitude. The modulated microwave beam is then transmitted, either by channeling it through a metallic waveguide or by propagating it through the atmosphere. Since waves become attenuated in transit, a longdistance communication system of this type requires in addition a series of intermediate relay stations, where the microwave signals. are detected, amplified, reshaped to their original modulated waveform: and sent on to their ultimate destination. There the beam is again detected, amplified, and reshaped before being processed to recover the information impressed on it at the point of origin.

Extension of the microwave communication system to a biological communication system for visual information is not difficult to entertain, provided that "carrier" waves can be shown to possess the property of "coherence". The eye as a laser system is a concept which allows for such an extension in the coding of intensity information, such as the perceived lightness of a color. (It has been shown that differences of quality, such as visual contours, are encoded by having a different nerve cell and nerve fiber for each quality) (Young, 1978).

\section{Characteristics of Laser Systems}

Goldman (1973) provides a simplified account of laser theory, in which he lists several features which are common to all types of lasers (various solids, liquids, gases, and junction diodes) (see Figure 11).

1. The Laser Media...this is the substance, either solid, liquid gas, or junction between two dissimilar materials, which by virtue of its molecular structure, is capable of sustaining stimulated emission.

2. The Source of Excitation Energy...the "pump" energy, which contributes to a redistribution in the laser media of a number of atoms 
A Laser

Light Amplification by Stimulated Emission of Radiation

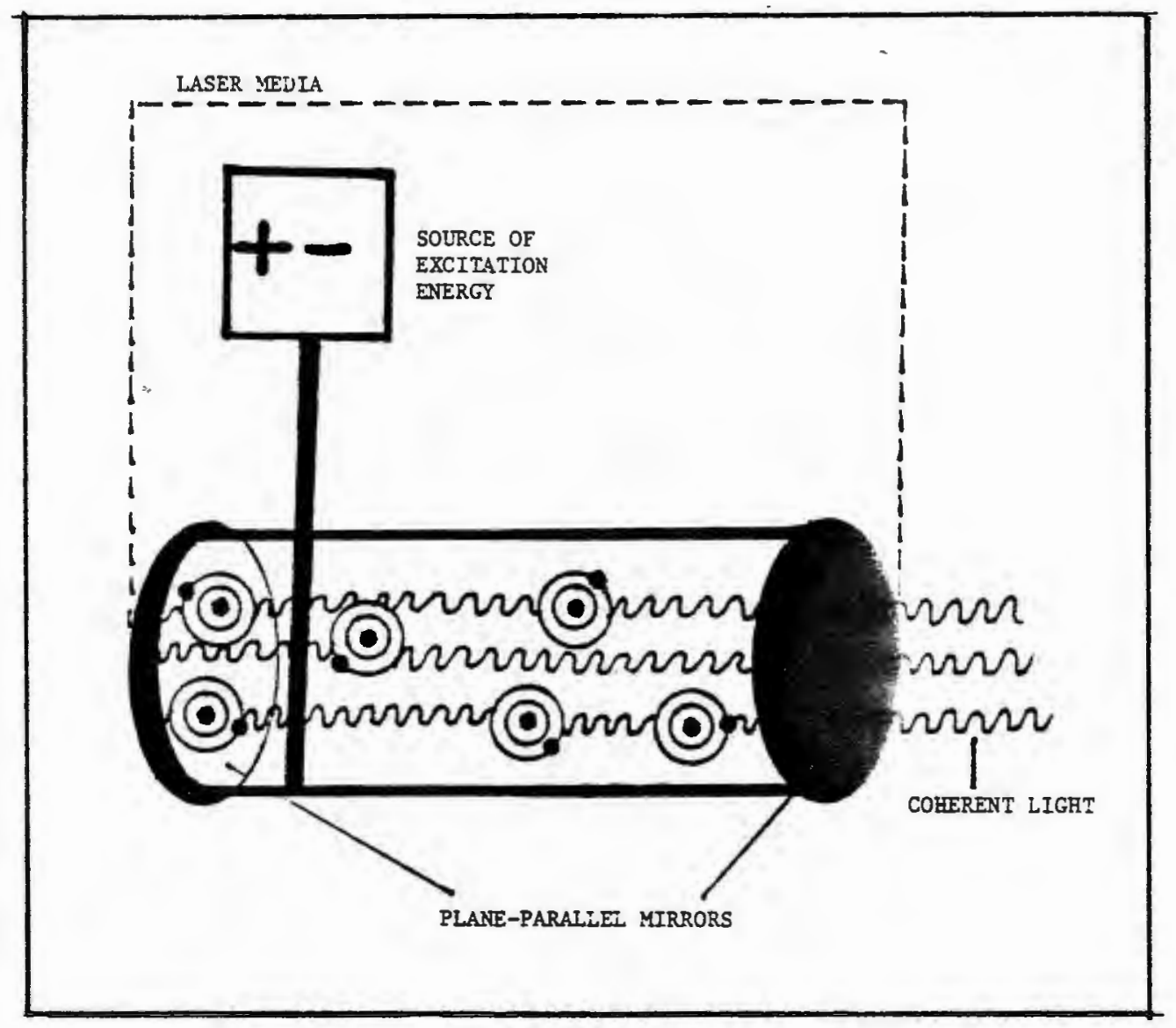

Fig. 11. A laser is a device for generating highly coherent light waves. Atoms are brought to a high-energy state within the laser media by pumping in energy. Some of the atoms begin to produce light by normal emission, while mirrors at each end reflect the light and produce stimulated emission until all the atoms are in a low-energy state. Coherent light leaves the laser through one of the end mirrors. (Goldman, 1973) 
which normally exist in certain atomic energy levels, to produce the laser beam.

3. A Fabry-Perot Interferometer...consisting of plane-parallel mirrors, for reflecting within the laser media.

In a most general manner, excitation energy is vigorously supplied to the active media to produce a condition called population inversion. In this condition more atoms of the laser media are in an excited energy state than in the lowest "ground-state" level. (One way for an atom in an excited state to release excess energy is by the spontaneous emission of light in discrete units, called photons.)

What makes the laser unique is that because of the population inversion the energy release can be accomplished by a process known as stimulated emission. In this process a photon released by one excited atom will cause (stimulate) an excited atom it comes into contact with in its path also to release a photon of excess energy, resulting in the combination of two photons with identical phase relationships (coherence), so that their energies are added together to produce a beam of twice the intensity.

As the beam progresses through the excited laser media, its amplitude is rapidly increased, while its coherence properties remain unaltered. When the total reflection mirror is reached, the direction is reversed, thus allowing for another pass through the excited laser media; and hence, further amplification occurs. Upon reaching the partial reflecting mirror, a portion of the beam escapes, which becomes the active emission from the laser.

The fundamental characteristics of the emitted laser light, there- 
fore, include: monochromaticity, coherence, parallel beams of light, polarization, and high intensity (with electromagnetic field strengths).

Since fiber optics (used as wave guides) (see Figure 12) serve not only to conduct light images, but can also act with magnifiers and converters to electricity, multimode optical fibers in conjunction with "thin film" techniques (pulsed impacts on thin films). can service carrier waves for encoded signals, forming the basis of a light wave communication system. Yariv uses a semiconductor-diode laser to provide the model for his system (Yariv, 1979) (see Figure 13).

Basically, this device typically consists of a thin film of galIium arsenide between two layers of gallium-aluminum arsenide. When an external voltage is applied across the single-crystal stack, electric current flows at right angles to the layers. This flow between the positive and negative type layers results in a recombination of charges within the central core, with excess energy being emitted in the form of laser light.

By incorporating periodic corrugated sections in several of the interfaces of the waveguide, it is possible to replace the function of the usual end-face mirrors as the laser reflectors. Adjusting the reflectivity of the corrugated sections allows a predetermined fraction of light to emerge in the output beam. Further, since the high degree of wavelength selectivity of these reflectors forces the laser to emit an extremely monochromatic light, one can alter the corrugation scheme to "tune" the laser to the desired wavelength simply by changing the angle of incidence to the corrugation (see Figure 14). In addition, since waveguard properties of a material depend strongly upon their indices of 


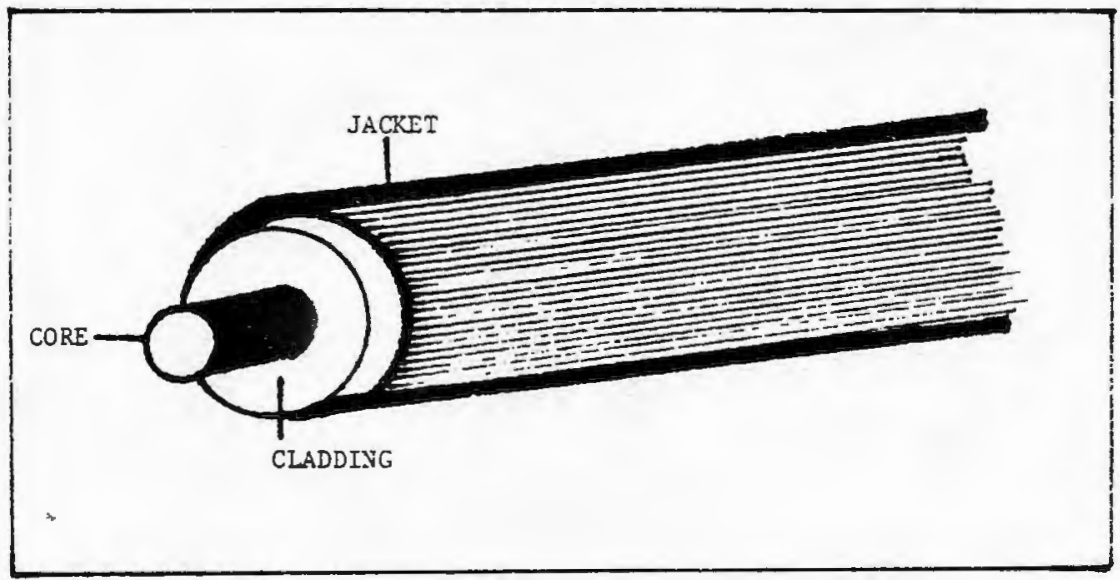

(Adapted from Goldman, 1973)

CROSS-SECTION

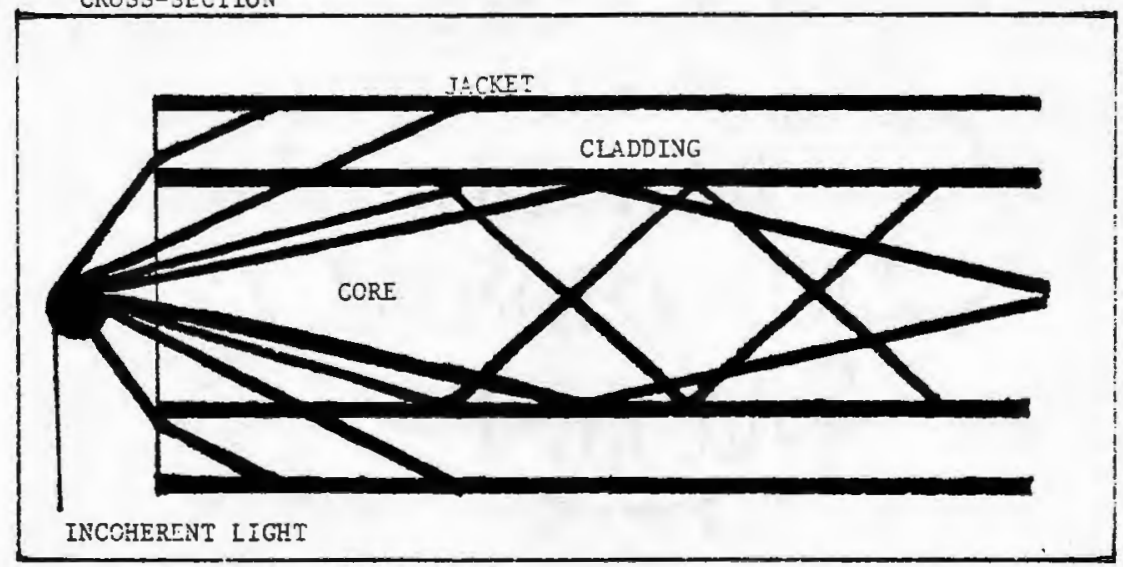

Fig. 12. Multimode optical fibers, showing path of incoherent point light source (lower portion of figure) by internal reflection. 
A Semiconductor-Diode Laser

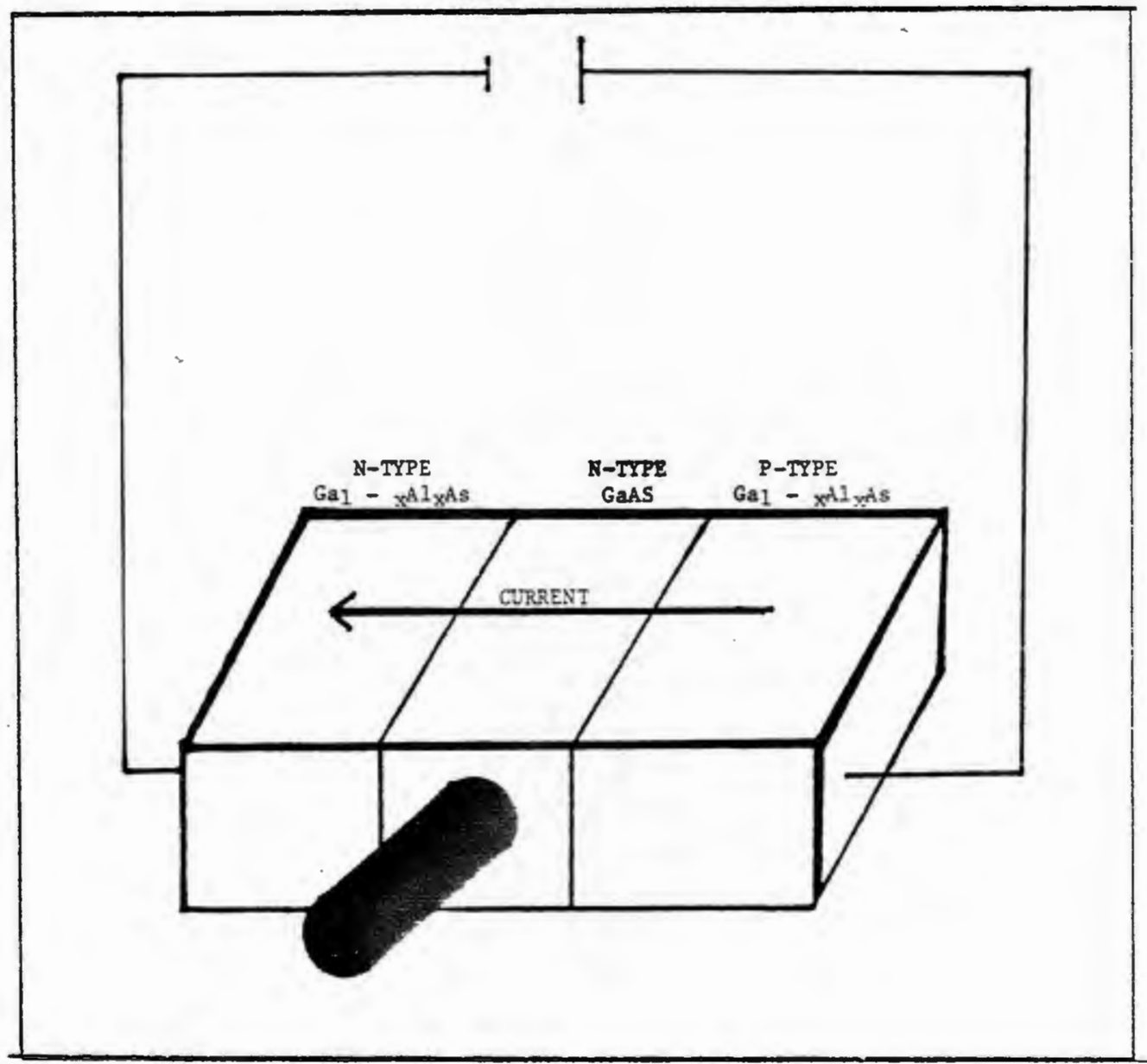

Fig. 13. Consisting of a thin film of gallium arsenide between two layers of gallium-aluminum arsenide, the semiconducting diode laser emits energy in the form of visible light with the application of an external voltage across its singlecrystal stack. (Yariv, 1979) 


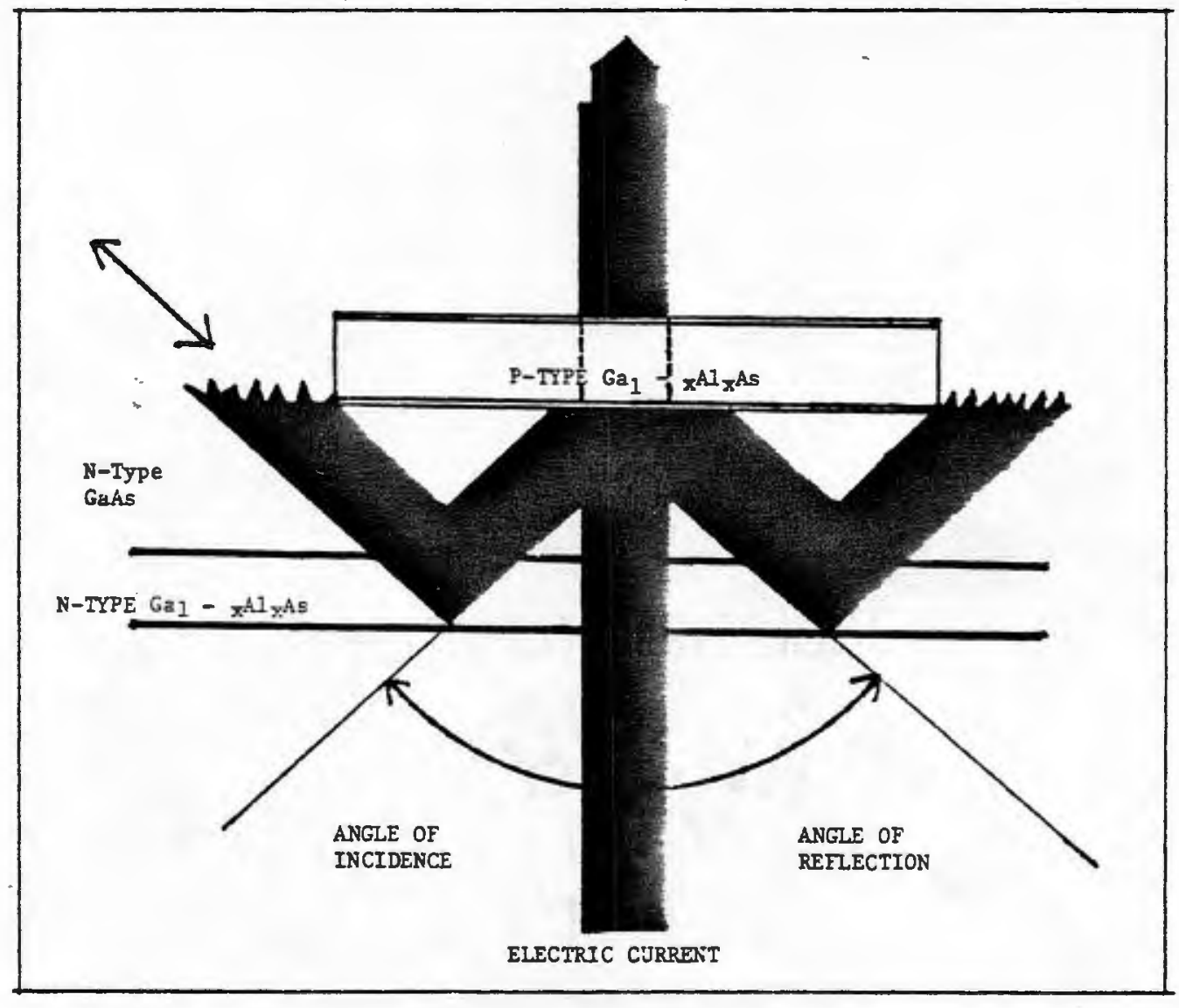

Fig. 14. The reflectivity of the corrugated sections can be adjusted to let a predetermined fraction of the light emerge as the output beam. (Yariv, 1979 adaptation) 
refraction, the application of an electric field can substantially modify the nature of the propagated light. This control method allows for modulation, switching, and coupling of light beams (the ultimate purpose of which involves impressing pulse-coded binary information on to the emerging light wave).

A stream of data encoded onto a train of binary. ("on" and "off") voltage pulses, therefore, can be later reconverted to a nearly perfect replica of the original electrical signal. This process of waveguiding light in transparent films, and its manipulation by impressed fields and currents, provides the basis for an optical communication system. (see Figure 15) Research is currently underway to build even more complex optical circuits on a single-crystal chip, ones which provide for feedback loops in the modulation of optical beams with electrical signals (Yariv, 1979).

\section{Evidence for a Biological Laser System}

Essential to viewing the eye as a laser system is the mechanism for converting multichromatic and incoherent light into monochromatic and coherent light. Animal eyes with mirror optics, as described by Michael Land (1978) appear to provide for such a mechanism.

Land uses the following example to explain the operation of multilayer mirrors, structures which he recently discovered to exist among scallops, shrimp, crayfish, and lobsters.

Thin films, such as soap bubbles, generate reflectance from the interference of light waves reflected from the outside and inside surfaces of the films. If two wave fronts are reflected from the interfaces in phase (the crests and troughs line up), then reflectance is 
An Optical Communications System

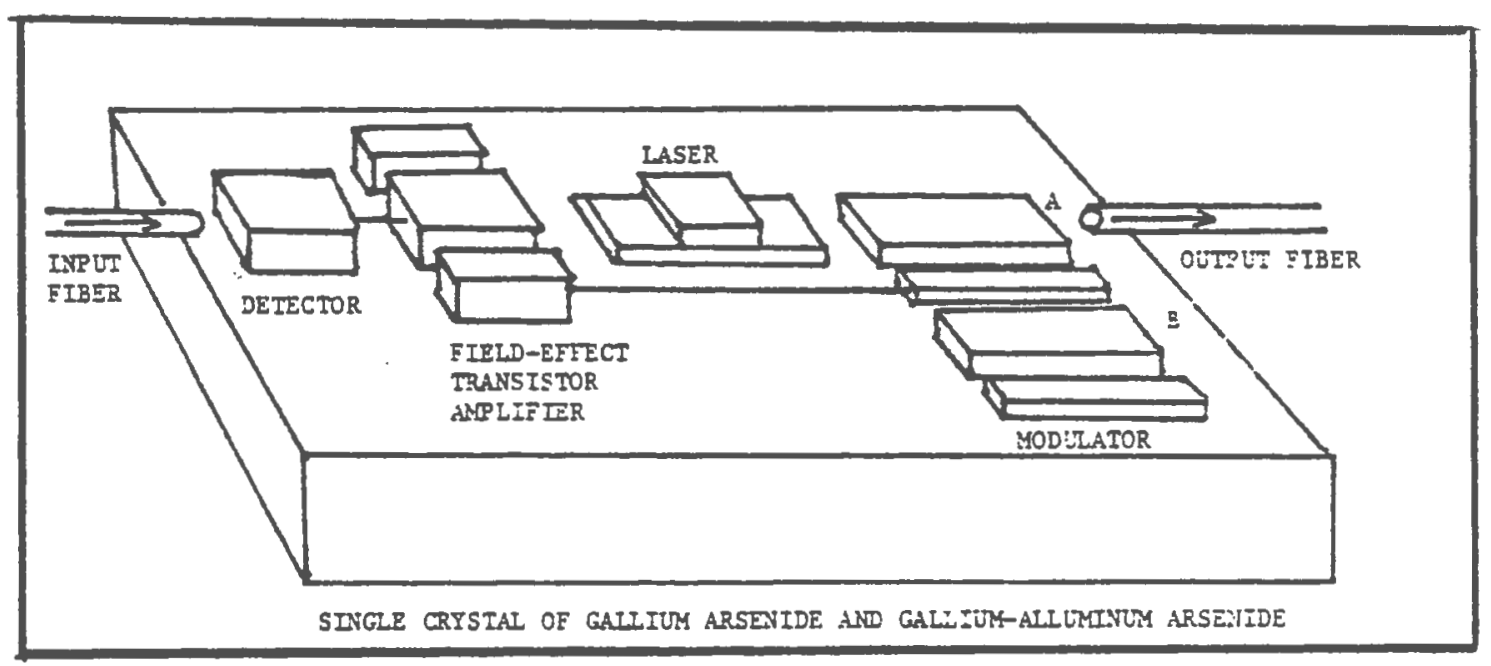

Fig. 15. An entire circuit can be produced with today's technology on a single-crystal chip of semiconducting material. More complex circuits should become feasible in the near future. (Yariv, 1979) 
high. If they are out of phase, then reflectance is reduced to zero. Mirrors reflecting most or all of the incident light can be obtained by stacking several films of specified thickness in between spaces of the same thickness. This arrangement apparently ensures that light of a particular wavelength is reflected in phase from all the interfaces in the stack, yielding a reflectance higher than that of polished metal (see Figure 16).

Multilayered mirrors (physical and biological) can be made from a variety of materials, provided that there is a large difference in the refractive index between adjacent layers in the stack. In addition, multilayer mirrors have certain properties that are not possessed by metallic mirrors, such as reflection of monochromatic colored light, as well as white light (see Figure 17).

The color of a multilayer mirror changes toward the shorter wavelength as the angle of incident light is increased; hence, like the tunable laser, this phenomenon results from changes in the propagation of light waves through the layers of the stack. In addition, multilayer mirrors absorb almost no light; the wavelengths that are not reflected are transmitted as the complementary color.

The reflecting eye of the lobster is comprised of a square array of mirrored plugs, acting as corner reflectors, and behaving like a single mirror at right angles to the incident ray. This design greatly intensifies an image under low-light conditions, making the reflecting eye of the lobster most sensitive to differences in brightness. The refractive eye of the diamondback moth, however, is found by Land to be comprised of a hexagonal array of reflectors, making the refractive eye 
The Scallop Eye

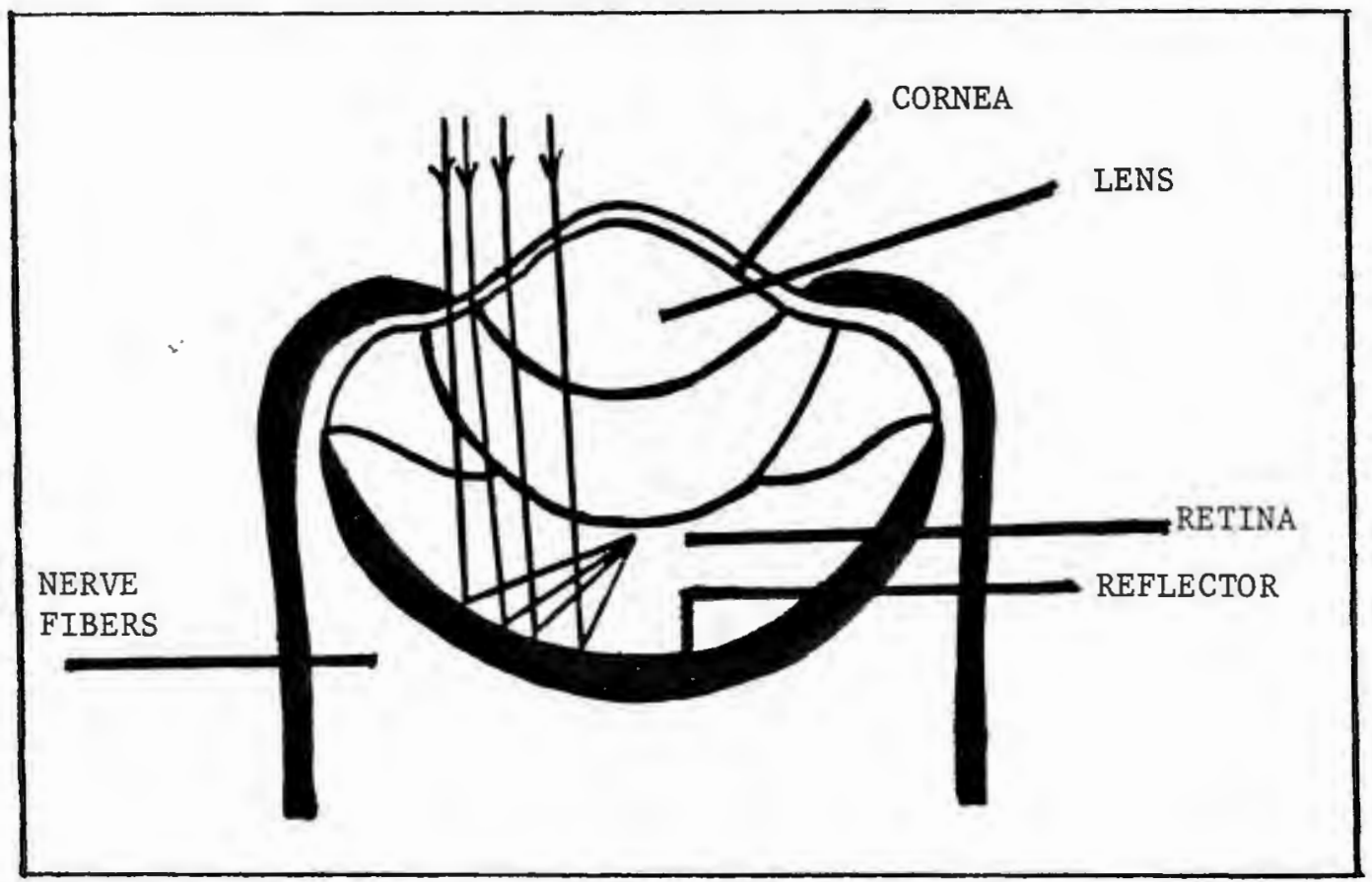

Fig. 16. The light rays (which are only weakly refracted by the lens) pass through the retina to the reflector, which focuses them back to the distal photoreceptor cells in the upper layer of the retina. Because the light must pass through the retina once before it is detected, the scallop eye does not have good contrast acuity. (Land, 1978) 
Propagation of Light Waves in Mirrored Layers

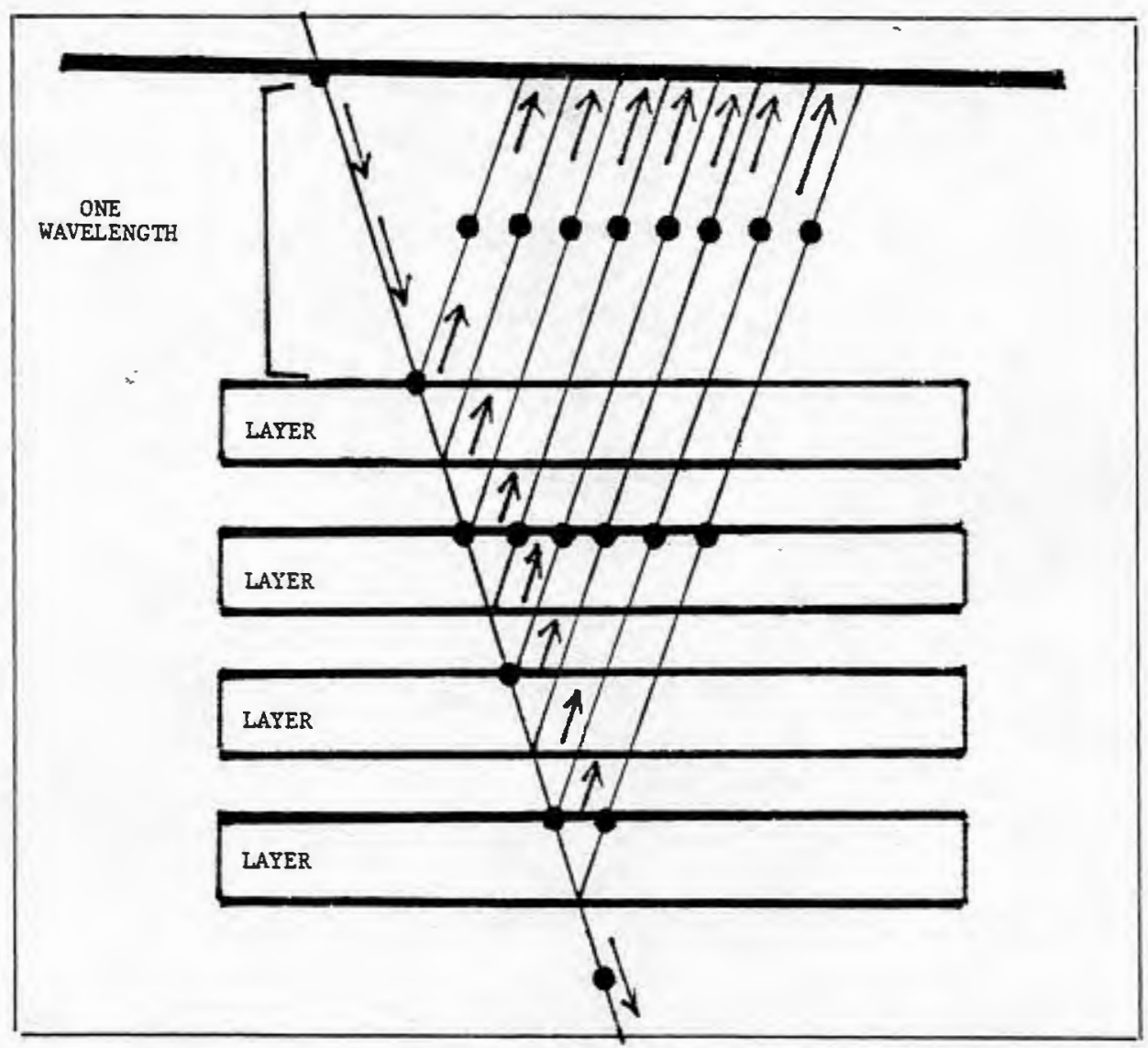

Fig. 17. Multiple layers of high and low refractive-index materials produce a mirror surface with a high degree of reflectance. Each layer in the stack must have a thickness of one-quarter the wavelength of the illuminating light, so that the light waves are reflected in phase from all the interfaces in the stack. Color shifts toward the blue end of the spectrum as the path length through the layers decrease and the angle of incidence of illuminating light increases. (Land, 1978) 
the more geometrically economical one for acuity.

It can be seen, therefore, that the arrangement of layers within the stack to provide for the multilayer mirror is also, in effect, allowing light to be transmitted in only certain narrowly defined directions; and wavelengths that are not reflected, as mentioned, are transmitted as complementary color. This effect can likewise be achieved by using polarizing filters, where complementary color appears as the rotation of one of the two filters approaches 90 degrees, the direction of minimum transmission (Kuppers, 1973).

The first four characteristics of laser light are theoretically possible in animal eyes with mirror optics, it appears: monochromatic, coherent, parallel, and polarized light. (High intensity necessitates modulation through some type of feedback mechanism involved with the electrical coding of emerging light waves, a process which presumably could involve the central nervous sytem.)

Likewise, the basic characteristics of a laser system are theoretically present in these animals. The laser media, patterned after the semiconductor-diode laser, could be comprised of single-crystal stacks of biological material with different refractive indices (alternating cytoplasm and guanine crystals, as in the scallop eye). The source of excitation energy could come from incoherent light or from the sodiumpotassium pump (Gardner, 1975), which helps to maintain the membrane potential and ionic concentration differences responsible for excitation, conduction, and transmission of impulses across a cell. The function of the Fabry-Perot interferometer, for reflection within the laser media, could be accomplished internally by changing the angle of incident light. 
Coding for a triplet of lightness (in the Land sense) would be technically feasible in the laser communication paradigm, with Land's "retinex" analogous to the feedback modulation process in a physical light wave communication system. Consistency with opponent-process theory is likewise maintained, through pulse coding of binary ("on" and "off") information about wavelength, illumination, and lightness combined. Further, these concepts support Pribram's hologram model at the cortex level: not only from its abstract usefulness in thinking about visual memory; but from its physical realizability.

\section{Color Vision Deficiencies}

The classification of color vision defects has important theoretical implications for both color vision theory and for critical evaluation of color vision tests. Many of the techniques developed over the past one hundred years for the assessment of color vision were not formulated from apriori predictions, but represent a trial and error approach. An examination of how defects are classified leads to a better understanding of how tests were constructed, and why some tests are more efficient than others.

It becomes impractical to classify color vision defects on the basis of one theory of color vision alone, since no one theory to this point in time has been able to account for all the diversity that is found among individuals. (The Land theory has not been thoroughly researched with respect to its ability to account for all the various types of color vision defects, given the recency of its publication.) Therefore, in order to describe all the various types of defects, one must use the language of apparently opposing systems. 
The simplest way to classify color vision defects is to consider whether they are construed as either congenital or acquired. With the congenital type, no underlying pathological basis is implied; with the acquired type, a disease process or toxic etiology is assumed. It is further assumed in the case of acquired color vision defect, that at some stage, color vision was normal.

Congenital Color Vision Defects. One of the interesting features of the congenital type is the large difference in its incidence between males and females. This, together with the increased incidence of such defects in successive generations of some families, point to a genetic basis of some varieties. Linkage between deuteranopia (green blindness) and bipolar affective illness has been established (Reich et al., 1969; Mendleweicz \& Fleiss, 1974; Baron, 1977); with manic-depressive illness viewed as an X-linked dominant trait (manifesting itself in both males and females), and color blindness as an $\mathrm{X}$-linked recessive trait (1atently carried by females and manifested in their male offspring.) In general, congenital color vision defect is thought to affect approximately eight percent of the male population and less than one-half of one percent of the females (Padgham \& Saunders, 1975) (see Table 1). Acquired Color Vision Defects. Pathological changes due to external sources may induce a color vision defect in the originally normal visual system. A person so afflicted may show effects similar to congenital types, with a general progression occurring from normal trichromatism through momochromatism. Drugs used in the treatment of non-ocular diseases, such as digitalis, have been known to produce color vision defects (Lakowski, 1971). The excessive consumption of tobacco, 
TABLE 1

PERCENTAGE FREQUENCY OF

OCCURRENCE OF COLOR VISION DEFECTS

(CONGENITAL)

\begin{tabular}{|c|c|c|}
\hline Type & Male & Female \\
\hline \multicolumn{3}{|l|}{ Trichromats } \\
\hline Protanomalous & .900 & .200 \\
\hline Deuteranomalous & 4.500 & .380 \\
\hline Tritanomalous & smal1 & $\mathrm{sma} 11$ \\
\hline \multicolumn{3}{|l|}{ Dichromats } \\
\hline Protanopes & 1.200 & .020 \\
\hline Deuteranopes & 1.500 & .010 \\
\hline Tritanopes & .002 & .001 \\
\hline \multicolumn{3}{|l|}{ Monochromats } \\
\hline Rod & .003 & .002 \\
\hline Cone & sma11 & small \\
\hline TOTAL & 8.100 & .430 \\
\hline
\end{tabular}

Padgham \& Saunders, 1975 
alcohol, quinine, cannabis, and salicylates have also been associated with a deterioration in color vision (Poulsen, 1971). Birth control pills have likewise been linked to deterioration of color vision (Marre et al., 1973).

Ocular diseases such as glaucoma, occular hypertension, and those diseases which affect central vision, as well as aging of the lens, have been described in association with the acquired defects. Frequency data on the acquired type are not as readily available as on the congenital type, for the problem has only recently come under study; while preliminary results are suggesting a higher incidence than previously suspected (Lakowski, 1969; Padgham \& Saunders, 1975).

One may also classify defects in terms of major color vision theories. For example, if Hering's terminology is accepted, one can group defects according to the most characteristic pairs of colors which individuals confuse with a target stimulus; thus one may have red-green or blue-yellow confusions, as well as light-dark confusions. If one accepts the Young-Helmholtz theory, however, one can classify defects according to the number of primary colors required to reproduce all colors in the color space, observing that most people require three (normal trichromats) (see Table 2).

Another classification method for color vision defects involves prediction as to which part of the visual mechanism may be impaired. First suggested by von Kries (1924), three systems may be involved. The essential characteristic of the absorption system is that the retinal mechanism remains normal, while color deviation is due to prereceptoral changes in either the cornea or the lens. In the alteration 
TABLE 2

COLOR VISION CLASSIFICATION AND DESCRIPTION

\section{Trichromats}

Normals

Red-Green Deviants

Color Weak

Anomalous Types

Protanomalous Deuteranomalous Tritanomalous

Dichromats

\section{Protanopes}

Deuteranopes

Tritanopes

Tetartanopes

Monochromats

Rod Type

Cone Type require three primary colors (red, green, and blue), or four primaries in the Hering model (red-green and blue-yellow) to make a match

no difficulty in discrimination of hue/1ightness

slight deviation from normal in red-green hue

generally less able to discriminate in most hues; but this may also represent color aptitude

use different proportions of three (or four) primaries to make a colorimetric match; is hypothesized to have to do with less ability (or more difficulty) with discrimination among various saturations

red affected

green affected

blue affected

use only two primaries to complete a color match; represented by confusion among hues; classification generally thought of as typical color blindness red affected

green affected

blue affected

yellow affected

use either one primary alone to complete a color match, or merely lightness and darkness to discriminate among hues

lightness and darkness are affected; use only one primary; extremely rare

no chromatic response; lightness and darkness not affected; not common 
and reduction systems, the problem is attributed to a defect in the retinal mechanism. The alteration system is characterized by nonacceptance of certain normal color matches, and these are referred to as the anomalous types; whereas the reduction system involves acceptance, not only of the color matches of normal subjects, but also of the anomalous types. (Usually the reduction system is defined as dichromatism) (Padgham \& Saunders, 1975).

It remains beyond the scope of this discussion to describe in detail the various diagnostic categories of color vision dysfunction. Interested readers are referred to Verriest (1974).

Tremendous progress in photopigment research has recently produced new data to lend support to the theoretical positions of various color vision theorists. Weal (1957) and Rushton (1958) are associated with the development of "reflection densitometry," a method for measuring the output of a series of wavelengths upon the photopigments of human cones. However, since this method has been insufficiently sensitive to measures in the short-wave spectral region, a blue-sensitive pigment (cyanolabe) has merely been hypothesized, but not yet isolated. Two additional pigments (chlorolabe and erytholabe) have been designated as the green-sensitive and red-sensitive pigments, respectively.

In contrast to those persons with normal color vision, measures of the protanope's pigments reveal that only one photosensitive pigment (chlorolabe) in the so-called red-green spectral region can be found; while deuteranopes have been demonstrated to possess only erythrolabe (Rushton, 1963). Since normal trichromats show evidence of two photopigments, it was anticipated that the anomalous trichromat would like- 
wise give evidence for two photopigments (though probably in different quantities; for the anomalous three-variable color matches differ from those of the normal type.) This was not the case, however. "Measured by densitometry, they (the anomalous type) are indistinguishable from dichromats: only chlorolabe is found in the protanomalous subject (like the protanope), only erythrolabe in the deuteranomalous" (Rushton, 1970). Explanations for this discrepancy vary, but one which has been proposed by (Hurvich 1973) appears completely consistent with the facts.

Hurvich reasons that since both the protanopes and the protanomalous have a deviant long-wave photopigment, undistinguishable from one another by retinal densitometry, that the differences between these two types of color defectiveness occurs at the neural level. Whereas protanopes are not efficient (or operative) in their coding of cone responses, the anomalous types retain the neural process that signals red-green and blue-yellow (to different degrees) to the brain. In other words, the anomalous types have merely retinal (or peripheral) deviance; whereas the "opes," (protanopes, deuteranopes, etc.) have neural coding difficulties.

A large body of electrophysiological data on animals with color vision strongly supports this notion, in that hue coding is organized in an opponent fashion, and measured responses are mutually antagonistic (excitatory or inhibitory). While it is quite clear that both protanopes and deuteranopes completely lack red-green responses, they do manage to generate grays to the stimuli evoking chromatic responses in individuals with normal color vision. Thus, it would not appear unreasonable to postulate the absence (or inactivity) of such opponent red- 
green neural coding systems, over and above the peripheral photochemical system in the retina (Hurvich, 1973).

Land's Retinex Theory $(1959 ; 1977)$ is quite consistent with photopigment research findings, as well as with Hurvich's reasoning. Land has suggested that rods and cones operate together at the receptor level, and that coding carries both wavelength and lightness information, already mixed. The dichromat, therefore, would presumably have the ability to code merely lightness information in the spectral range of his insensitivity; while the anomalous type would retain the ability to code both Iightness and hue, but his deviant photopigments would render an inaccurate or faulty signal to the brain.

The characteristics of color vision deficiencies are also easily understood through reference to the psychophysical functions that are dependent upon a subject's ability to discriminate lights of different colors.

Wavelength Discrimination. The study of wavelength difference sensitivity for subjects with normal trichromatic and with dichromatic vision has yielded results which suggest that the dichromat shows no color discrimination in the region of the spectrum where a single cone response function predominates. Hence, the protanope and deuteranope have no ability to distinguish monochromatic colors at or about 550 nanometers, and the tritanope cannot distinguish the shorter wavelengths. Anomalous trichromats, likewise, suffer a reduction in sensitivity, which can vary considerably among subjects by wavelength (Padgham \& Saunders, 1975). Accordingly, insensitivity to various wavelengths is experienced as difficulty in discriminating hue; and dichromats, as well 
as anomalous trichromats, behave similarly in this context, according to their respective regional difficulties.

Luminous Efficiency Function. The study of the relative luminous efficiency functions of dichromats yielded results which suggest that the protanopes show a decrease in sensitivity at long wavelengths, and a shift of their maximum discrimination to the shorter wavelengths. The deuteranope's function appears to be similar to that of the normal trichromat, while the tritanope's function shows a small decrease in sensitivity at the shorter wavelengths (but not reaching the level of significance). Anomalous trichromats, meanwhile, have functions similar to their corresponding dichromat, though the corresponding decrease to sensitivity is often smaller (Padgham \& Saunders, 1975). Therefore, decreased sensitivity to lightness, which is the psychophysical correlate to luminous efficiency, is characteristic of protanopes and the protanomalous types; while other types of dichromats and anomalous trichromats respond similarly to individuals with normal color vision.

Purity Discrimination. A study of the purity differences for normal trichromats and for dichromats yielded results which suggest that both dichromats and the anomalous types have a decreased sensitivity to purity differences; and the extent of this phenomenon depends upon the degree of anomaly (Padgham \& Saunders, 1975). Put another way, the ability to discriminate the saturation of a field from white is shown by the purity discrimination function, and only individuals with normal color vision show no difficulty in this area.

It may be concluded from these functions, therefore, with respect to their related difficulties in the discrimination of hue, lightness, 
and saturation that color vision theory and color deficiency detection had best take into account the varieties of color vision dysfunction, as well as the psychophysical correlates upon which comparisons can be made. Land's theory (1977), together with Gilchrist's expansion (1979) to the coding of illumination, appear congruent with psychophysical findings (see Table 3).

\section{Tests for Color Blindness}

Lakowski (1969) has made a comprehensive review of the color vision testing literature, presenting information on how each test was designed, how it detects defects, and why it is able to measure individual differences. It should be mentioned that in his review he makes no specific recommendations about which tests are best, but rather leads one to consider the costs, benefits, and purposes for which the test is intended.

Among the things that have to be considered in evaluating a test is, of course, the financial cost. If it is only necessary to exclude major defectives at the lowest cost possible, then the pseudo-isochromatic plates would be the logical instruments to consider.

Pseudo-Isochromatic tests, such as the Dvorine (Dvorine, 1944) or the Ishihara (Ishihara, 1925), as well as the more modern Tokyo Medical College plates (1957), American Optical Hardy, Rand, and Rittler plates (1957), and all their revisions, can be used to classify individuals into normals and defectives (Lakowski, 1969), at least, theoretically. However, because they are viewed as simple and are easily administered (and therefore widely used), this does not suggest that when used alone they necessarily are adequate for any purpose other than gross screening. 
TABLE 3

SYNTHESIS OF COLOR VISION DYSFUNCTION WITH HYPOTHESIZED THEORETIC EXPLANATIONS

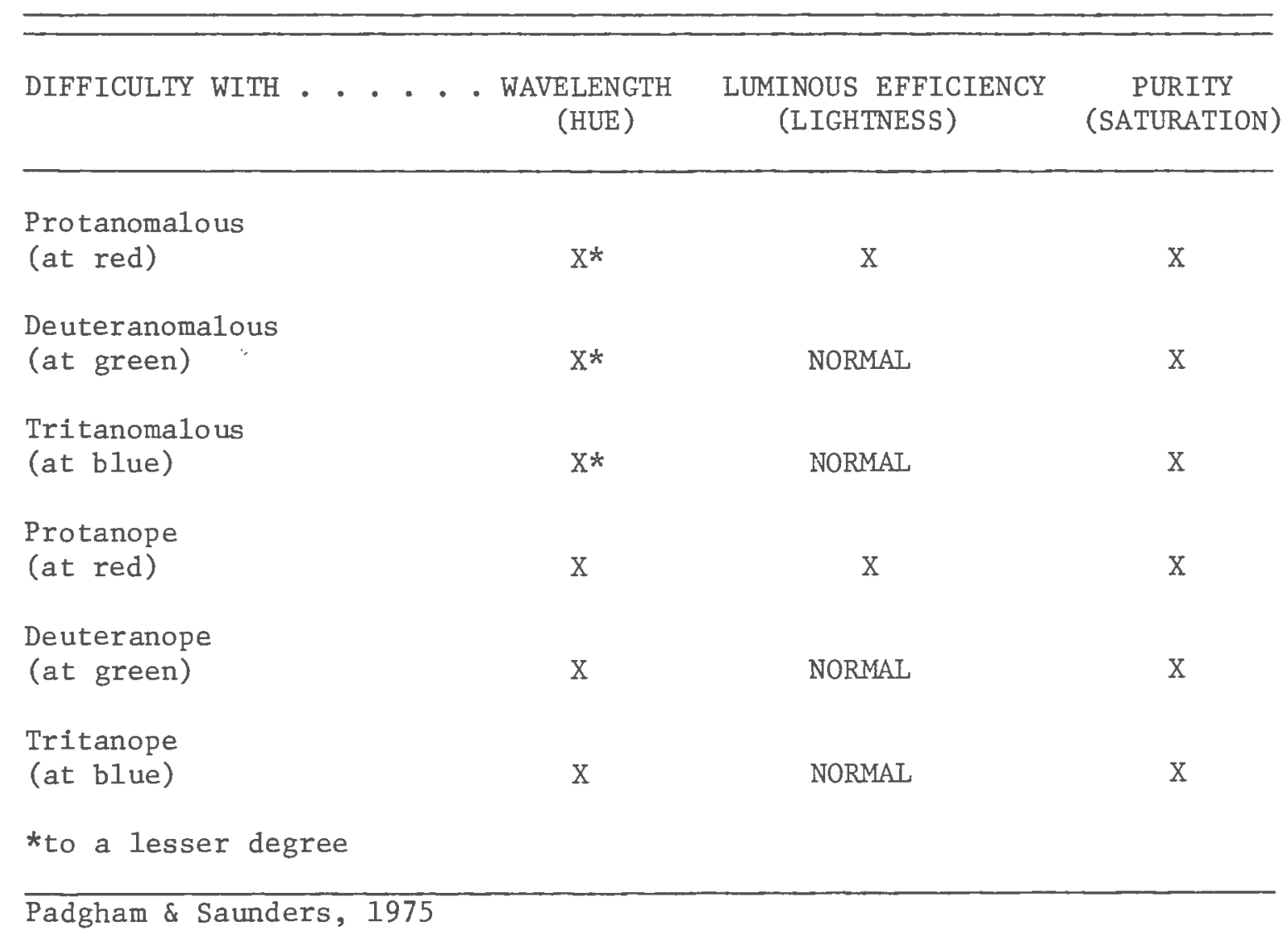

\begin{tabular}{l|r}
\hline Inability to Accurately Code & $\begin{array}{r}\text { Cone Information } \\
\text { Rod Information } \\
\text { Interaction Information }\end{array}$ \\
\hline Land, 1977 & $\begin{array}{r}\text { Inter } \\
\hline\end{array}$
\end{tabular}

\begin{tabular}{l|r}
\hline Inability to Accurately Code & Angle of Illumination \\
Intensity of Illumination \\
Interaction Information
\end{tabular}


In design, the pseudo-isochromatic tests are very complex, for they became available before accurate colorimetric measurements were developed. These tests are called pseudo-isochromatic because, in theory, at least, only normal observers should be able to distinguish between individual colors in a plate to read the intended figures. Basically, each plate employs dots to show a multi-colored figure against a multi-colored background. Unfortunately, variations in the size of the dots, and the employment of arabic numerals and geometric designs have also introduced ambiguity in interpretation; for problems of form-perception are also reflected in the scoring (Lakowski, 1956).

In brief, therefore, it is not possible to ascertain the degree of defect from pseudo-isochromatic test scores (Umazume \& Harutake, 1962; Hardy et al., 1945). This is because the anomalous types can make either a very large or a very small number of errors; and though difficulties in interpretation may be fewer with the outright dichromats, they none the less exist (Lakowski, 1969).

Color Discrimination tests, such as the Farnsworth-Munsell 100-Hue test (Farnsworth, 1949; 1957) and the Farnsworth Dichotomous Test (Farnsworth, 1947), are based upon recognition of surfaces by reflection. In addition to detecting color confusion 1ines, tests of this type can also indicate small differences in color discrimination ability.

The task in these tests generally involves arranging small moveable caps (in which Munsell standard colors are mounted) into a continuous color series among the primary wavelengths. By selecting Munsell colors which are fairly equidistant under standard lighting conditions, color stimuli have been controlled for saturation and for brightness levels 
(Lakowski, 1969).

The validity and reliability of the 100-Hue test (an enlarged version of the Dichotomous Test) for detecting the congenital types of dichromats are well established; for the test correlates extremely well with similar findings on the more expensive and elaborate anomaloscopes and colorimeters (Lakowski, 1968). In addition, Verriest (1964) has shown that the 100-Hue test is useful in the detection of the "scotopictype" confusion, particularly characteristic of many subjects with acquired color vision defect.

In short, Poulsen (1971) cites Verriest et al. (1962) and Roth (1966) in concluding that "The 100-Hue Farnsworth discrimination test is excellent and without any doubt is the most important test to be performed in acquired dyschromatopsias." It should be noted, however, that tests of hue discrimination (such as the 100-Hue) were not designed to separate the anomalous types of defects from normals, and occasionally a protanope is able to use his lightness discrimination to compensate for his lack of hue discrimination; this can happen occasionally because the test was standardized on a normal population with respect to lightness; but the protanope may see some gradation in lightness not apparent to the normal, since reds look darker to him anyway (Wright, 1971).

Highly sophisticated tests, such as the Pickford-Nicolson Anomaloscope (1960), are generally reserved for highly technical experimentation in color vision theory. Because they are optically complex instruments, requiring a high degree of sophistication on the part of both the experimenter and the observer, Lakowski (1969) concludes that they are impractical for routine color vision testing. Normally, these 
instruments are the ones upon which validation research is conducted, for their use as an appropriate criterion measure for new instruments has been widely accepted.

Essentially, these are instruments which require subjects to mix primary lights to produce a match to a given stimulus. They represent a class of devices with a high degree of spectral purity, utilizing complex mixture ratios; and are the only means for detecting anomalous types of defects reliably. Of all the tests, the anomaloscopes are the most difficult to use, and specialized training is absolutely required (Lakowski, 1968).

Color Theory and Measurement

The term "color" is sometimes used as a name for materials, such as dyes and pigments; the term "colorant" is perhaps more precise in this context. In physics, the spectral composition of radiant energy and the spectral transmittance or reflectance of a substance is called "color". The psychophysical concept of color, however, as a characteristic of light and dependent upon human vision, is that which will serve as the primary definition of "color" for purposes of future discussion (Optical Society of America, 1963).

"Colorimetry" is the technique of the measurement of color. It is based upon the idea that a relationship can be found between physical specifications of color stimuli, and the sense perceptions that arise from them (Judd and Wyszecki, 1975).

"Surface color", a term used to refer to color that is perceived as a characteristic of a surface, varies in hue, saturation, and lightness. However, two surface colors that have been equated on the basis 
of these three attributes will not necessarily appear identical; for a surface color changes its appearance with changes in illumination (Beck, 1975).

Subtle changes in the appearance of surface colors can also result from differences in composition and texture of the surface. Metallic colors, such as gold, silver, and copper, are also possible. In addition, surface color may vary along dimensions from glossy to matte; from transparent to opaque; and from fluorescent to nonfluorescent. In other words, color is normally regarded in terms of wavelength and intensity, but surface color is actually much more complex (Beck, 1975).

The CIE System. A system adopted by the Commission Internationale D'Eclairage (International Commission on Illumination) in Paris in 1931, has attained great importance in the "science" of color. Known also as the Standard Valency System, the CIE system represents a theoretical ideal for spectral color sequencing, and is built upon the assumptions of additive mixture.

Mathematically precise definitions of all manifestations of color are central to the CIE model (see Figure 18). The references are the straight lines $X, Y$, and $Z$, situated outside the color solid itself. The primary vectors (red, green, and blue) had to be converted to the mathematical valencies ( $X, Y$, and $Z$ ), since it was not possible to cover the entire color space with the red, green, and blue vectors. Because the reference system lies outside the solid, mathematically exact calculations are possible; however, the gravest disadvantage of the CIE model concerns the distances between hues in the color space. These distances are strongly distorted when compared with the distances found to evoke 
The CIE System

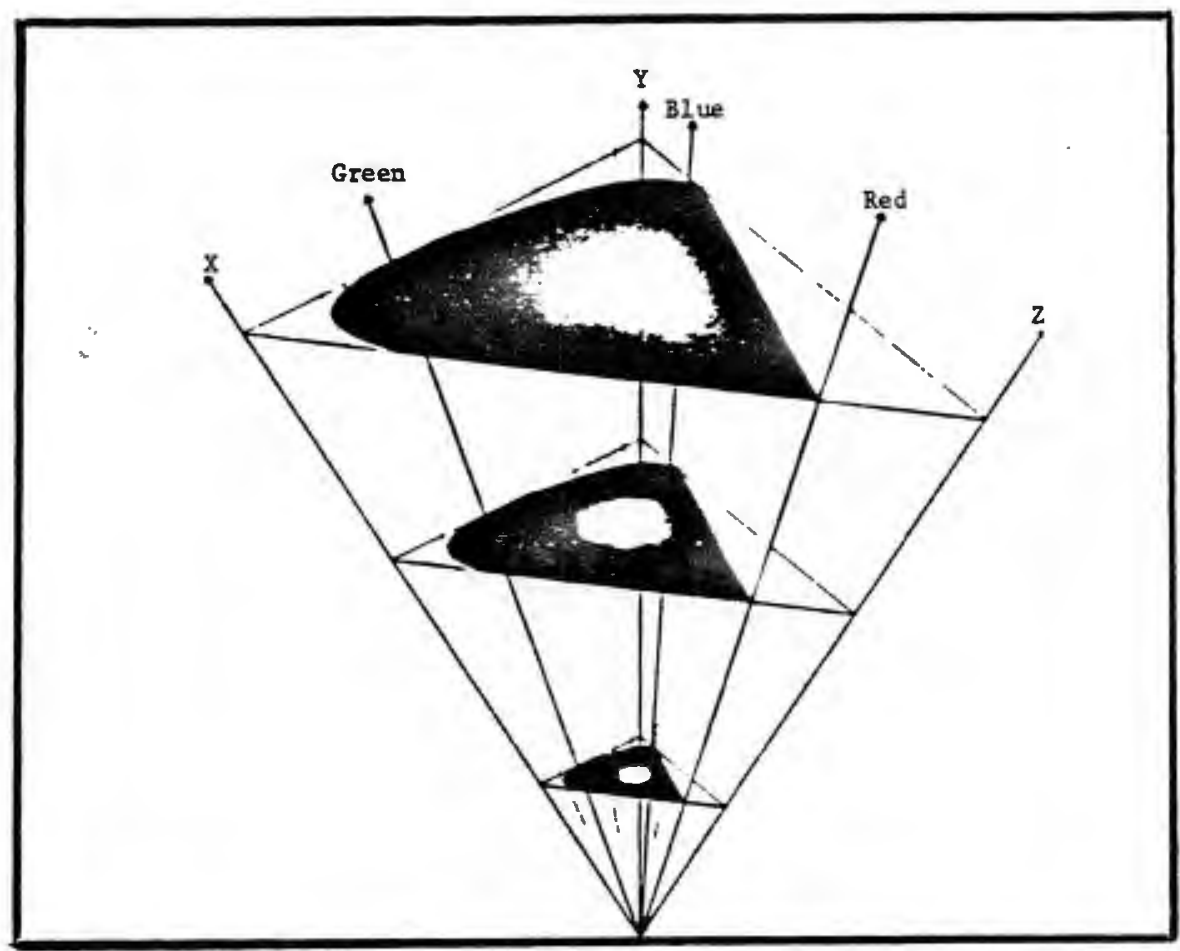

Fig. 18. Since it is not possible to cover the entire color space with the primary valencies (red, green, and blue) the mathematical primary valencies ( $\mathrm{X}, \mathrm{Y}$, and $\mathrm{Z}$ ) are used as reference points. From the spectral color sequence of this system, the colors become progressively darker the closer they approach the point source (at the bottom of the figure). (Kuppers, 1973 adaptation) 
The Spectral Color Sequence Curve Surface of the CIE System

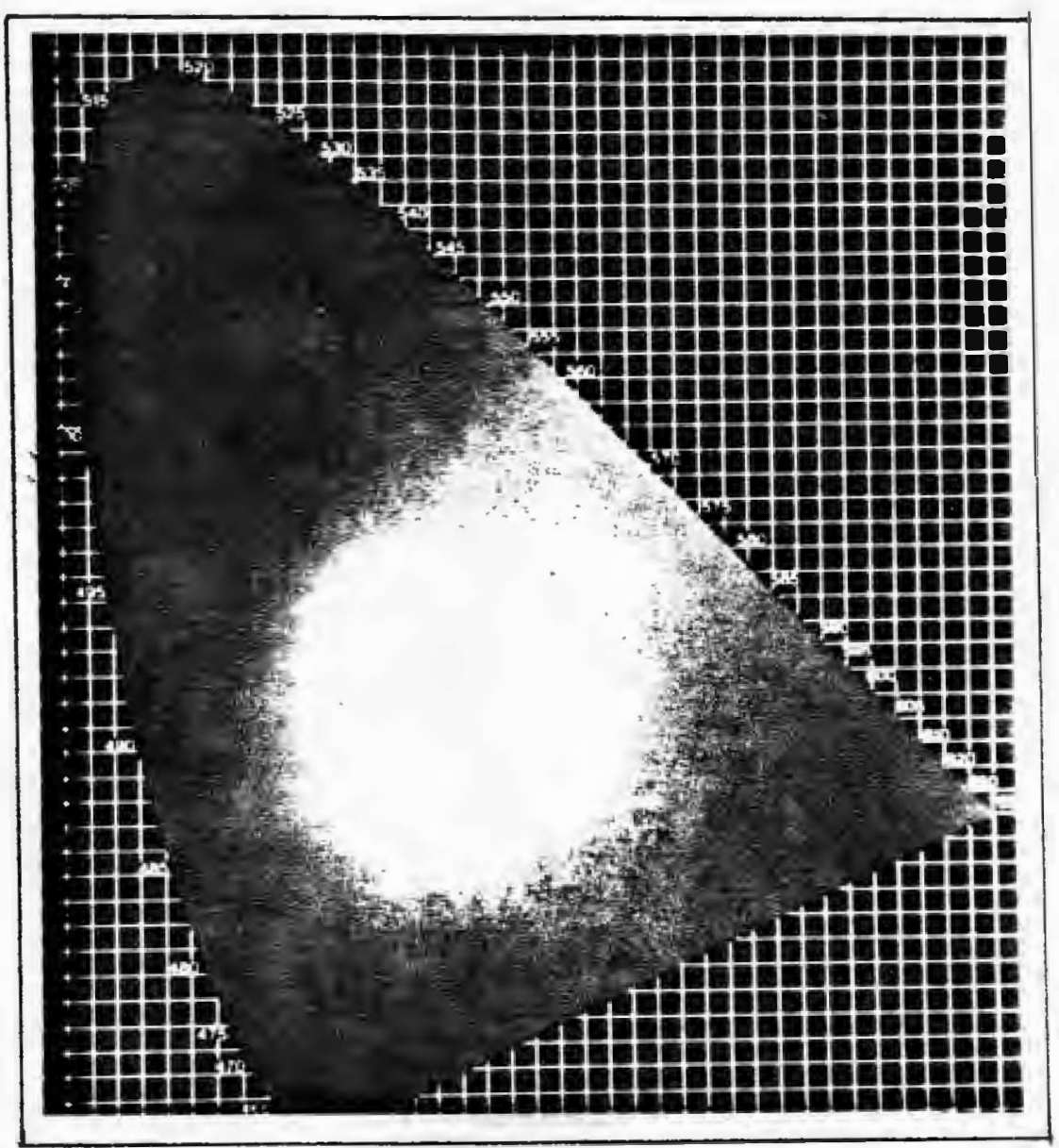

Fig. 19. The monochromatic colors, whose wavelengths are shown, progress along a curve from blue to red. The straight line connection between these points is called the purple boundary. The position of the white point in this system changes with the quality of the light. (Kuppers, 1973) 
equal degrees of sensation among humans (Kuppers, 1973).

In the United States, Judd (1935) was the first to attempt to eliminate the drawback of the deviation of distances from equal degrees of sensation. His system has undergone several modifications, resulting in the Uniform Chromaticity Scale, and the newly improved DIN 6164 System (DIN-Farbenkarte DIN 6164, Berlin, 1962). However, neither the CIE System, the Uniform Chromaticity system, nor the DIN 6164 system is very satisfactory; for each proceeds only from additive mixtures and has no reference to the physiological process of vision, nor to the laws of mixture pertaining to body color, or pigment. Further, all monochromatic colors are arranged equivalently on the spectral color sequence curve (see Figure 19). Primary colors do not take precendence over other colors. So as a demonstration model, neither of the three most popular systems is thought to be adequate (Kuppers, 1973).

The Munse11 System. The construction of the Munsell system (Munse11, 1946) is somewhat more satisfactory, for it has been built upon practical considerations. Munsell tried to create a system in which priority was given to insuring equal distances among all levels of hue, saturation, and lightness, the psychological attributes of color sensation. This strategy results, however, in a completely asymetrical color solid, one which is difficult to work with in applied research. Munsell's system of color notation identifies color in terms of the three psychological attributes: hue, value, and chroma. The method arranges the three attributes (Munsell terminology used) into scales of equal visual steps (American Society for Testing Materials, 1974); with the scales used as parameters for the specification and description of 
The Munsell System

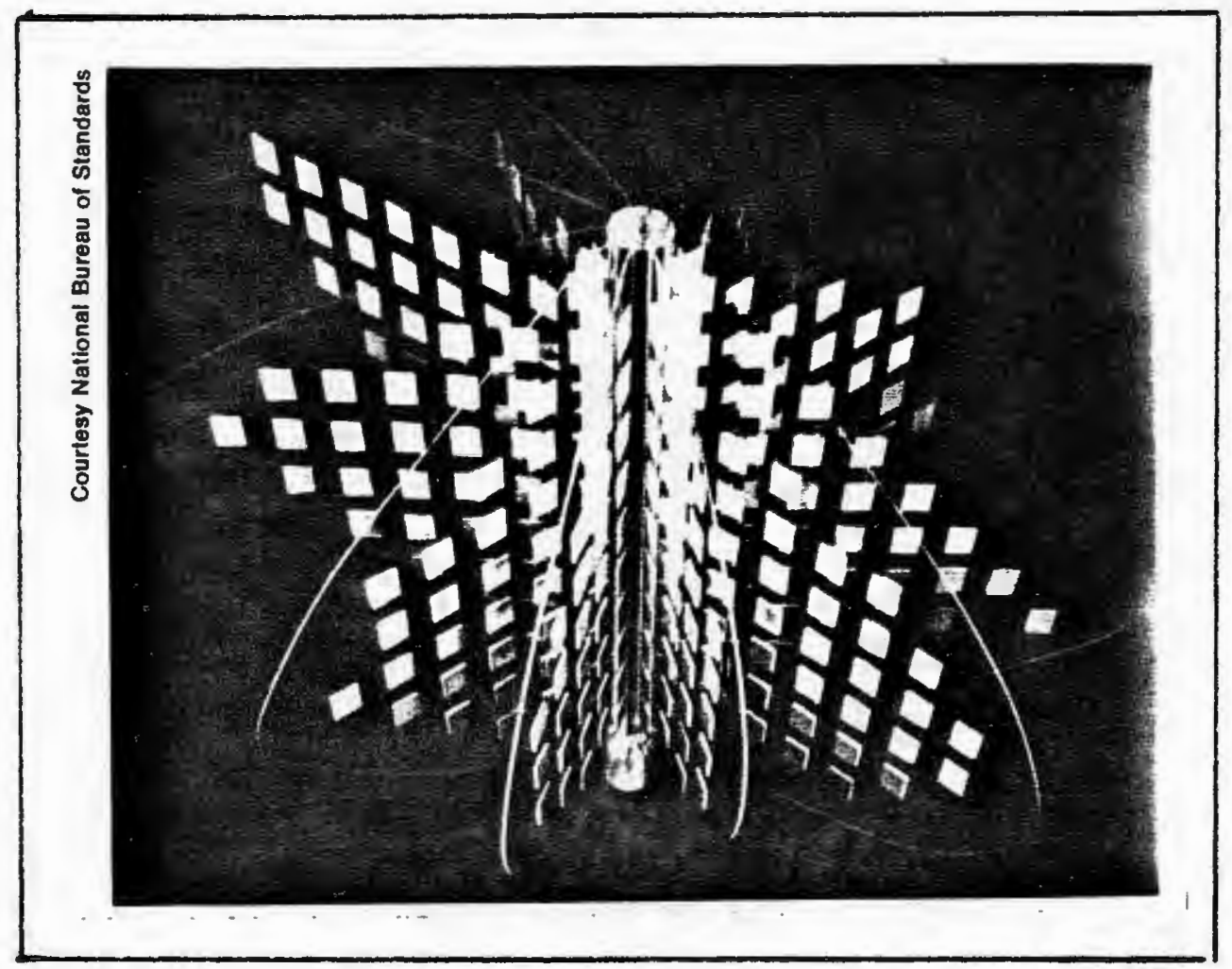

Fig. 20. Hue varies around the perimeter of the color solid. Chroma (saturation) varies from the perimeter to the center; that is, colors are rich and vivid at the outside, but become paler as one follows any one radius in toward the center. Value (lightness) varies along the vertical axis. (Munsell Color Company) 
color under standardized illumination and viewing conditions. The estimated precision within which a color notation can be determined by visual comparison (in a normal color vision observer) is .5 hue step, .1 value step, and .4 chroma step (American Society for Testing Materials, 1974).

Hue is the name of the color: red, yellow, green, blue, etc. Value is the lightness of a color, ranging from dark to light. Chroma is the saturation, or strength, or purity of the color, as compared with a gray of the same value (see Figure 20). Much work has been done on this relationship, and the optical Society of America's Subcommittee on Spacing of Munsell Colors (Newha11, Nickerson, \& Judd, 1943) has published a table for converting value intervals to CIE "Y" equivalents. The first Munsell Atlas of Color, published in 1915, displayed color scales which were representative of the Munsell color space up to that time. Improved scales, published in the 1929 edition, resulted from studies done with the National Bureau of Standards (Nickerson, 1940). In 1943, the scales were once again revised to conform to the CIE standard observer and coordinate system for color specification. The Munse11-CIE correlation affords a method for converting spectrophotometric measurement data to Munsell and CIE notations, and provides the first psychophysical specification for production of color standards. Many government and industrial color specifications are written in Munsell notation. The American National Standards Institute and the American Society for Testing and Materials have incorporated Munsell notation into their standards. The Inter-Society Color Council and the National Bureau of Standards specify color-name limits in terms of the 
Spectral Emission Curves

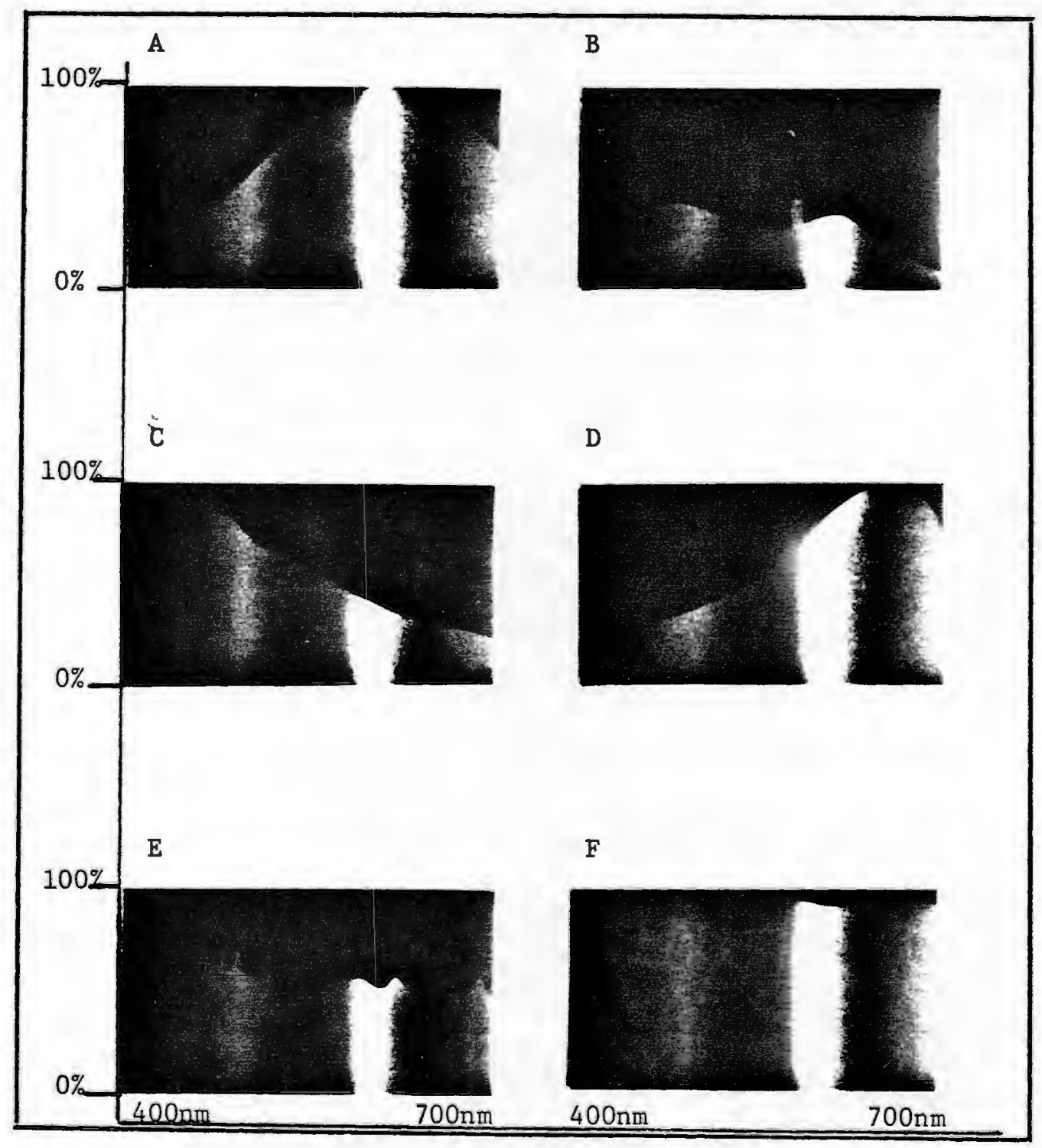

Fig. 21. Percent of light reflected at each wavelength: (A) yellowish light of a tungsten filament lamp (B) daylight fluorescent lamp (C) natural summer noon daylight (D) sunset daylight (E) Xenon light (F) color analysis lamp (Kuppers, 1973 adaptation) 
Munsell notations. The Japanese Industrial Standard for Color, as well as the British and German Standards, is based upon the Munsell system. Munsell color standards are produced from opaque pigmented films on cast-coated paper for over 1,500 notations. Samples are subjected to spectrophotometric measurement to insure quality control. CIE data and the Munsell notations derived from them, as well as spectrophotometric measurement data, are provided by the manufacturer, Munsel1 Color Company, of Baltimore, Maryland.

\section{Illumination}

Daily experience has taught us that the quality of light varies considerably. The reason for the different appearances of a piece of fabric, for example, in daylight and in artificial light has to do with the "color" of the light. Light can be composed of the visible radiations of the spectrum in almost any proportion. If certain regions of the spectrum are not present in the viewing light, they cannot be reflected. The color of light, therefore, depends upon its spectral composition, the spectral distribution of electromagnetic vibrations which are visible (see Figure 21).

Spectral emission curves provide information about the spectral composition of light. The procedure involves the measurement of the intensity of the light at various wavelength intervals. The relevant range of the spectrum usually extends from 380 to 680 nanometers, and is entered on the abscissa of a graph. On the ordinate are entered the relative intensities in percent. When the values are obtained for a particular light source, they can be entered into a coordinate system to obtain a curve, which can then be evaluated for quality (or spectral 
Color Temperature

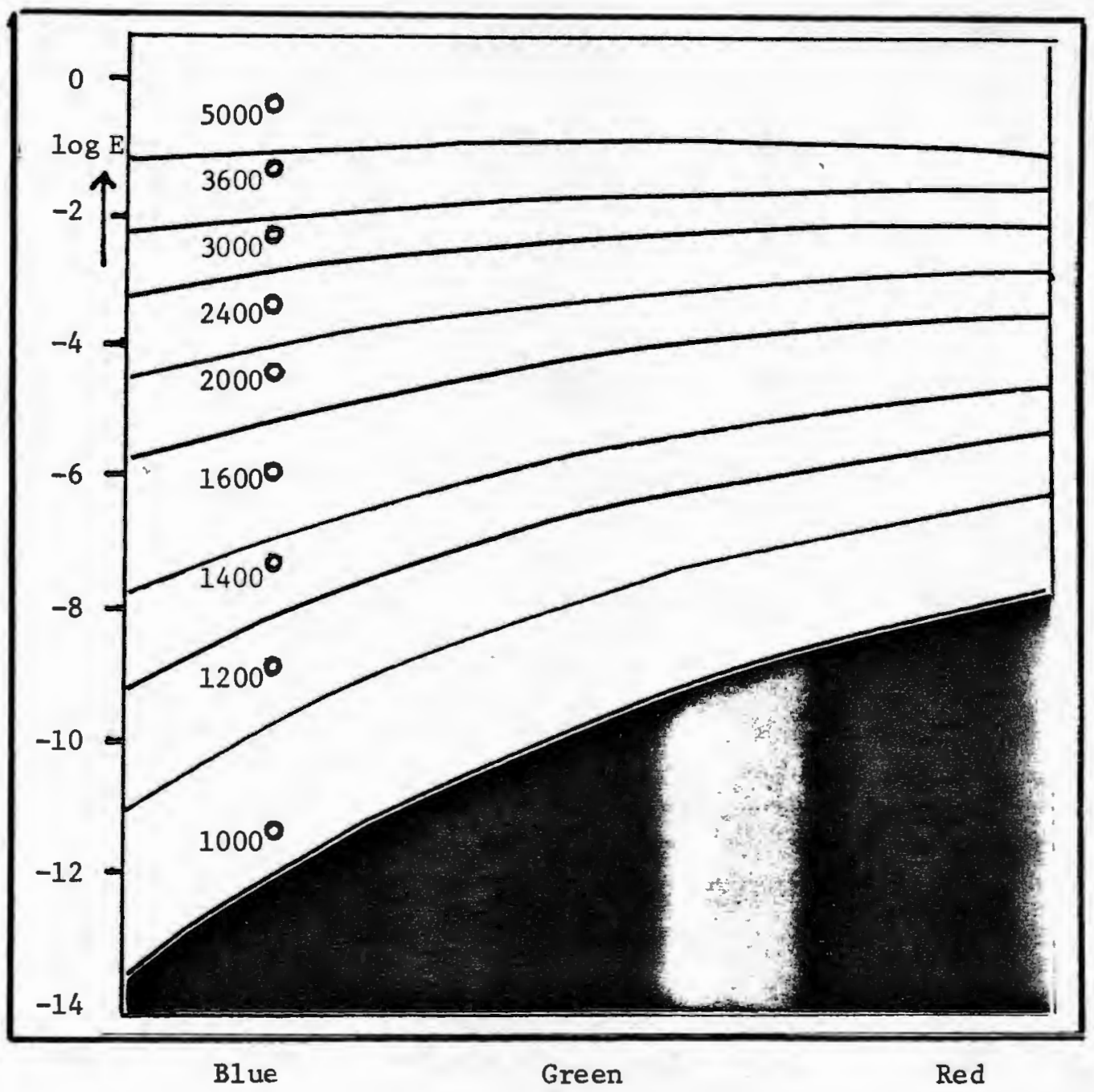

Fig. 22. A spherical, earthenware, hollow body emits light rays through a small opening. The more the body is heated, the higher its color temperature. At low color temperatures the long-wave (red) portion of the spectrum predominates. At about 5000 degrees Kelvin the spectrum is balanced. When color temperature rises beyond this figure, the short-wave part (blue) will predominate. (Kuppers, 1973) 
The Effect of Illumination on Perceived Color

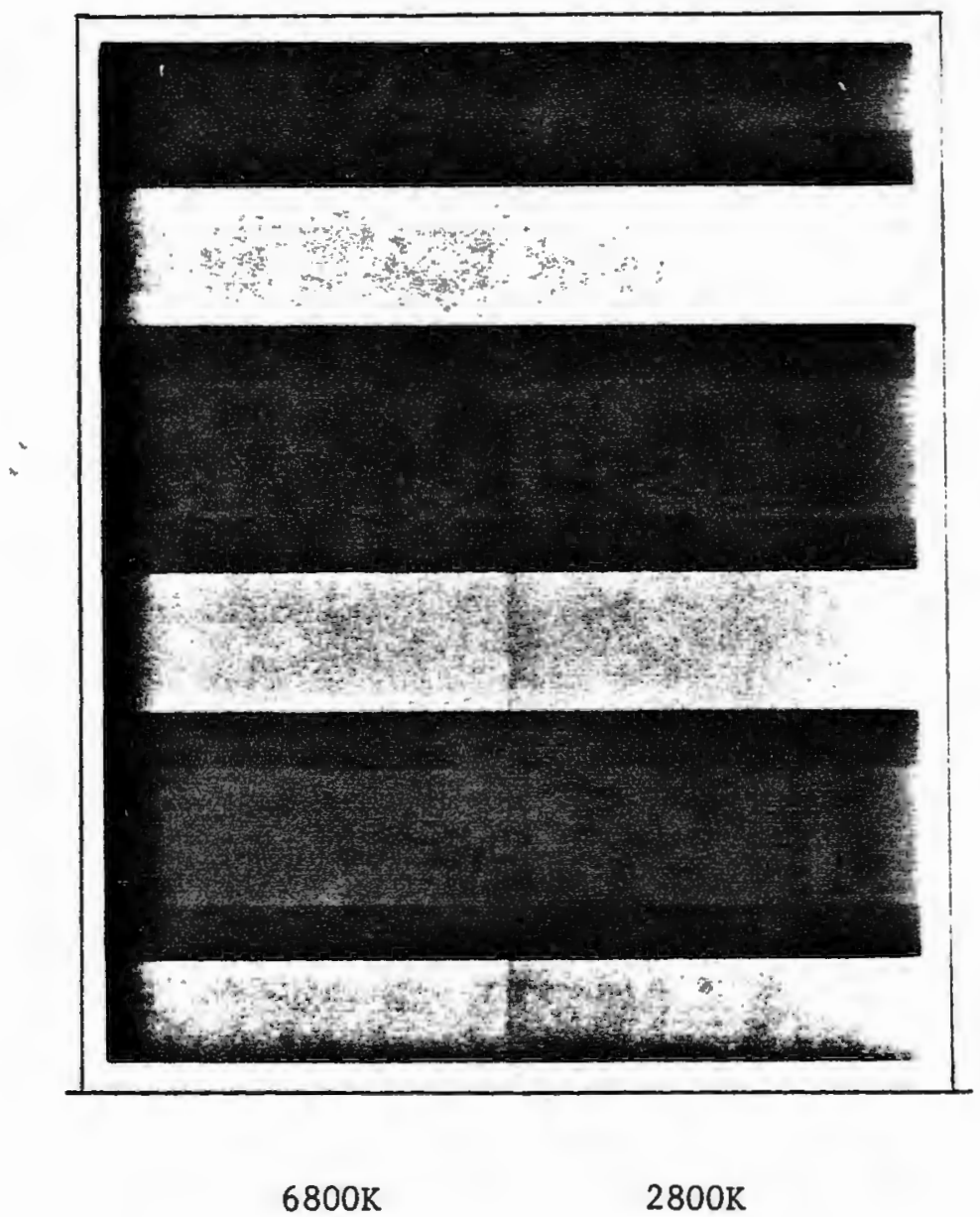

Fig. 23. These typical colors in daylight (6800 degrees $\mathrm{K}$ ) appear quite different when viewed in tungsten filament light (2800 degrees K). A light blue, for examle, is no longer perceived as a saturated hue when it is illuminated with a light of low Kelvin value. It appears gray. On the other hand, colors in the red region appear more luminous and intense than they really are. 
composition) relative to the purpose for which the light is to be used.

It can be seen that the daylight lamps (typically fluorescent) are often far from producing truly "white" 1ight. "Spiking" (sudden and transient increases in intensity) is caused by the specific properties of the gases used in fluorescent lamps, and as a rule are not appropriate for viewing colored objects. Nor is daylight always white. Depending upon the position of the sun, the weather, and the angle of viewing, the mixture of the wavelengths making up daylight can vary widely. Color analysis lamps emit a light of balanced spectral distribution, for the intensities at the various wavelengths are nearly equal. In some such lamps, different types of light are mixed to meet the requirements of the CIE theoretical ideal (Kuppers, 1973).

Another way to think about the various qualities of light is to think in terms of color temperature, expressed in degrees Kelvin (see Figure 22). As the temperature at which a light source burns to produce radiant heat, the emission curve flattens out, approximating the horizontal at 5000 degrees Kelvin. It can be seen, therefore, that the shift with increasing temperature is toward the short-wavelength or blue range. Between 7,000 and 10,000 degrees blue light predominates.

It is remarkable to see just how radical a change can be observed in the perception of surface colors when different light sources are used (see Figure 23). The left side of each color card was illuminated with an artificial daylight lamp of 6800 degrees; while the right side with light resembling an ordinary tungsten filament source of 2,800 degrees. A light blue, in this case, is not perceived as the blue that it represents when illumination is at a low temperature, and it appears 
gray. On the other hand, colors in the red and green family appear to be brighter and more saturated than they actually are.

CIE has set standards for various light sources, and in 1965 adopted a new set of curves to represent typical daylight. Though the more recent "S" source, the deep blue of a clear north sky at a color temperature of infinity, is more theoretically pure; CIE Illuminant "C", average daylight at 6,700 degrees Kelvin, forms the basis for nearly all psychophysical research. Spectrophotometric measurements made on the Munsell color standards, for example, were derived from the CIE data for Illuminant "C" (Judd \& Wyszecki, 1975).

The relative spectral power distributions for CIE Illuminants "A", "B", and "C" can be compared (see Figure 24). It can be noticed that "C" provides the more balanced distribution in the visible spectrum (Judd \& Wyszecki, 1975).

CIE has made no recommendations for artificial sources to produce any of the "D" Illuminants, for difficulties lie in the rather jagged spectral distribution of what is considered to be representative of global daylight $(6,500$ degrees Kelvin). For this reason, Kuppers (1973) cautions about being misled by color temperature values; for though a given light source produces the optimum color temperature value, the intensity at some of its spectral regions may be deficient.

In addition, CIE has recommended the standard illuminating and viewing conditions, with respect to the specification of opaque specimens. Among the procedures listed is one which Judd and Wyszecki describe as most closely representing typical viewing conditions for evaluation research in color preference: 


\section{Spectral Power Distributions of \\ CIE Illuminants $A, B$, and $C$}

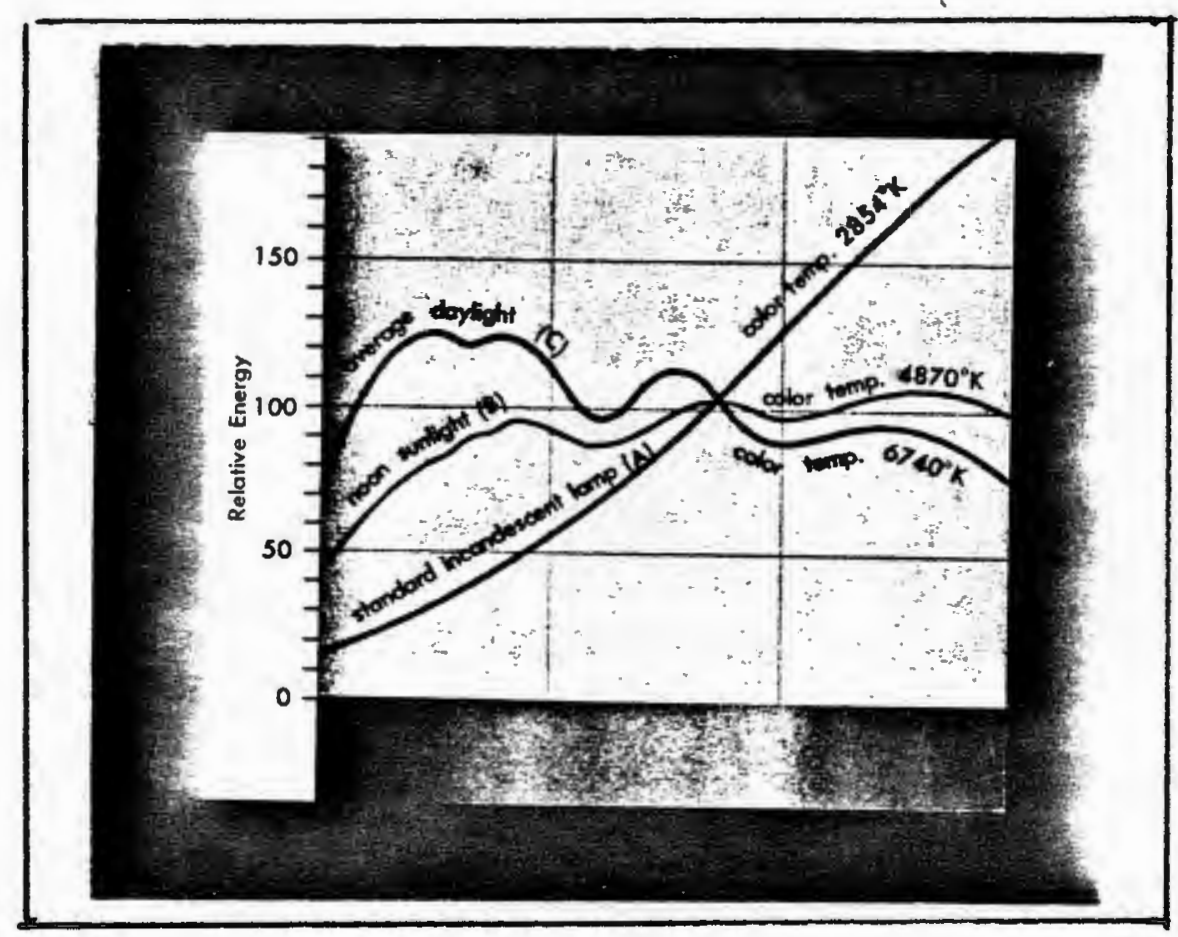

Fig. 24. The energies of the three internationally accepted light sources are plotted for the visible region of the spectrum. Notice that the curve for the standard incadescent lamp, because of 1 ts tungsten filament, is the same as that for 2854 degrees Kelvin. Source "C" provides more energy at each wavelength, and its spectral power distribution is more balanced. (adapted from Rainwater, 1971) 
0/45: The specimen is illuminated by a beam whose axis is at an angle not exceeding 10 degrees from the normal to the specimens. The specimen is viewed at an angle of $45 \pm 5$ degrees from the normal. The angle between the axis and any ray of the illumination beam should not exceed 5 degrees. The same restriction should be observed in the viewing beam. 
III. COLOR RESPONSE RESEARCH--COLOR PREFERENCE

The Methods of Research

The body of literature concerning the methods and materials employed in efforts to discover the psychological meaning of color is abundant. Historically the work has been undertaken in several directions, each with its own group of strategies aimed at testing the relevant hypotheses.

Since, the focus of the present research concerns the colorpersonality hypothesis, discussion will be limited to previous approaches within this context, particularly with respect to the color preference model. In general it can be noted that major criticisms render most of the conclusions reached by previous authors to be less than impressive. Serious shortcomings in previous work concern the small samples of subjects studied, the limitations inherent in the physical materials used, problems associated with the various methods of stimulus presentation, as well as with statistical treatment of the data. In short, control for error sources of variation have been sadly neglected for the most part, and generally do not inspire much confidence in the results.

The "Method of Paired Comparisons". This method requires each color stimulus to be paired with every other one, which results in an ordinal scale.

Used by Farnsworth and Chichizola (1930) to study the color pref- 
erences of adolescent boys, with judgments expressed in sigma units, the method of paired comparisons produced results which suggested that red was the preferred color, whereas prior work had led to the conclusion that blue was the most preferred (Chandler, 1928).

When this method is used, therefore, the small numbers of color stimuli and/or subjects frequently results in conflicting findings among studies. Further, the amount of time involved in obtaining data with this method is substantial, and the introduction of additional colors (to control for lightness or saturation) is not possible, for it has the effect of promoting fatigue (Norris et al., 1911).

When color stimuli are not clearly specified (Milton Bradley papers matched "by eye" to approximate Munsell standards), and Munsell notations are then entered into the analysis (as Guilford did in the classic work on color preference), precision becomes impossible.

Though the method of paired comparisons, when repeated with the same subjects, yields information about the stability of judgment within subjects, its practical use is limited to samples of less than ten colors.

The "Method of Choice". This procedure involves the comparison of all the color stimuli, which are displayed simultaneously.

With this method the question arises as to whether subjects are making choices from all the colors, or from subgroups of colors, which may not then be recompared among one another by the subject. When this method is used issues concerning the effects of afterimages and simultaneous color contrast are also brought into question. In this method we also run into the practical limitations placed upon the number of 
color stimuli that can be handled together.

The "Modified Method of Choice". This adaptation of the method of choice involves the comparison of color, dependent upon the presentation of color names.

The difficulties with this method become apparent when one considers that for the same person, the term "red" may imply a highly saturated color and the term "blue" may imply a color. of medium or low saturation. Further, different people may ascribe different meaning to various hues. What one person may describe as "red", another may describe as "crimson". The "Method of Serial Presentation". With this method color stimuli are arranged in a series according to hue, lightness, or saturation. The asymmetrical shape of the color space makes parallel presentation of the three psychological attributes impossible at the higher levels of saturation in a single series presentation.

When color stimuli are presented in a series, therefore, the separate colors operate not as members of a continuous series, but as independent qualities. In addition, the ability to generalize to reallife judgment is poor with this method, for the color of objects is usually judged with the three attributes operating simultaneously. One cannot attend selectively to hue, for example, while at the same time ignoring the effects of lightness and/or saturation.

The "Q-sort" Method. In this method subjects are asked to judge color stimuli, presented one at a time, on a Likert-type rating scale (Stephenson, 1935).

Instead of correlating test items for a large group of subjects, emphasis in this method is placed upon correlating persons. Results can 
be analyzed for discrimination among "types" of color raters. This method lends itself quite readily to stability-of-judgment information within subjects.

Unfortunately, in the only two studies that reported using the Q-sort technique, color stimuli were neither standardized nor clearly specified. For example, in the original Stephenson work (1935), color samples were taken from an artist's kit. In addition, results were formulated from Stephenson's own subjective impressions as to the personality traits of his subjects.

Schaie (1960) used Stoelting colored papers in his Q-sort study, which he then went on to describe in Munsell terms. U1timately the study failed to control systematically for saturation and brightness; did not make mention of standard illumination and viewing conditions; and used a criterion measure that suggested no evidence for reliability.

Hence, of the five techniques that have been most commonly employed to study color preference, the method of paired comparisons and the Q-sort method appear to be least problem ridden. The Q-sort method possesses the added advantage of paying attention to color "selection", and also has the practical advantage of allowing one to sample a larger surface of the color solid without promoting subject.fatigue. The key to the Q-sort's utility, however, rests with the careful use of control: control for color stimuli specification; control for a standard light source and viewing conditions; control in the selection of a representative sample, with respect to saturation and brightness; control for adequacy of color vision among viewers; as well as control for unreliability in the selection of a relevant criterion. 
The extent to which control measures are not employed can have profound effects upon the interpretation and generalizability of results. It is not surprising to see, therefore, little evidence for a systematic relationship of color to psychological variables (see Table 4). The question of whether discrepant results should be attributed to affect (that is, reflecting both transitory mood states and the more enduring characteristics of personality, as in the Schaie (1966) summary), or to the inadequate use of control measures, is unanswerable in retrospect.

In summary, therefore, the methods used for the measurement of response to color typically involve presenting to the subject some combination of color stimuli that are hypothesized to sample the surface of the color model that is referenced, together with some descriptions of mood or behavior; and then some type of scaling operation is performed with respect to the subjects' responses to each of these presentations. A different kind of approach, however, involves that which is implicit in most clinical personality descriptions: a technique which employs the use of color. The most well known of such techniques, of course, is the Rorschach (1942); however, it treats chromatic color as a unitary stimulus material. The confusion introduced by the parallel presentation of different hues, saturations, lightnesses, and form; together with the difficulties inherent in the scoring of the Rorschach itself (Goldfried et al., 1971), bring about conflicting results among studies specifically designed to related color response to psychological variables (Cerbus \& Nichols, 1963).

Two additional techniques concerned with the use of color, and whose procedures do not treat color as a unitary stimulus material, are 


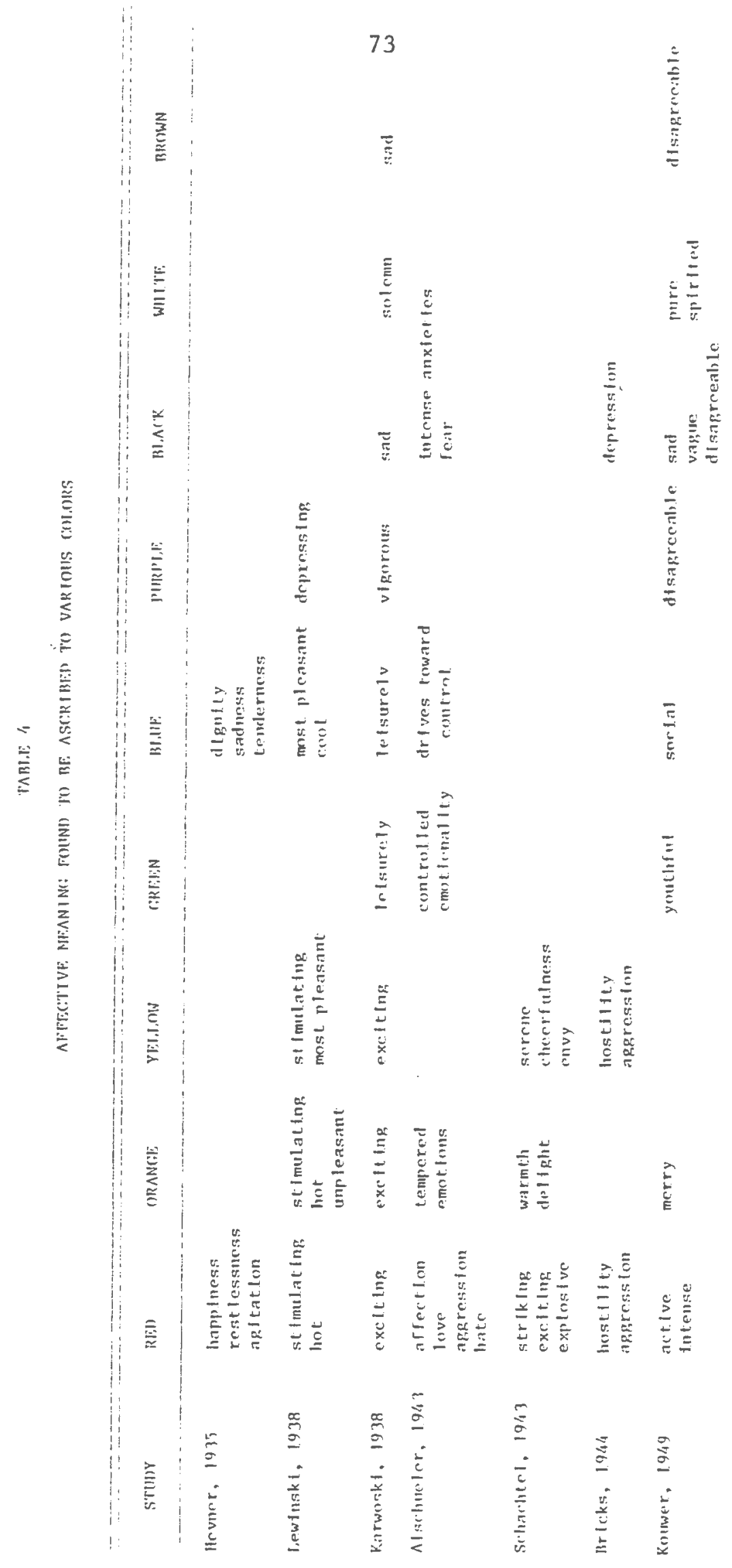




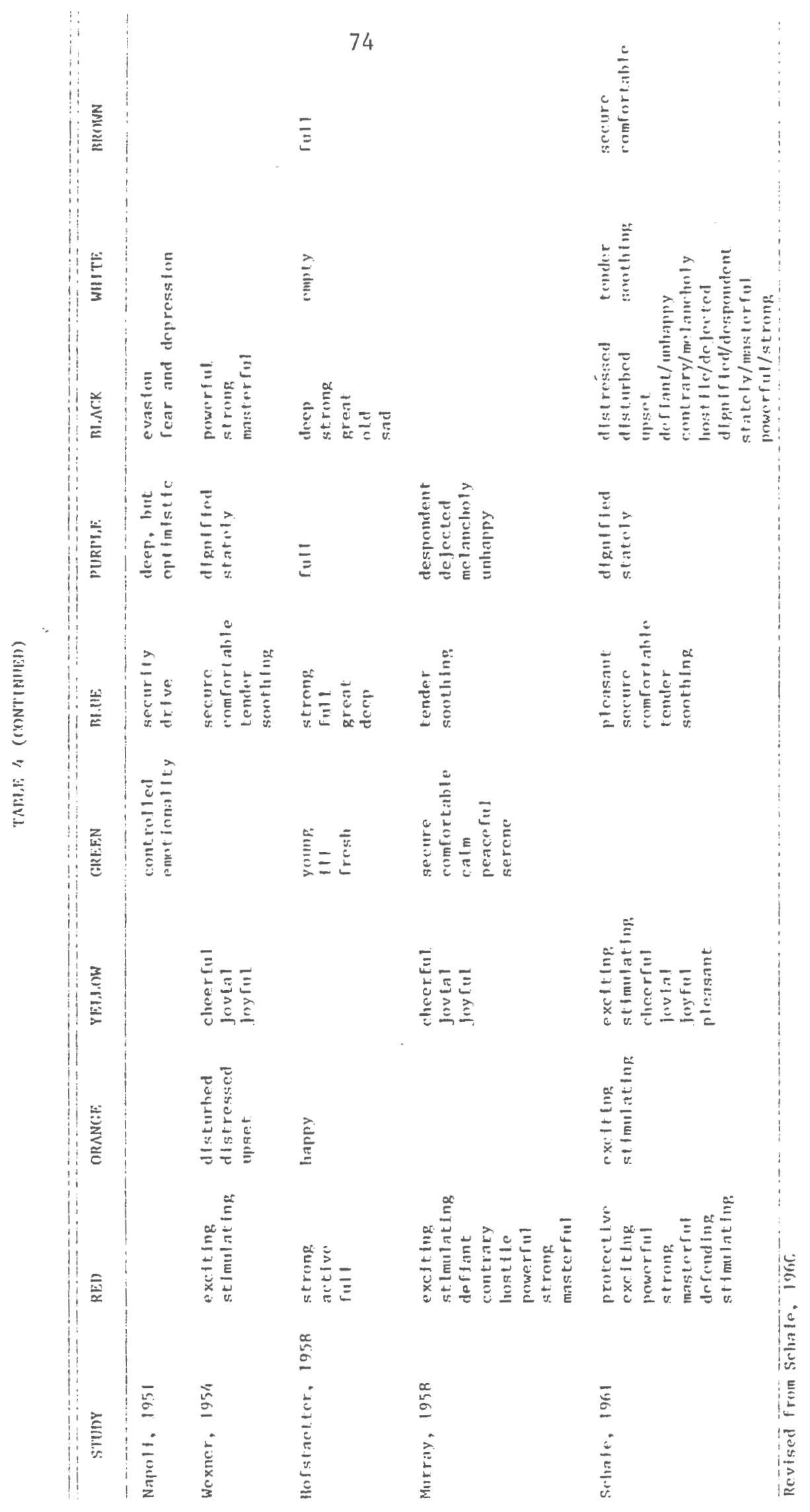


difficult to defend. The Luscher Color Test (Luscher \& Scott, 1969) uses a forced-choice technique, while the Color Pyramid Test (Schaie \& Heiss, 1964) reflects projective assumptions for interpretation of color and form interactions.

The Luscher, though described by its authors as a "deep psychological test," provides little supporting evidence for either reliability or validity. Test-retest reliability coefficients reported for the test in this country by Donnelly (1974), for a 45-day interval, range from .04 to .60 ; with the mean correlation at .36 . Concurrent validity work is similarly disappointing. Donnelly (1977) concluded that there were "no significant relationships between any specific personality descriptions" on the Luscher and the Taylor-Johnson Temperament Analysis scale, for example. Though the manual includes an extensive bibliography of work done in Europe on the Luscher, the vast majority of studies cited make use of "clinical judgment" as the sole criterion measure of its effectiveness in describing personality. A problem with regard to quality control in the production of materials is also apparent, for the color stimulus cards are merely of the punch-out variety (which are included in the inexpensive paperback edition). No information or assurance however, is provided with respect to color stimuli specifications. The Color Pyramid Test (Heiss \& Hiltmann, 1951; Schaie \& Heiss, 1964), possesses a somewhat higher reliability than the Luscher, as its mean test-retest correlations are in the .50's and .60's (Jolas, 1953; Pflanz, 1954; Brehmer, 1960); none the less, this test remains nearly impossible to interpret. At the base of interpretation lies a rather simplified system of hypothesized color relationships, most of which are 
rooted in symbolism. Thus, "...red is known as the violent colour of revolution, but at the same time represents the human characteristics of the International Red Cross..." (Schaie \& Heiss, 1964).

The subject is given more than 200 chips representing 24 hues, but no attempt has been made to stratify color samples across levels of hue, lightness, and saturation. Though selection evolved from Munsell notations, there is no indication that the test materials conform to Munsell color production specifications. Though asked to make a total of three "pretty" and three "ugly" pyramids, neither the subject nor the examiner are given any indication of what constitutes "pretty" vs. "ug1y"; for scoring criteria are never quite clearly specified (see Figure 25).

The manual is replete with statistics of many types, and a variety of quantitative indices are yielded by the scoring. However, the reader is given many special cautions, i.e., "...for the re-analysis it was decided to count as prediction error only those ratings where the predicted rating disagreed with both criterion raters. The revised procedure leads to far more encouraging results..." (Heiss \& Hiltmann, 1964).

Lee (1972) has summed up the validity question regarding this test most candidly:

Probably the statement that sticks most in my gullet is: "The content validity of the CPT is demonstrated simply by showing (as in Fig. 2) that an adequate sample of hues in the color spectrum has been included in the test material." Validity for what?

\section{Reliability--The Key Issue}

It would appear reasonable that if psychology, qua science, were truly interested in establishing a relationship between color response and personality, and it regarded personality as a fairly stable 
Color Pyramid Test Stimuli

\begin{tabular}{|c|c|c|c|c|c|c|c|}
\hline $\begin{array}{l}\text { Color } \\
\text { Sample }\end{array}$ & $\begin{array}{l}\text { Color } \\
\text { Code }\end{array}$ & $\begin{array}{l}\text { Color } \\
\text { Name }\end{array}$ & $\begin{array}{l}\text { Munsell } \\
\text { Value }\end{array}$ & $\begin{array}{l}\text { Color } \\
\text { Sample }\end{array}$ & $\begin{array}{l}\text { Color } \\
\text { Code }\end{array}$ & $\begin{array}{l}\text { Color } \\
\text { Name }\end{array}$ & $\begin{array}{l}\text { Munsell } \\
\text { Value }\end{array}$ \\
\hline & 11 & Red 1 & $\begin{array}{l}2.5 \mathrm{R} \\
7 / 10\end{array}$ & & 51 & Blue 1 & $\begin{array}{l}10 \mathrm{~B} \\
6 / 6\end{array}$ \\
\hline & 12 & $\operatorname{Red} 2$ & $\begin{array}{l}5 \mathrm{R} \\
4 / 15\end{array}$ & & 52 & Blue 2 & $\begin{array}{l}5 \mathrm{~B} \\
6 / 8\end{array}$ \\
\hline & 13 & Red 3 & $\begin{array}{l}5 \mathrm{R} \\
3 / 12\end{array}$ & & 53 & Blue 3 & $\begin{array}{l}5 \mathrm{~PB} \\
4 / 10\end{array}$ \\
\hline & 14 & Red 4 & $\begin{array}{l}2.5 \mathrm{RP} \\
2 / 8\end{array}$ & & 54 & Blue 4 & $\begin{array}{l}7.5 \mathrm{~PB} \\
2 / 12\end{array}$ \\
\hline & 21 & Orange 1 & $\begin{array}{l}2.5 \mathrm{YR} \\
6 / 14\end{array}$ & & 61 & Purple 1 & $\begin{array}{l}10 \mathrm{~PB} \\
8 / 4\end{array}$ \\
\hline & 22 & Orange 2 & $\begin{array}{l}2.5 \mathrm{YR} \\
7 / 16\end{array}$ & & 62 & Purple 2 & $\begin{array}{l}5 \mathrm{RP} \\
4 / 12\end{array}$ \\
\hline & 31 & Yellow ! & $\begin{array}{l}5 Y \\
8 / 14\end{array}$ & & 63 & Purple 3 & $\begin{array}{l}5 \mathrm{RP} \\
2 / 4\end{array}$ \\
\hline 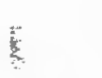 & 32 & Yellow 2 & $\begin{array}{l}2.5 Y \\
8 / 12\end{array}$ & & 71 & Brown 1 & $\begin{array}{l}2.5 \mathrm{YR} \\
4 / 6\end{array}$ \\
\hline & 41 & Green 1 & $\begin{array}{l}2.5 \mathrm{GY} \\
8 / 12\end{array}$ & & 72 & Brown 2 & $\begin{array}{l}2.5 Y \mathrm{YR} \\
3 / 4\end{array}$ \\
\hline & 42 & Green 2 & $\begin{array}{l}7.5 \mathrm{GY} \\
.7 / 10\end{array}$ & & 8 & White & N 9.5 \\
\hline & 43 & Green 3 & $\begin{array}{l}2.5 \mathrm{G} \\
5 / 10\end{array}$ & & 9 & Gray & $\begin{array}{l}5 Y \\
7 / 2\end{array}$ \\
\hline & 44 & Green 4 & $\begin{array}{l}2.5 \mathrm{G} \\
2 / 4\end{array}$ & & 0 & Black & N 1 \\
\hline
\end{tabular}

Fig. 25. It should be noted that color samples are not stratified across levels of hue, chroma, and value, (Schaie and Heiss, 1964) 
collection of personal attributes or behavioral predispositions, then the issue of reliability of color preference within subjects would be a central one. Though formal consideration of the state-trait argument (Mischel, 1968) has only recently come to the attention of personality researchers, one questions the wisdom of investing so much energy into a topic of investigation which at the outset is regarded to reflect momentary or fluctuating states and conditions. Generalized response dispositions, such as color preference, have been merely assumed to possess the characteristic of stability over time; for it is widely believed that people are variably reliable with respect to many preferences, such as food tastes.

Indeed, the influence of the culture upon any class of preference judgments cannot be ignored. Ellis (1900; 1906) was the first to predict that the color which is preferred at one period of history will not be the color which is preferred at another time. Over the years, consequently, statements about general changings over the color space have been based upon group data, with interindividual differences classified as error variance or "noise." The body of data has been typically reduced to matrices of averages (over subjects) by colors and by various scales; reliability has been defined as the consistency or stability of a group. The implication is that the culture affects nearly everyone in the same way.

Interindividual differences have been studied quite extensively, therefore, and generate results which conflict greatly among studies; while intraindividual consistency has received very little attention. Reliability in this context, that is, how consistent an individual is in 
two or more successive judgments, is basic to the prediction of differential effects of the culture (or of biology, for that matter) upon individuals. Further, evidence for intraindividual stability over time is essential to the construction of instruments which aim to describe and explain individual behavior; instruments which treat error variance as consisting of differences within the individual. If there is a system in color preference, therefore, would not the logical place to start in the measurement of it be with the individual?

Color Preference Reliability Studies--Within Individuals

Cohen (1894) deriied the existence of any general order of color preference, for he found that among equally saturated colors the preference order depended exclusively upon individual taste. Major (1895) concluded that the whole question of the "affective tone of colors" was a difficult one: due partly to the "unaccustomedness of the affective judgment," partly to individual differences, and partly to the notion that the "centrally excited influences which meet the incoming stimulus, and which are very strong, differ from time to time in one and the same individual."

Intraindividual reliability for a preference order was studied for the first time in this century by Bradford (1913), who found a strong correlation between successive tests (two weeks and one year) as to the order of preference ( $r^{\prime} s=.81$ to .94 ). It must be kept in mind, however, that his results were based upon an $\mathrm{N}$ of 3 ; his 15 color stimuli were specified by color name only; and the work suggests no evidence for control of lightness factors, illumination, or standardized background and viewing conditions. Further, his procedure involved the simulta- 
neous presentation of 15 colors (method of choice), and for reasons described elsewhere remains difficult to defend.

Valentine (1914) used a method similar to the method of paired comparisons to study the color preference order of an infant during its fourth and eighth months. He concluded that at seven months the one infant that he studied still liked the same yellow skein of yarn that he had preferred at four months. Control, of course, was clearly not achieved by Valentine's procedure.

The subject of reliability within subjects was not looked at again until Guilford (1939) had 40 students (20 males and 20 females) rate 105 colors on two different days (interval unspecified). The reliability coefficients for the single judges for the males ranged from .62 to .81 . When the judgments of single colors were pooled, the estimated reliability for the males was reported to be .94 , the Spearman-Brown formula having been used.

The illumination in Guilford's experiment consisted of four frosted blue Mazda lamps, which he incorrectly maintained, provided a constant artificial daylight. Each color was exposed for only five seconds, and judgments were given in terms of a numerical scale of eleven steps, ranging from "the most unpleasant imaginable," to "the most pleasant imaginable." Color blindness tests (unspecified) were given to insure normal color vision. It was emphasized, however, that due to "the excessive cost of the Munsell color papers, we proceeded to collect the samples from more available sources," and that the color stimuli (from among three different manufacturers) were matched "by eye" to Munsel1 standards (Guilford, 1939). 
In 1940, Guilford extended his findings to include the reliability coefficients he calculated for the women, ranging from .53 to .84; and he reported a pooled reliability estimate (stepped up by Spearman-Brown) of .93. Guilford concluded, therefore, that "there is a system in color preferences," and that sex differences do exist among groups of subjects.

In 1959, Guilford and Smith reported a replication of his experiment with 40 new subjects: and for the 10 color stimuli that were common to both studies, he found the correlations between the two sets of median values to be .86 for the men and .91 for the women. (Note that Guilford is talking about correlations between groups of subjects.)

The Guilford studies, therefore, served as the primary frame of reference for all future studies of color preference; though reliability within subjects was predicated upon the median judgments of 20 men and 20 women over an unspecified period of days. In addition, although five "good" observers matched Guilford's samples for hue, tint, and chroma to Munsell hue, lightness, and saturation, unspecified color stimuli materials from several different sources were those actually used in the studies.

Guilford and Smith's concluding statement (1959), therefore, has been taken to represent prima facie evidence for a reliable relationship between color preference and affective meaning.

One thing that can be said of the results is that they possess a very high degree of internal consistency, and hence reliability, for the population that they do represent. In addition to whatever norm-value they possess, they demonstrate a high degree of predictability of color-preference values from knowledge of the attributes of color, they bring out some general principles of color preferences, and they incidentally indicate some systematic sex-differences. 
In the meantime, Barrett and Eaton (1947) published results of their work, using a combination of the method of choice and a serial presentation of color stimulus material. A total of 18 hues were presented, each with their corresponding tints and shades ( 3 stimuli presented at one time) to 63 subjects, over an interval which varied between two weeks and twelve months. (The interval was reported to be a matter of six months for most members of the test group.)

The color stimuli (Milton Bradley papers, which were unspecified) were mounted into $20 \mathrm{~mm}$ caps with a small hole in the center, and were exposed beneath a Macbeth Illuminant " $\mathrm{C}$ " 1amp. Correlation coefficients for individuals who preferred hues $(r=.79)$ and for those who preferred tints $(r=.83)$ suggested stability of color preference over time; however, it remains unclear how many of the subjects that were retested (reported to be 60 in one part of the article and 63 in another part) preferred hues and how many preferred tints. Further, the criteria for interpretation consisted of a collection of tests, most of which suggested little evidence for reliability themselves.

Warner (1949), in his discussion of the color preferences of psychiatric groups, quickly sumed up the issue of intraindividual reliability by using the following logic, which is misleading:

...since each color-pair is presented four times (using the method of paired comparisons), the percent agreement among these trials (four each for the hue, saturation, and brightness series...across subjects) is readily determined. An average was taken of the percent agreement in each of the 9,000 sets of four trials contained in the data, which equals 81.5 . This figure is 59.8 times as large as the standard error of the theoretically expected percent agreement of 50, and strongly indicates that the consistency from trial to trial (at the same session) cannot be explained in terms of chance. 
It becomes apparent upon a careful reading of Warner's method that the same color stimuli sample is not being compared 12 times, but rather different degrees of lightness for a particular hue are being compared with different degrees of saturation of a particular hue; and the red hue, for example, is what is being used to determine percent agreement among trials.

Other problems with the Warner work include unstandardized background color (Milton Bradley paper used with Munsell standards); lack of uniformity with respect to lightness in the saturation series; and his neglect to test for color blindness. In addition, it would be difficult to generalize findings to non-psychiatric groups, and to maintain that his design attests to the stability of color preference judgments over time.

The study of intraindividual reliability does not appear to have been attempted again until 1974, when as part of a larger effort to measure the semantic meaning of color, Sivik calculated test-retest correlations (over a 30 minute interval) for 10 subjects. Sivik does caution one to consider his coefficients (ranging from .50 to .95) in light of his extremely small sample, however, and goes on to suggest strong differences in the consistency of some subjects' judgments over others. (Sivik does not speculate as to the reason for this inconsistency.) It should be noted, though, that results are for but one strong yellow only.

The weight of the evidence for color preference as a stable entity appears to rest primarily with the Guilford work (1939; 1940; 1959), which is not without its problems, as mentioned. No doubt the question 
of availability of a sample over time, together with the high cost of Munsel1 standards, have discouraged researchers from attempting major work in this area. Nevertheless, intraindividual reliability of color preference is a subject of great importance to a fundamental understanding of color preference. Until such time that a definitive statement can be made about color preference consistency within individuals, however, informed interpretations about the "psychological" meaning of color cannot be justified. 


\section{CRITERION MEASURES}

The search for a suitable criterion mesure upon which to interpret color response findings, if taken seriously, is a long and arduous task. Personality is a fairly broad concept, and its measurement is a function of the particular view of man that the theorist espouses. Needless to say, the "search for truth" about what characteristics are valid in describing a person, or about what motivates his/her behavior, has preoccupied generations of psychologists, with little agreement. Further, theories may not be totally unrelated to the historical and social context in which they are developed; leaving some hypotheses untestable, others irrelevant, and some blatantly biased.

The vast majority of color response studies have used clinical judgment, rational thought, or symbolic meaning as a basis for interpretation, or have limited their discussions to demographic kinds of information for small and ungeneralizable samples. The Rorschach, as mentioned, has been the most frequently used psychological measure, rendering uninterpretable results with respect to personality correlates of color.

Few studies have utilized a psychometric test as a criterion for interpretation; and though each has been fraught with problems in methodology, the studies taken together at least hint toward an introversionextraversion component to color preference responses (Eyseneck, 1941; Gotz \& Gotz, 1973; 1975). Conclusions based upon these studies are not unequivocal, but do suggest that the question merits further attention. 
Meanwhile, the past decade has given birth to a new generation of psychometric methods and instruments, where critical issues are finally being raised and attended to: issues such as those concerning social desirability and response distortions, construct validity evidence, and situation vs. trait theory (Anastasi, 1976; Sundberg, 1977; Lanyon \& Goodstein, 1971). As a result, greater confidence can now be placed upon conclusions drawn from among the more psychometrically sophisticated devices.

The selection of an appropriate criterion measure upon which to evaluate color preference need begin with a comparison of various personality theories; for an instrument can be no more useful than the theory upon which it was formulated. The decision, at this point, is somewhat of a subjective one; for there exist dozens of theories, each focusing upon a different aspect of behavior, and thereby each possessing a characteristic view of the nature of man. of practical consideration, of course, is that the model chosen lends itself to validation research.

\section{Murray's Need Theory}

Henry Murray (1938) talks about "the scientific study of the total person," and coined the term "personology." His concepts deal with the personality, the environment, and the history of the organism. He has taken a holistic approach, viewing the individual as highly complex and unique. Through his meticulous efforts, Murray (1959) has sought to develop working concepts for understanding and classifying behavior and its causes, both environmental and intrapsychic. Consequently, he places a great deal of emphasis on the personality as a 
tangible structure with active forces; and comprised of needs, abilities, and achievements.

Murray holds that knowledge of a person's needs (or motives) will allow for the understanding of that person's behavior; and enables one to predict future courses of action, and to effect therapeutic change through manipulation of needs. Since needs are considered to be the sources of behavior, all of the elements associated with them are undifferentiated. These elements include the triggering stimulus (press); the deficit state itself (need); the instrumental activity (action) associated with emotions and percepts; as well as the goal or incentive which satisfies the need. A certain goal is sought, for example, and the activity and the environment are then structured to attain this goal. The conjunction, or interaction, of press and need result in themas (behaviors produced by needs); and directed toward a person, object, or event. (DiCaprio, 1947).

The essential proof for the existence of needs, according to Murray, is the degree of readiness of the person to respond to the same stimulus situation at different times. A positive press (stimulus or situation), as well as a negative press, produces a state of disequilibrium; which is restored through appropriate activity. The goals are the concrete ways in which the need is expressed; and the ease with which needs are satisfied is inversely proportional to their significance in personality. As Murray points out (1954), though the need for sexual expression is not absolutely required for existence (1ike the need for oxygen or water is), its importance in personality growth and development is substantial. 
Needs are believed to fuse, and to operate as one motivational unit. Behavior is thus seen as the outcome of that fusion (Murray, 1938). The satisfaction of needs is accompanied by positive feelings, while dissatisfaction is associated with frustration and/or failure in effecting gratification. Therefore, Murray subscribes to a tension reduction model as a source of motivation, as well as to the generation of positive tensions (Murray \& Kluckholn, 1953); through the "greater" pleasures, he concedes, come from attainment of appetitive (vs. deficiency) needs.

In the early formulation of his theory, Murray (1938) stressed the role of needs as determinants of behavior; but later (1951) emphasized the "end states" of needs (values); for many needs are able to produce the same end state. In a similar manner, he also classified the various means for attaining values (vectors), which may be comprised of many actions having a common direction. Popularly known as a taxonomist (one who classifies and describes phenomena), Murray further distinguishes between two major categories of needs: the viscerogenic (bodily) needs, and the psychogenic (personality) needs (see Table 5).

Murray's list of press (see Table 6) provides another example of the richness in his thinking, for Murray's descriptive concepts and categories have been employed in a number of popular psychological tests.

\section{Psychological Tests Based Upon Murray's Formulations}

Although Murray has continually modified his theory, his system is still incomplete; for like other theorists, he is more concerned with the significance of the problem area, than with the precision of measurement. Since he frequently engages in speculation about many aspects of 
TABLE 5

\section{MURRAY'S LIST OF NEEDS}

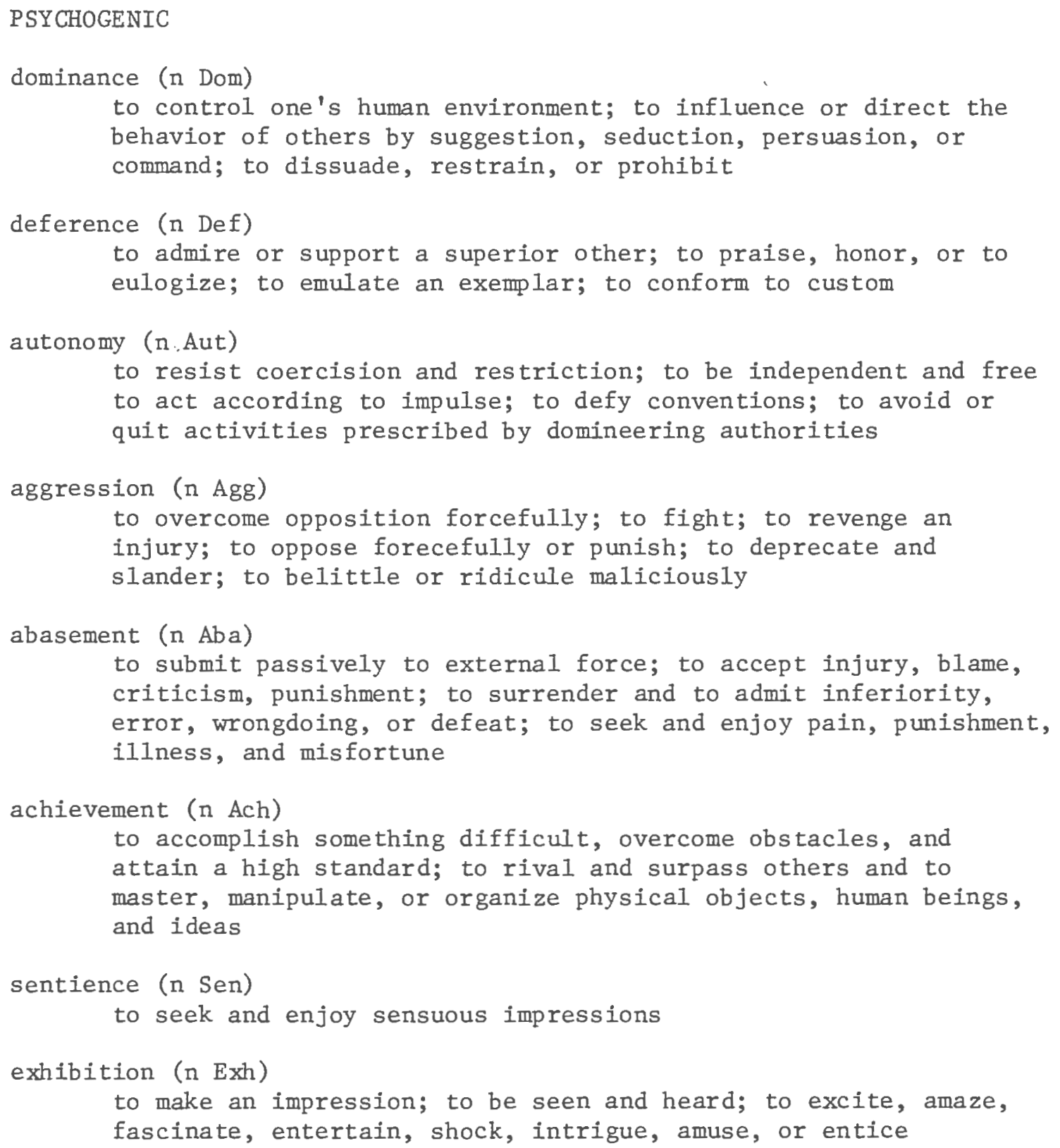


TABLE 5 (CONTINUED)

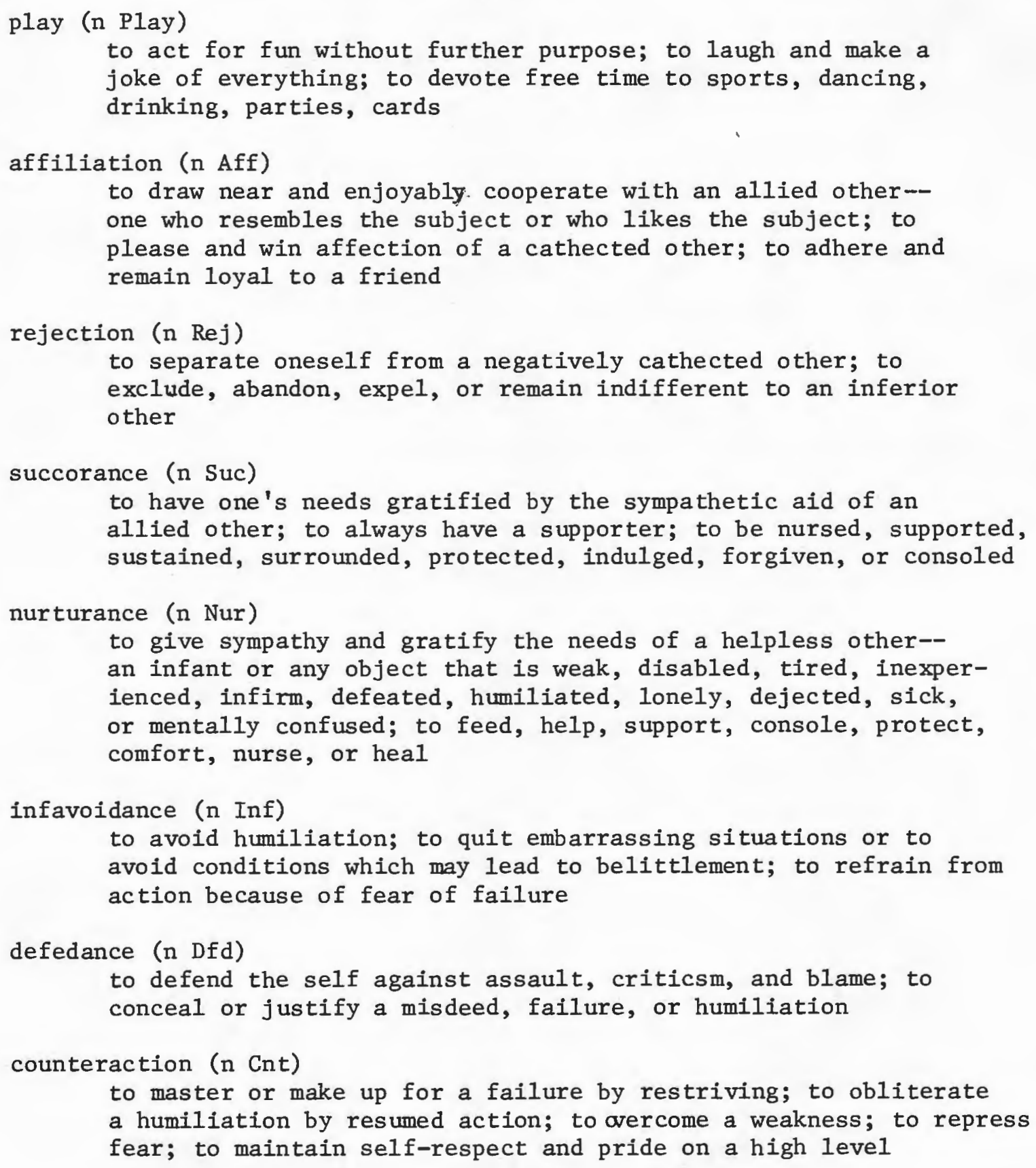


TABLE 5 (CONTINUED)

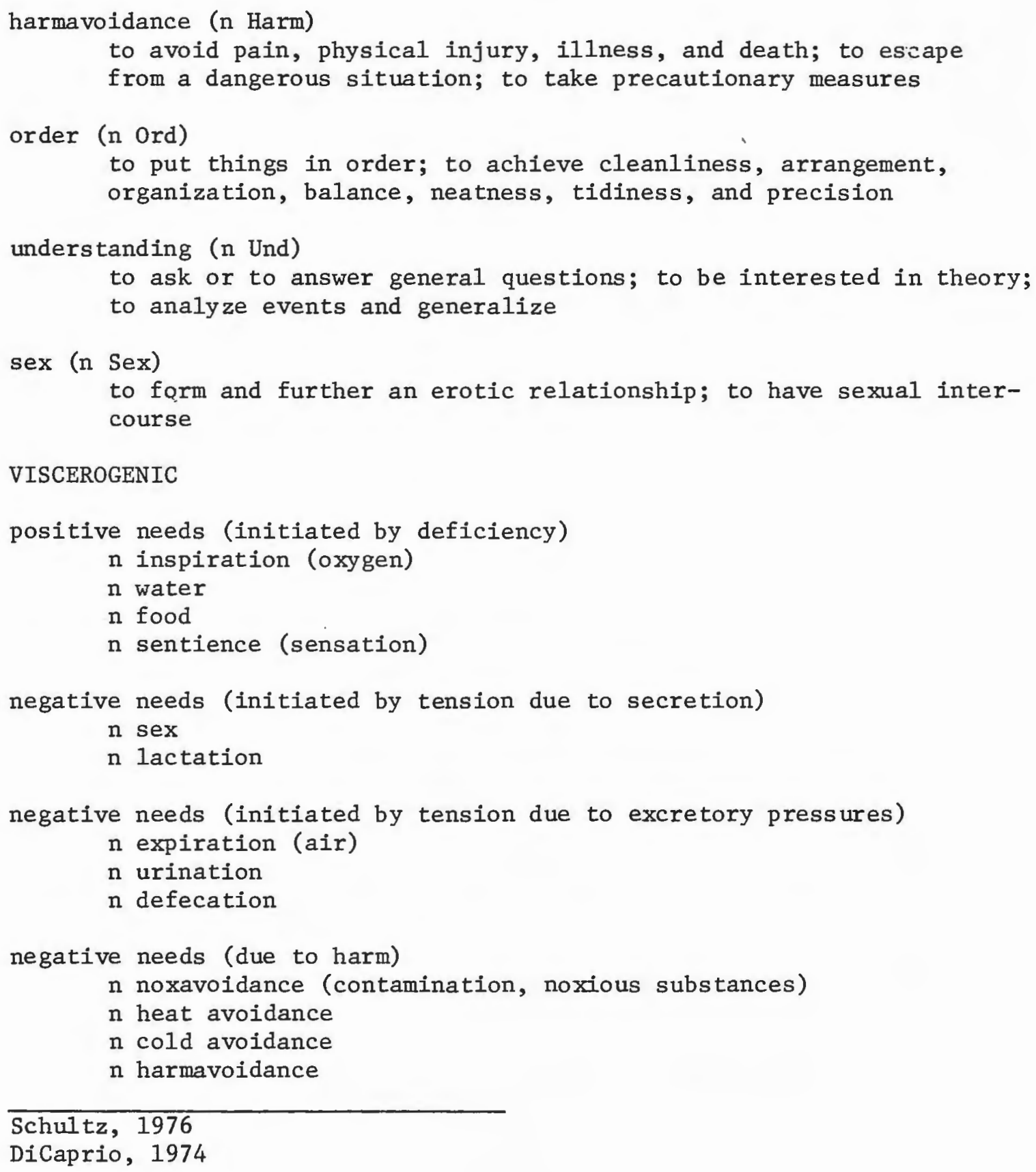


TABLE 6

MURRAY'S LIST OF PRESS

Family Insupport

Cultural Discord

Family Discord

Capricious Discipline

Parental Separation

Absence of Parent

Parental Illness

Death of Parent

Inferior Parent

Dissimilar Parent

Poverty

Unsettled Home

Danger of Misfortune

Physical Insupport

Height

Water

Aloneness

Darkness

Inclement Weather

Lightning

Fire

Accident

Anima I

Lack or Loss of

Nourishment

Possessions

Companionship

Variety
Aggression

Maltreatment by elder male

Maltreatment by contemporaries

Quarrelsome contemporaries

Rejection

Unconcern

Scorn

Rivalry and Competition

Dominance, Coercion, and Prohibition

Dominance-Nurturance

Parental Ego Idealism

Physical

Economic

Vocational

Caste

Intellectual

Possessive Parent

Oversolicitous Parent

Fears

Accident

IIIness

Bad Influences

DiCaprio, 1974 
personality, he opens himself up to criticism. Yet despite the 1imitations, his formulations have inspired the development of several psychological tests, as well as an abundance of research.

Of all the needs that Murray has catalogued, the need to achieve ( $\mathrm{n}$ Ach) is the one that has been studied most extensively. Research on the need to achieve was begun by David McClelland (1953), and has since been carried on by Atkinson (1966) and Atkinson and Feather (1966). The availability of Murray's own Thematic Apperception Test (1938) no doubt, has contributed to the substantial interest in his concepts.

The Thematic Apperception Test, a projective device, attempts to describe personality in terms of basic themas (interactions between press and needs), with special attention given to the consistencies and conflicts among them. The examinee is asked to make up a story to fit each of several stimulus cards, representing ambiguous scenes, and to focus upon such questions as: "What led up to this event? What is happening now? What is this person (the hero) thinking? What is going to happen?"

Although normative data do exist for the TAT, Anastasi (1976) notes that time consuming scoring systems with good reliability are often ignored by clinicians; and that criterion-related validity of the TAT for specific uses has not been clearly established.

A modification of the technique, using four cards (two from the TAT) formed the basis of need to achieve research initiated by McCle1land (1953). Another independent set of cards was developed for use in a national survey of the needs to achieve, affiliate, and possess power (Veroff et al., 1974); employing highly standardized instructions, but 
retaining the oral response feature of the Murray edition.

The Edwards Personal Preference Schedule; incorporates fifteen of Murray's needs into a self-report measure of personality (Edwards, 1954). Examinees are asked to make a forced-choice between two statements, each keyed to a specific need scale. Unfortunately, problems with the forced-choice format (rendering ipsative scores vs. normative scores) makes for technical difficulties, and eliminates valuable information about the relative strength of a need, compared to others. Further, the test has been demonstrated to be susceptible to faking (Borislow, 1958), and remains particularly vulnerable to socially desirable response style (Corah et al., 1958).

The Adjective Check List (Gough, 1960; Gough \& Heilbrun, 1965); reflects the influence of Murray's classification of needs, as well. of the 24 scales derived from an examinee's marking of all the adjectives he considers to be descriptive of himself, 15 scales relate to each of the 15 needs covered by the Edwards Personal Preference Schedule. The scales, however, were constructed rationally (on a content basis), and do not correlate well with the TAT and the Edwards (Megargee \& Parker, 1968), though purporting to measure the same constructs.

The Personality Research Form (Jackson, 1968; 1974); reflects

several technical advances in test construction methods, and uses Murray's needs system as its starting point. It should be noted from the outset that the Personality Research Form does not correlate well with the TAT, the Edwards, or the Adjective Check List (Megargee \& Parker, 1968; Fiske, 1973); suggesting that these measures are not equivalent in their efforts to assess common needs. The Personality 
Research Form (PRF) does possess a greater degree of psychometric soundness than the other instruments, however; and validity data, though still meager, show much promise (Anastasi, 1976).

The PRF is a self-report inventory of manifest needs. The examinee is asked to read a statement and to decide whether or not it describes him/her; a true or false format is employed. Raw scores for each scale are plotted on to a profile sheet of T-scores, and conversion to percentile equivalents is accomplished through reference to a table in the manual. It should also be noted that the manual meets the standards for development of psychological and educational tests (American Psychological Association, 1974) quite well.

Norms are based upon separate samples of male and female college students, representing over thirty institutions. Intercorrelations among the scales are low to moderate, suggesting that the scales are unique in the assessment of personality.

Kuder-Richardson formula 20 reliability coefficients for both the original item pool and the best 40 items per scale range from .52 to .94 . (The .52 is for the infrequency scale, which should be low, due to the skewed distribution.) Most coefficients are in the .80 's and .90 's, suggesting good internal consistency. Test-retest reliabilities over a one-week interval range from .46 (for the Infrequency scale, which should be lower) to .90 . Most were in the .80 's. Reliability for parallel forms is likewise impressive over a two-week interval (Jackson, 1974).

The evaluation of the freedom from response biases of the PRF scales, such as acquiescence or desirability, is also impressive. For 
example, the extent to which content scales correlate with the especially constructed Desirability Scale is .20; indicating that on the average, less than 5 percent of the total variance on the content scales can be explained in terms of the tendency to respond desirably. In addition, the PRF scales do not intercorrelate substantially; so as to work against a hypothesis for one general factor, such as desirability (Jackson, 1974). Apparently the relative independence of the scales from a common desirability factor (and from one another) has also fostered the opportunity for obtaining discriminant validity, as well as providing evidence for each scale's uniqueness.

Using a multi-trait/multi-method evaluation procedure (Jackson \& Guthrie, 1968) both convergent and discriminant validity are suggested. Further, when the procedure was cross-validated against two independent samples (Kusyszyn, 1968), consistent results were obtained.

With respect to concurrent validity, correlations with scales on the Strong Vocational Interest Blank are predictably low (Seiss \& Jackson, 1967); as are those correlations with scales on the California Psychological Inventory (Jackson, 1974). (Exceptions are limited to scales carrying the same or similar headings; i.e., PRF Dominance scale with CPT Dominance scale: $\mathrm{r}=.78)$.

Though evidence for predictive validity of the PRF is still fairly scant, as is factor analytic structure information (at the item level), the test holds much promise for future research; and at the present time, the PRF is probably the least problem ridden of the various measurements reflecting Murray's needs system. 


\section{THE RESEARCH PROBLEM}

What do different colors mean, if anything, to different people? Are different people influenced differently by various colors? Is color preference stable enough over time to suggest a systematic process under1ying its existence? Can color preference, if reliable within individudals, be reflective of personality? What might the structural components of color preference be?

The present investigation has been undertaken in several phases in an effort to lend support to the notion that personality and color preference are associated; put another way, in an effort to discover the "psychological" meaning of color preference, as it relates to an important dimension of personality: manifest needs (Murray, 1938). Its final emphasis is on how two of the three psychological attributes of color perception (hue and lightness) relate to needs for achievement, order, harm avoidance, social recognition, and exhibition.

Phase 1. The first study was conducted to determine whether preference for color was sufficiently reliable to warrant further study.

Phase 2. The second study was to be conducted (if the first study rendered encouraging results) in an effort to describe the underlying structural components of color preference; hence, to build a scoring key for the instrument that was to be especially designed to test the reliability of color preference judgments, within individuals. 
Phase 3. The third study, a validity study, was to relate color preference to the various manifest needs of interest.

Specifically, the various research hypothesis being tested were as follows:

1. that color preference can be reliably measured, within subjects, and represents a stable characteristic of the,person.

2. that the underlying component structure responsible for color preference judgments, within subjects, can be described.

3. that color preference can be related to specific manifest needs; hence, that in a general sense, color preference and personality are associated.

The limitations of the work, of course, concerned the limitations of the variables themselves, and the technology available today to measure them. Attempts have been made to address critical problems with previous work in the area, and to improve upon quantitative methods of analysis.

Major assumptions which were maintained from the outset to underlie both the study as a whole, and the methodology that was to be followed, included:

1. that color preference could be demonstrated to be reliable, within individuals, using the instrument that was to be designed and constructed for this investigation.

2. that previous work in the "scientific" investigation of color had sound theoretical bases to support further study.

3. that manifest needs are an important dimension of the overall measurement of personality, and represent trait characteristics. 
4. that a positive outcome in the final phase of the project would indeed suggest a relationship between color preference and personality, as defined, in a normal college population.

5. that a negative outcome in the first phase (reliability study) would none the less contribute greatly to a wide body of literature, one which merely assumes that color preference is stable, within individuals.

6. that a negative outcome in the final phase (validity study) would not rule out such a relationship between color preference and personality, in an unusual population; or given another set of color stimuli, of higher saturation, perhaps; or given another personality criterion measure.

The main emphasis in undertaking this project has been with the identification of error sources of variation, particularly with respect to intraindividual differences in stability of color preference judgments. A great deal of emphasis, therefore, has been placed upon theoretical considerations, as they relate to implementing control (see Chapter 2). It is within this context that the present work is believed to afford a vast improvement over prior work in the area, and should eventually contribute greatly to a fundamental understanding of the "psychological" meaning of color. 


\section{METHODOLOGY}

\section{Subjects}

Approximately 150 students in first and second year psychology courses at Rhode Island Junior College were invited to participate in the experiment. The introductory presentation included a general discussion of the goals of the research and the method to be followed. A brief demonstration was conducted of the testing to follow, and an opportunity to ask questions about any phase of the experiment was given. Rhode Island Junior College has an open admissions policy, atatracting students from a wide range of cultural experiences. Psychology courses are extremely popular at the college, drawing students from the technical areas, nursing, humanities, sciences, and social sciences. Students in psychology courses, from which the sample was drawn, are quite varied in their abilities as well. There was no reason to suspect that they were unrepresentative of the college population.

At the conclusion of the introductory phase it was determined that 141 subjects were interested. This number was reduced to 102 after the second testing session, with 91 subjects completing the experiment. Since one subject from the final pool was believed to be highly suspect for color vision dysfunction, the data to be analyzed were based upon a minimum of 90 cases. Further, in that ten males and one female failed to complete the experiment, forty males and fifty females incorporated the final sample, ranging in age from a minimum of eighteen years to forty years, 
with a median age of 19 years. All subjects in this final pool were Caucasian, suggested no evidence of drug impairment, and demonstrated at least a minimum adequacy of color vision.

\section{Instruments and Procedure}

Time Frame. The Personality Research Form (Jackson, 1974), Form $A A$, was administered to six groups of approximately 25 subjects each. Conventional testing conditions prevailed. Within several days the Farnsworth Munsell 100-Hue Test for Color Discrimination (Farnsworth, 1957) was undertaken by subjects individually, under standardized lighting conditions. During this same session, a color preference sort was completed as well (The Color Preference Test), and repeated five weeks later during a third testing session.

The Personality Research Form. A group administered, paper-andpencil-type assessment of needs, the Personality Research Form is a highly reliable instrument, one whose normative sample closely resembles the sample under investigation. (Extensive review of the test was made, the results of which have been summarized in Chapter 4 of this thesis.) Scales of interest were those relating to needs for achievement, order, harm avoidance, social recognition, and exhibition. Several validity scales were also of interest, in an effort to screen for haphazard and/or socially desirable response sets.

The Farnsworth-Munsel1 100-Hue Test for Color Discrimination. An individually administered, fairly sophisticated test for color vision dysfunction, the 100-Hue Test is also highly reliable. Normative data for an unselected adult population were reported by its author in 1957 , and had more recently been supplemented by work with a contemporary 
college sample (Malone \& Hannay, 1977). (A detailed review of the 100Hue Test was likewise conducted, the results of which have been summarized in Chapter 2.)

The Color Preference Test. An individually administered Q-sort for color preference, the test was especially designed for use in the present investigation. Stimulus items ( $3^{\prime \prime} \mathrm{x} 5^{\prime \prime}$ ) were constructed from among Munsell Color standard papers, balanced for hue and lightness. Control for saturation and finish were important considerations in item selection. Seventy-seven items comprised the final sample (Munsell notations appear in Appendix A); and though forced distribution to the normal curve is inherent with the method (Stephenson, 1953) it is maintained that "selection for color" versus "passive reaction to color" was essentially provided for (see Figure 26).

Ten hues, in addition to neutral, were represented across seven levels of lightness. Saturation was at a constant low level for all items; excepting the neutrals, which by definition are devoid of saturation. Though it was initially believed that all papers were of matte finish, it was subsequently discovered by accident that one item actually possessed a glossy finish. The investigation continued with the one glossy item, and its possible effect upon results is discussed. Scales for the Color Preference Test were developed using a principal components method (Hotelling, 1933), with varimax rotation of axes to simple structure (Kaiser, 1958). Reliability of the instrument was assessed through several procedures, including an item analysis (Baker, 1939), canonical correlation analysis (Cooley \& Lohnes, 1971) and redundancy analysis (Stewart \& Love, 1968). Validity was explored, with 
Q-Sort Procedure

Forced Distribution to the Normal Curve

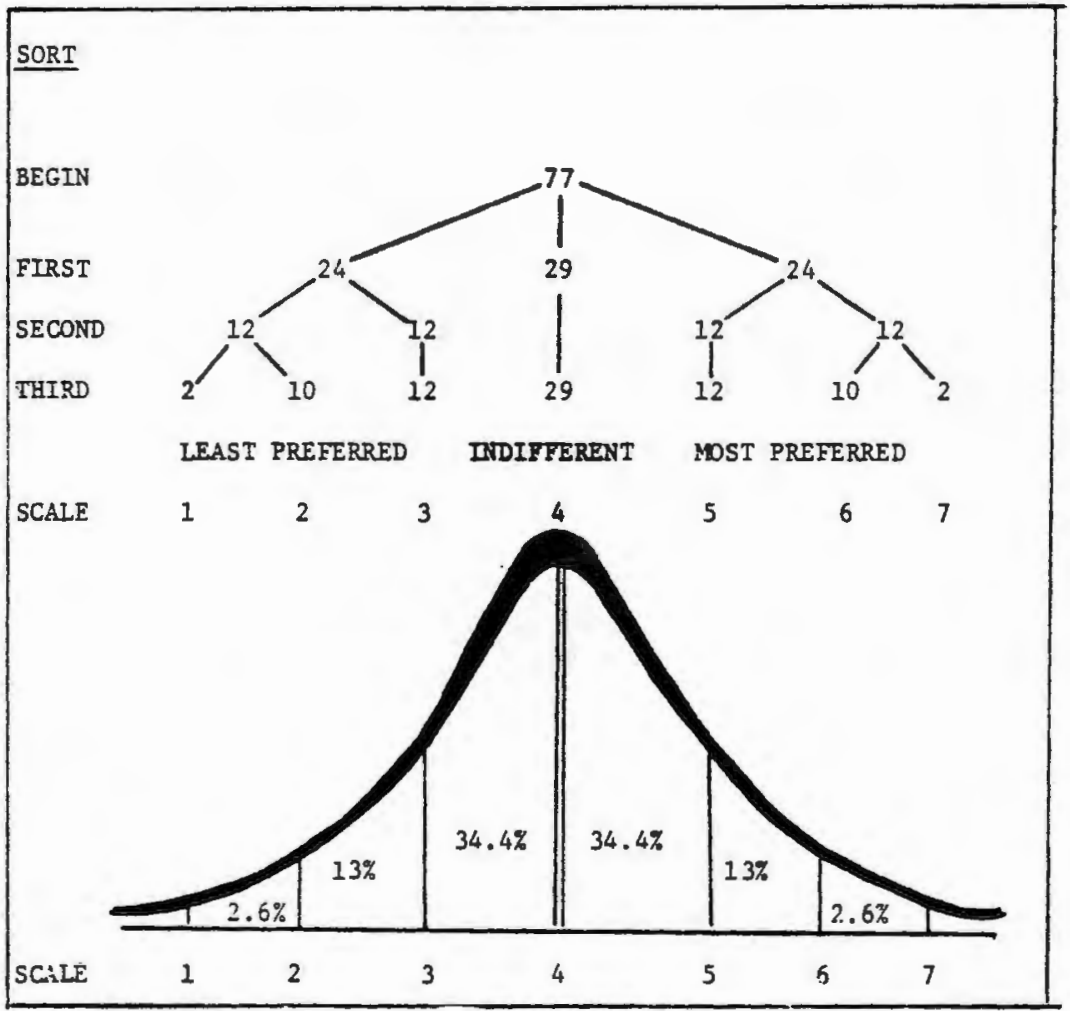

Fig. 26. Each of 77 items has an equal probability of being placed into the first three categories. Subsequent sorts result in the forced placement of items into a normal distribution, ranging from least preferred to most preferred. 
profiles extracted from several scales of the Personality Research Form serving as the ultimate criterion.

Experimental Conditions. Except for the Personality Form which was administered in a classroom setting, all testing was conducted in a self-contained laboratory. The only source of direct illumination was from a standardized lamp (Macbeth Model ADE-10 Easel L’amp, simulating CIE Illuminant "C"), though indirect fluorescent lamps were used to illuminate two small writing surfaces away from subjects' direct line of vision.

In an effort to ease adjustment to the experimental lighting, several minutes were afforded each subject to get comfortably seated. A matte gray middle lightness surface (24" $\left.\times 11^{\prime \prime}\right)$ formed the immediate viewing background, also of Munsell standard paper. Disposable latex gloves were worn as ad additional control for uneven surface reflection.

The angles of illumination and observation were in accordance with CIE recommendations (0/45), described in Chapter 2 . There were no time limits imposed upon performance, except where required for standardized testing procedure; with the 100-Hue Test, for example. A 1aboratory assistant was employed, both for sharing the individualized testing, which exceeded 100 hours, and for recording and coding responses.

Data Processing. Information was key-punched on to Hollerith cards, and subjected to various statistical analyses. Pre-programmed statistical packages, as well as experimenter written Fortran programs were used. Data were processed with an Itel Advanced System/5 computer at the University of Rhode Island, with program consultation provided by the Academic Computer Center's Office of User Services. 
VII. RESULTS AND DISCUSSION

\section{Color Vison Screening}

Screening for color vision dysfunction was accomplished by writing a Fortran program for the scoring of the 100-Hue Test, with profiles computer plotted for a visual inspection of the results.

Criteria used to discriminate poor from average to superior performance included: total error score greater than 75 points; significant midpoint error score in a bi-polar region; and significant errors along confusion axes. (Justification for the three-point criterion emanates from a review of the 100-Hue Test literature, which has been summarized in Chapter 2 of this thesis.)

One subject was found to meet all three criteria for possible dysfunction, and was consequently dropped from further study. Several other subjects, though demonstrating poor discrimination ability, did not meet the three-point requirement, and their data were kept for further analysis. (Sample profiles may be found in Appendix B.)

No screening effort, however carefully implemented, can insure equality of color vision. Vast differences were observed in the quantity and quality of errors on the 100-Hue Test; and one can only be reasonably assured that all subjects possessed at least a minimum amount of competence in their ability to evaluate color. Diagnosis of a color vision problem would, of course, necessitate examination by a physician; who would probably need to evaluate results from several administrations of 
the 100-Hue Test, to each eye separately.

It should be noted in this context, that approximately seven percent of the final sample was comprised of persons who wore prescription tinted lenses when tested. It remains unclear what effect the color of the tint may have had upon their performances, though successful screening was apparent. (Notations were made in their folders, and care taken to insure that the same lenses were worn to both testing sessions.)

Phase 1. Reliability Study

Within Subjects. The first analysis concerned itself with determining the extent of similarity between preferences expressed by subjects on two occasions, five weeks apart. Q-methodology (Stephenson, 1953), for the correlation of persons on two occasions, yielded information about the stability of preference judgments by individuals.

It happened that the mean, median, and mode for the final sample group of 90 cases were all represented by a Q of +.55 , with a standard deviation of .20 . (The interpretation of $Q$ is analogous to that of a Pearson $\mathrm{r}$. ) The range of $\mathrm{Q}^{\prime} \mathrm{s}$, however, extended from -.39 to +.86 . It can be seen, therefore, that while some individuals apparently were quite consistent in their preference judgments over the five week interval, that others were substantially inconsistent (see Figure 27).

A Fisher transformation of the sample Q's to statistic Z's was performed (Haber \& Runyon, 1973), and a significant difference was found between the mean $Q^{\prime}$ 's for males and for females $(F=5.33$; $d f=1$, $88 ; \mathrm{p}=<.05$ ). Females had a mean $\mathrm{Q}$ of +.58 (with a standard deviation of .16), while males only had a mean $Q$ of +.48 (with a standard deviation of .24). 


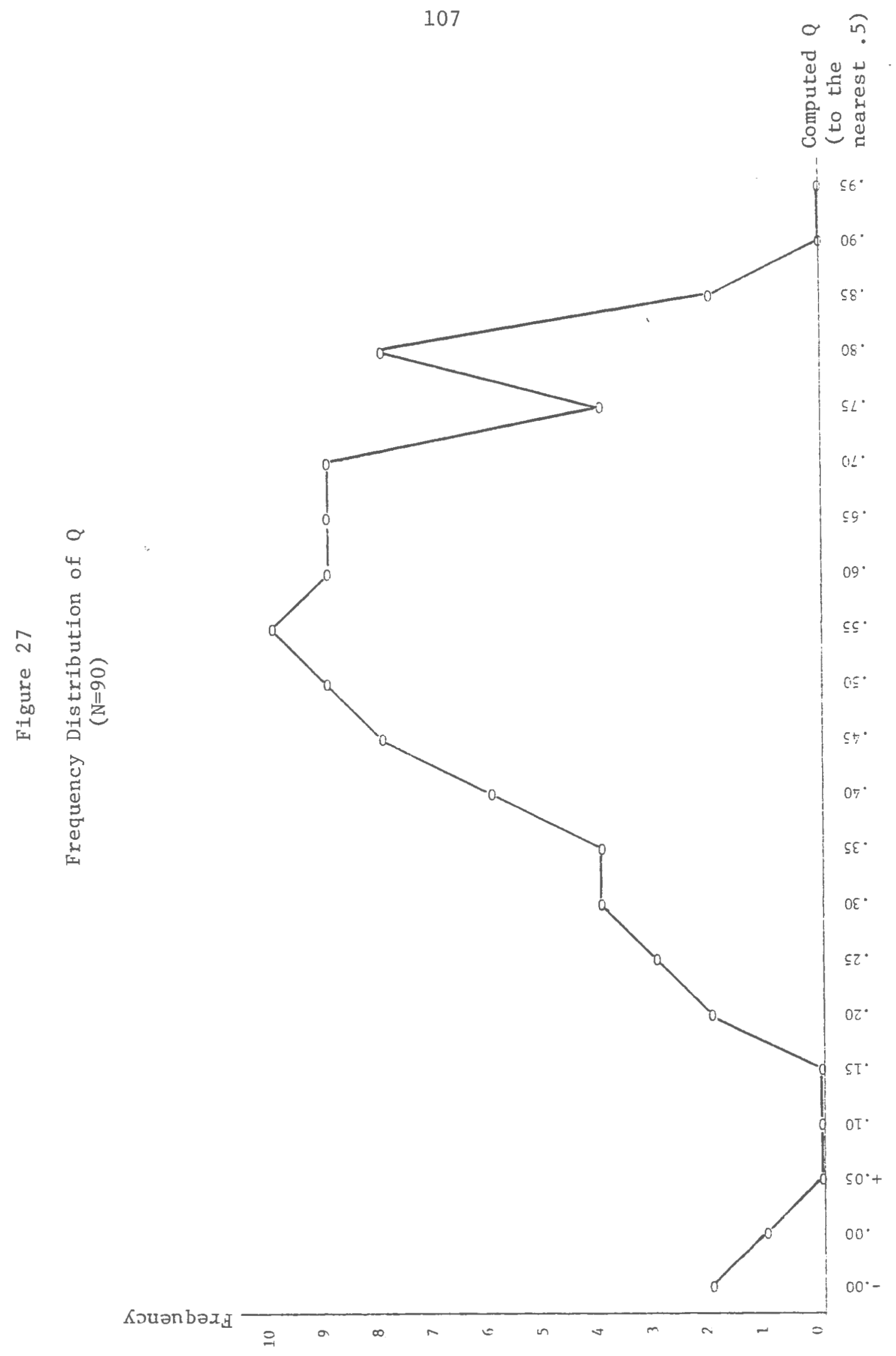


(Differences with respect to age were not tested for significance, given the relatively small number of cases in age groups other than ones typical for the junior college population.) .

That some persons demonstrated such high test-retest stability $\left(Q^{\prime} s\right.$ in the $+.70^{\prime} \mathrm{s}$ and $\left.+.80^{\prime} \mathrm{s}\right)$ was surprising, considering the speed with which most decisions were made. Although formal record of 1atency periods was not a part of the particular method chosen, it was observed that the usual time interval was less than five seconds. In addition, that some individuals at the outset of the second testing session casually remarked that they were in quite different moods than when asked to make their initial judgments; that they were quite confidant that the colors they were now chossing were quite different than the ones chosen five weeks prior (all the while demonstrating strong stability of preference, without apparent awareness), appears suggestive of a dependable process underlying color preference behavior, perhaps an unconscious one.

That some persons were not at all consistent in their color preference behavior was not surprising, however. Several persons, who because of cle rical errors on the researcher's part in the scoring of results, were asked to repeat the sort during the same session. It was observed for these persons (who were ultimately dropped from future analysis) that preference judgments could vary greatly within as short a time interval as five minutes.

Certainly other variables could have been silently operating with inconsistent individuals; such as differences in attitude toward the task at hand, or an undetected difficulty with the directions. In any 
case, the stability of preference judgments for some subjects (particularly for some males just could not be relied upon; and the reasons for such instability are not at all apparent.

The findings of this aspect of the investigation, therefore, bears heavily upon future work in the area of color preference. The notion that color preference may represent a dynamic process' for some individuals, but not for others, has never before been reported as the result of a carefully controlled study. In addition, that there may be sex differences in the dependability of some persons' judgments over others may in itself warrant further exploration; for cognitive, motivational, emotional, social, and/or personality variables could each come into play. Between Subjects. Reliability of a test, of course, is not dependent upon the stability of characteristics of the person. It rather has to do with what is built into the instrument, reflecting the ability of the test to reliably measure whatever it purports to measure.

Reliability of the Color Preference Test is a necessary condition for the ultimate explanation of color preferences among groups of persons. Very early results are encouraging; with the Q-sort technique proving to be a manageable and potentially useful procedure to follow-up in this regard. Ten scales were developed, using factor loadings derived from a principal component analysis of the first administration results (described in the discussion of Phase 2 to follow), and evaluated for internal consistency and stability over the five-week period of time. The results of the intemal consistency analysis for the scales constructed from the first administration results are presented in 
Table 7, and generally attest to the intemal consistency of items comprising each scale. The statistic reported is labeled Cronbach alpha (an overall measure of internal consistency for the scale); and it can be seen that Cronbach alphas were all above +.70 . This trend toward homogeneity of items comprising each of the scales held with results from the second administration, as well (see Table 8), suggesting that confidence may be placed in related findings.

Test-retest correlation coefficients for each of the ten scales (observed separately) ranged from +.39 to +.71 , with an average coefficient of +.60 (see Table 9). Although all were highly statistically significant $(p=\langle .01)$, the coefficients of stability may ultimately serve less practical significance; for four of the ten scales had correlation coefficients that were less than +.60 , while only one scale had a coefficient which exceeded +.70 .

The results of the canonical correlation with redundancy analysis, meanwhile, which served to provide a better impression of the repeated overlap in the profiles, are reported in Tables 10 and 11 . Although ten canonical variates were extracted, only six were highly significant $(p=$ 4.01). [Ten reaching significance at a most conservative alpha level would have been more desirable for confirmation of the scoring, given the small sample.] Generally speaking, the results of this analysis revealed that only some of the patterns that comprised the first administration of the test repeated themselves on the second administration. Although nearly all of the signs were the same, the canonical coefficients (weights) were not of nearly equal magnitude for several of the scales. Only a moderate degree of overall stability of patterns, therefore, was apparent. 
TABLE 7

INTERNAL CONSISTENCY ANALYSIS

FIRST ADMINISTRATION OF

THE COLOR PREFERENCE TEST

$(\mathrm{N}=90)$

\begin{tabular}{lcccc}
\hline Subscale & 非tems & Mean & SD & Y \\
\hline Component A & 32 & 1396.56 & 240.45 & .93 \\
Component B & 22 & 970.56 & 162.24 & .90 \\
Component C & 11 & 392.67 & 89.42 & .84 \\
Component D & 15 & 688.89 & 105.22 & .85 \\
Component E & 10 & 403.78 & 63.42 & .74 \\
Component F & 10 & 373.98 & 62.63 & .70 \\
Component G & 14 & 537.33 & 84.96 & .80 \\
Component H & 10 & 350.33 & 75.39 & .79 \\
Component I & 15 & 613.11 & 80.42 & .73 \\
Component J & 9 & 388.67 & 59.70 & .72 \\
\hline
\end{tabular}


TABLE 8

INTERNAI CONSISTENCY ANALYSIS

SECOND ADMINISTRATION OF

THE COLOR PREFERENCE TEST

$(\mathrm{N}=90)$

\begin{tabular}{lcccc}
\hline \hline Subscale & 非 tems & Mean & SD & Я \\
\hline Component A & 32 & 1440.44 & 236.95 & .93 \\
Component B & 22 & 1019.78 & 138.58 & .88 \\
Component C & 11 & 375.89 & 79.79 & .80 \\
Component D & 15 & 702.56 & 90.30 & .81 \\
Component E & 10 & 401.00 & 62.08 & .75 \\
Component F & 10 & 379.18 & 59.71 & .72 \\
Component G & 14 & 520.67 & 78.71 & .79 \\
Component H & 10 & 336.89 & 75.37 & .80 \\
Component I & 15 & 610.89 & 75.87 & .70 \\
Component J & 9 & 395.00 & 59.33 & .72 \\
\hline
\end{tabular}


TABLE 9

\section{TEST-RETEST RELIABILITIES \\ SUBSCALE SCORES \\ THE COLOR PREFERENCE TEST}

(FIVE WEEK INTERVAL)

$(\mathrm{N}=90)$

\begin{tabular}{lcccccc}
\hline Subscale & $\overline{\mathrm{x}}_{1}$ & $\sigma_{1}$ & $\overline{\mathrm{x}}_{2}$ & $\sigma_{2}$ & $\mathrm{r}_{12}$ & $\mathrm{r}^{2}$ \\
\hline Component A & 1396.56 & 240.45 & 1440.44 & 236.95 & .53 & .28 \\
Component B & 970.56 & 162.24 & 1019.78 & 138.58 & .71 & .50 \\
Component C & 392.67 & 89.42 & 375.89 & 79.79 & .62 & .38 \\
Component D & 688.89 & 105.22 & 702.56 & 90.30 & .68 & .46 \\
Component E & 403.78 & 63.42 & 401.00 & 62.08 & .69 & .48 \\
Component F & 373.98 & 62.63 & 379.18 & 59.71 & .66 & .43 \\
Component G & 537.33 & 84.96 & 520.67 & 78.71 & .39 & .15 \\
Component H & 350.33 & 75.39 & 336.89 & 75.37 & .51 & .26 \\
Component I & 613.11 & 80.42 & 610.89 & 75.87 & .61 & .37 \\
Component J & 388.67 & 59.70 & 395.00 & 59.33 & .51 & .26 \\
\hline
\end{tabular}




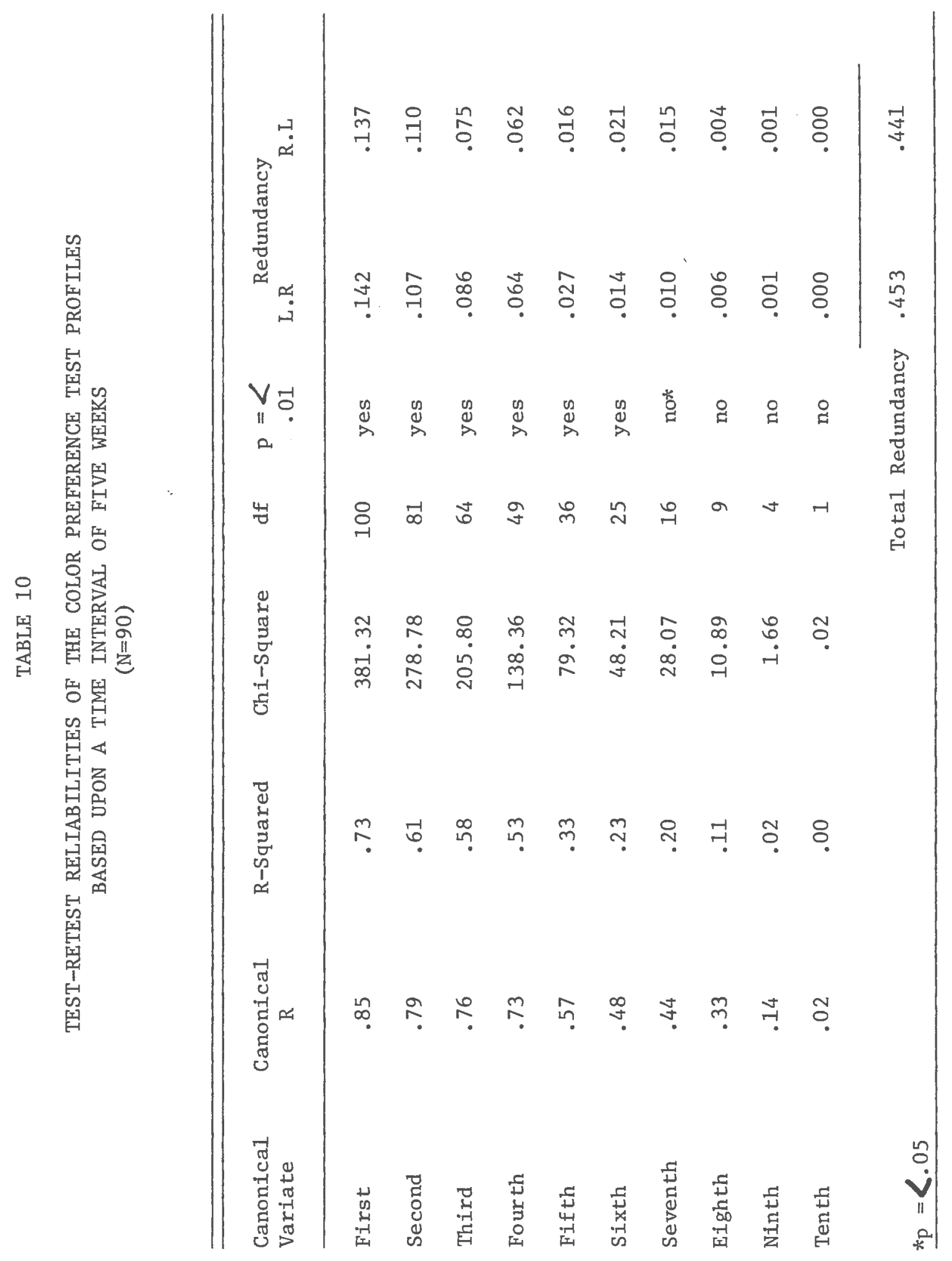




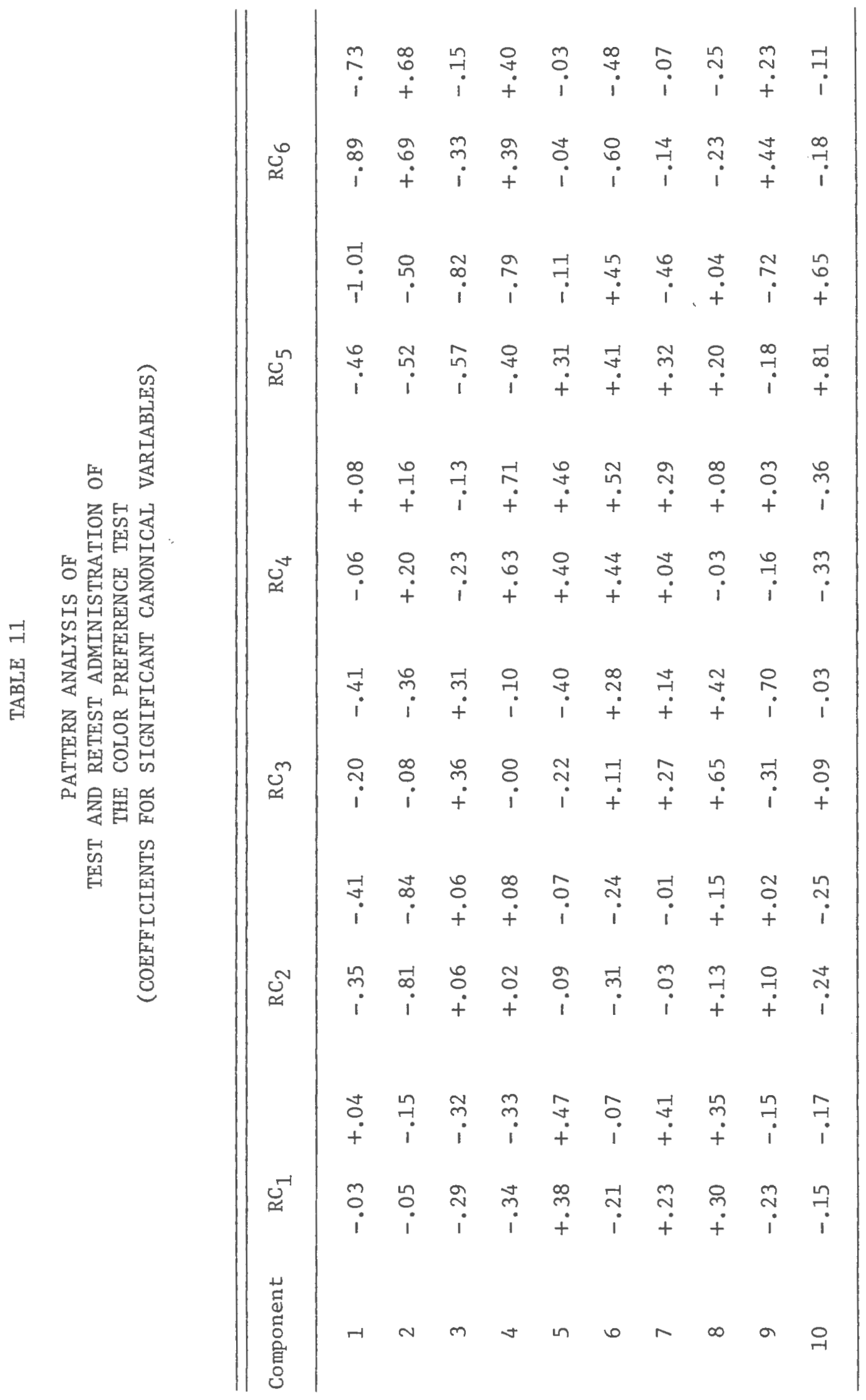


A redundancy analysis yielded a total redundancy of .45 for the left-hand set (first administration) given the right-hand set (second administration); and .44 , vice versa. (The total redundancy values indicate the percentage of variance in the two sets of variables accounted for by the canonical correlation analysis.) Further, about 70 percent of the total redundancy was assumed by the first three canonical variates.

From these results, therefore, a test-retest reliability coefficient of +.67 is estimated for the profiles, comprised of as few as six and as many as seven factors. Although the data do not present remarkable evidence, they nonetheless present substantial evidence that the profiles among individuals on the first administration of the color sort repeated themselves five weeks later on the second administration, as scored. It should be kept in mind, however, that within subject stability was not demonstrated for all subjects, and the results (although less than impressive) are extremely encouraging.

\section{Phase 2. Component Analysis Study}

In an effort to develop an initial scoring system for the color sort, a principal component analysis (at the item level) was employed. The larger subject group of 101 persons (50 males and 51 females) was studied. It was expected that results from the analysis would:

1. assist in the clarification of an underlying structural component in color preference behavior.

2. serve to facilitate construction of the various scales.

3. provide a reference for the purposes of comparison work, with results from the retest, for example. 
Although it had been decided a-priori that the principal components method with varimax rotation to simple structure was to be used, various methods of rotation (including over 20 oblique rotations) were attempted. In addition, since several conventions apply in deciding what number of components should be retained for rotation and ultimate interpretation, it should be noted that final emphasis was placed upon selection of a method that would best serve the theoretical tenants of the model.

Velicer's method for determining how many components to extract, based upon average squared partial correlations for different numbers of components (1976), suggested that ten components were needed to account for 60 percent of the total variance in responses on the first administration of the Color Preference Test. Parsimony was of further consideration in the decision to extract and rotate ten components; for while 19 components accounted for 76 percent of the total variance, using the eigen value greater than one rule (Kaiser, 1970), the last 9 components appeared to be each contributing such a small amount that uniqueness was unassured and interpretation would be hampered. Put another way, nearly twice the number of scales would be needed to explain but an additional 16 percent of the total variance in responses.

Therefore, the first ten components were the only ones subjected to various orthogonal and oblique rotations, with the result that vari$\max$ rotation produced the clearest structure. All 77 variables were entered into and accounted for by the analysis, with the minimum criteria set at .30 for salient loadings. Priority was given to the structure that would best accommodate all variables being measured; for the objective was not merely to reduce the item pool for use at some future point 
in time (and thus enhance internal consistency of the scales). For reasons that are inherent in the measurement of the model (hue and lightness need be measured simultaneously), an expected number of complex items were found. Very few items were eventually scored on more than two scales. Scale scores, equally weighted standard scores, were computed for each of 90 cases on both the test and retest data. Ten scales were constructed, as mentioned previously. Though the full and direct method of estimation of factor scores would have controlled for the influence of all variables entered into the analysis, with some variables serving only as suppression variables, the disadvantages associated with unstable weights for 77 variables and only 90 cases precluded its usefulness in the present situation (Schmidt, 1971; Wackwitz and Horn, 1971).

Reliability of the various scales was assessed (see previous discussion of Phase 1 results), and attempts made to lend interpretation to the scales which emerged. In general, results suggested that color preference is reflective of attention both to hue and to lightness information; for no component appeared to reflect exclusively hue or lightness dimensions. Schematic diagrams, detailing each of the scales and associated variables, for both the test and retest results, may be compared in the Appendix section of this thesis; and generally reflect a partial replication of the same components on both administrations. Briefly, results suggested that the first component, a general lightness by hue cluster, appeared to account for approximately 20 percent of the total variance on both administrations. Each of the other nine components (labeled arbitrarily) appeared to reflect more specific information, across various hues and levels of lightness (see 
Table 12).

No further statement can or should be made regarding the identity

of the ten components, with respect to specific colors, for several reasons:

1. It remains beyond the scope of the present research to describe color preferences among groups of subjects, other than to generally state how colors have apparently been grouped by the sample under investigation: by hue alone, by lightness alone, and/or by hue and lightness interacting.

2. The small number of subjects studied, in relationship to the number of variables, would attenuate such findings.

3. The lack of stability in preference behavior for some subjects precludes reliance upon the outcome, with regard to specific colors.

Phase 3. Validity Study

The ten scale scores, computed for the 90 subjects that completed the experiment, were correlated to the five scales of interest on the Personality Research Form; scales having to do with achievement, exhibition, harm avoidance, order, and social recognition. Inspection of the simple correlation matrix was disappointing. A canonical correlation was performed, and five canonical variates were extracted. None reached significance $(\mathrm{p}<.05)$. The results revealed that patterns that comprised the Color Preference Test did not correspond with the patterns of the five personality scales (see Table 13). A redundancy analysis yielded a total redundancy of .07 for the left-hand set (Color Preference Test scales) given the right-hand set (Personality Research Form scales); 
TABLE 12

PRINCIPAL COMPONENT ANALYSIS

TWO ADMINISTRATIONS OF

THE COLOR PREFERENCE TEST

(FIVE WEEK INTERVAL)

\begin{tabular}{|c|c|c|c|c|c|}
\hline \multicolumn{3}{|c|}{ First Administration $(\mathrm{N}=101)$} & \multicolumn{3}{|c|}{ Second Administration $(N=90)$} \\
\hline \multicolumn{3}{|c|}{$\begin{array}{l}10 \text { components } \\
\text { accounting for } \\
60.2 \text { percent of } \\
\text { the total variance }\end{array}$} & \multicolumn{3}{|c|}{$\begin{array}{l}10 \text { components } \\
\text { accounting for } \\
63.9 \text { percent of } \\
\text { the total variance }\end{array}$} \\
\hline Component & Eigen Value & $\%$ & Component & Eigen Value & $\%$ \\
\hline 1 & 15.11 & 20.3 & 1 & 15.57 & 20.2 \\
\hline 2 & 7.84 & 10.2 & 2 & 8.35 & 10.9 \\
\hline 3 & 5.12 & 6.7 & 3 & 6.16 & 8.0 \\
\hline 4 & 4.29 & 5.6 & 4 & 4.99 & 6.5 \\
\hline 5 & 3.24 & 4.2 & 5 & 3.38 & 4.4 \\
\hline 6 & 2.54 & 3.3 & 6 & 2.74 & 3.6 \\
\hline 7 & 2.12 & 2.7 & 7 & 2.53 & 3.3 \\
\hline 8 & 1.99 & 2.6 & 8 & 2.05 & 2.7 \\
\hline 9 & 1.81 & 2.4 & 9 & 1.76 & 2.3 \\
\hline 10 & 1.72 & 2.2 & 10 & 1.67 & 2.2 \\
\hline
\end{tabular}




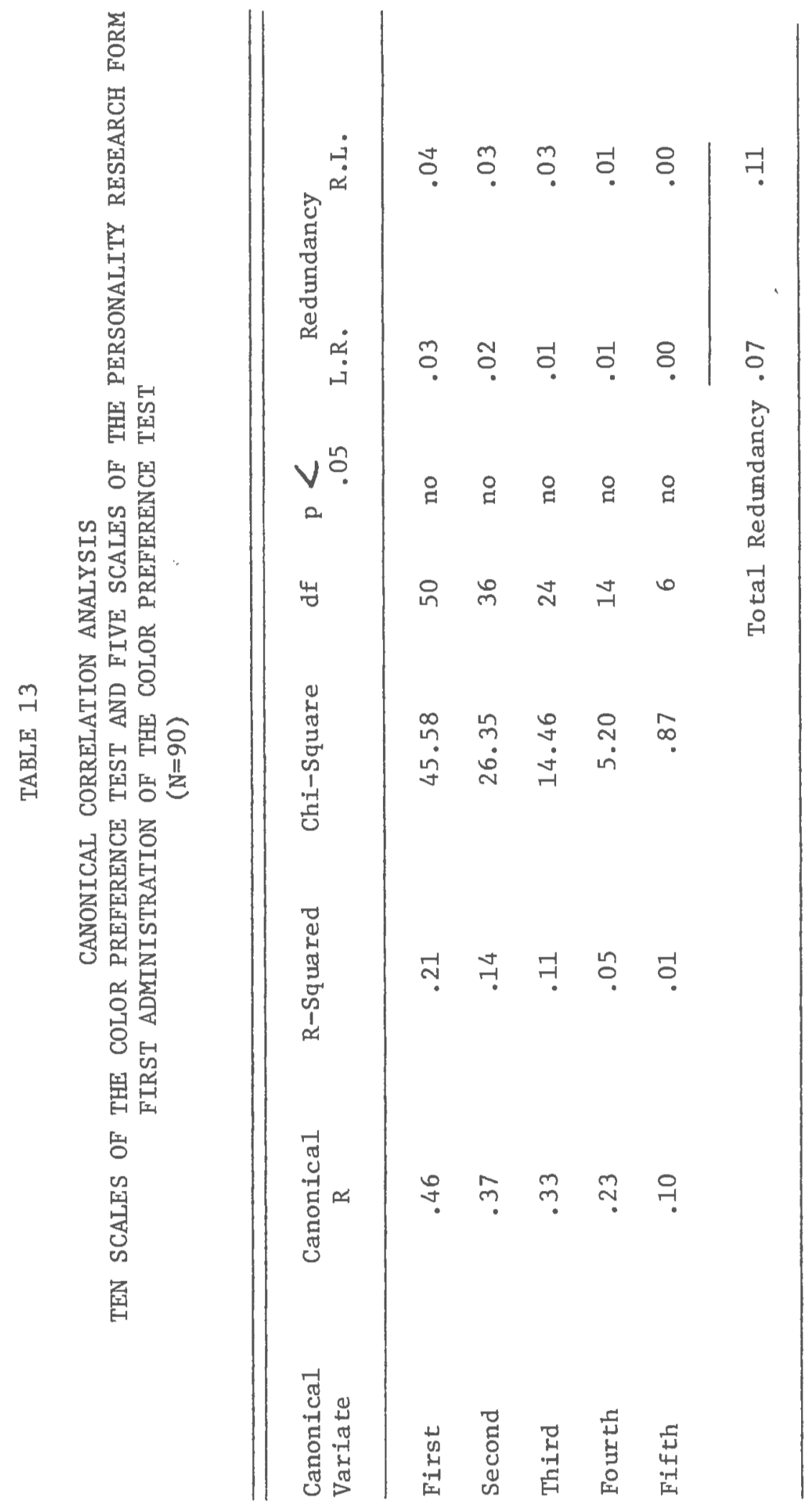




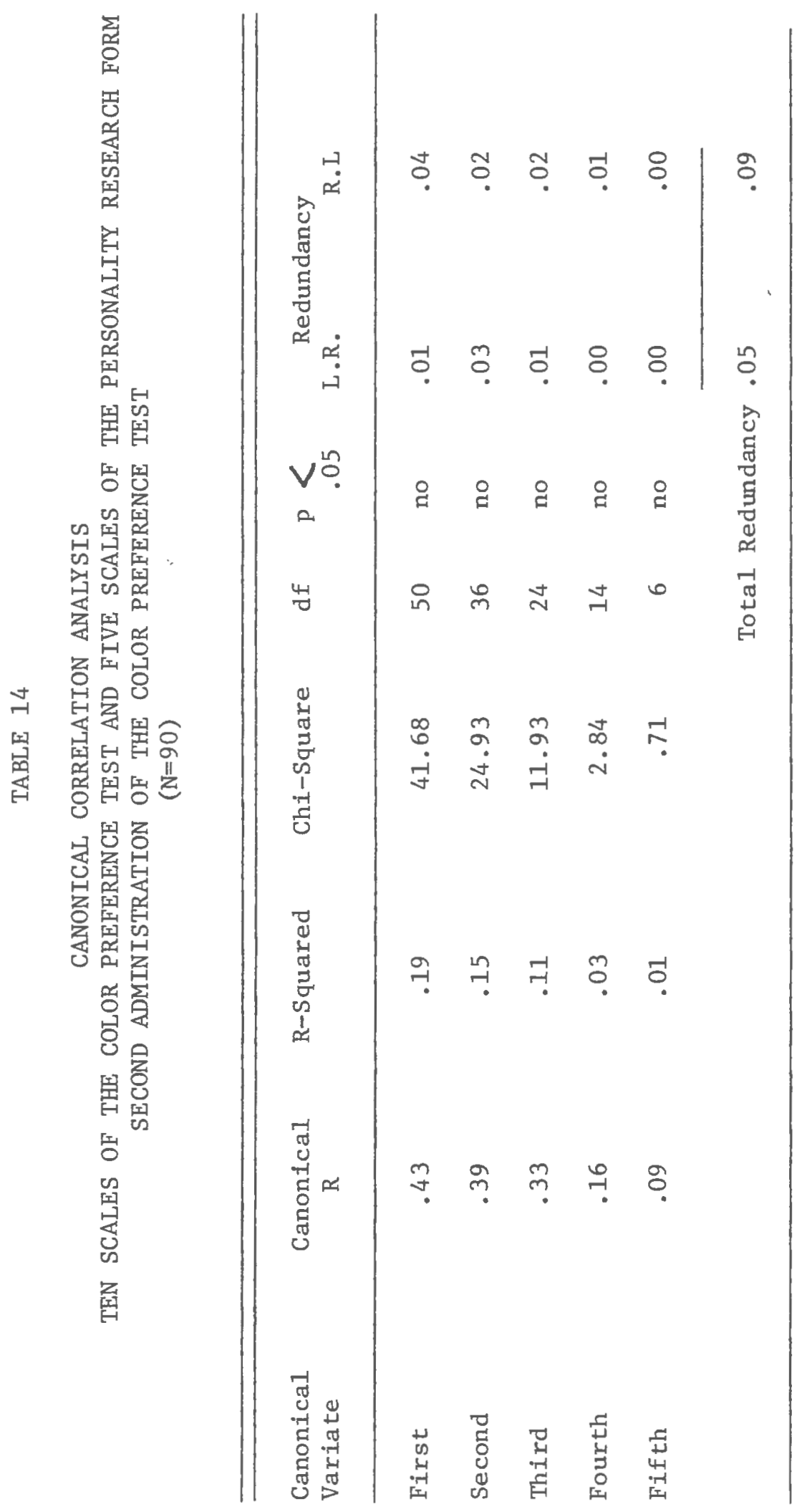


and .11 for the right-hand set (Personality Research Form scales) given the left-hand set (Color Preference Test scales). Put another way, knowledge of subjects' personality profiles did not provide knowledge of color preferences, nor did knowledge of color preferences provide knowledge of personality. (See Table 14 for retest results, which were similar.)

It might be argued, therefore, that the Color Preference Test findings do not lend support to the notion that color preference and personality are associated. Results, although disappointing, may not be conclusive, however; for the small number of subjects studied, in relationship to the number of scales, does not inspire confidence to be placed in the findings. In addition, the negative outcome does not entirely rule out such a relationship; in an unusual population; or given another set of color stimuli, of higher saturation, perhaps; or given another measure of personality.

It should be recalled that the concept of personality embodies a fairly broad set of characteristics; for there are many qualities which distinguish an individual as a person. Further, the measurement of personality in the final analysis is limited to the particular view of man advanced by the theory, and to the variables which the personality theorist has discovered to be centeral to the model.

The five scales employed as the criterion measure in this work reflect but a sample of one important dimension of personality--manifest needs. That a positive relationship to color preference could not be demonstrated does not imply that an association is nonexistent; but can only be taken to suggest that knowledge of color preference (as measured) does 
not lead to knowledge of the five needs measured. Given another personality test, a positive relationship could bery well be revealed.

\section{Additional Findings}

Al though every effort was made to exercise careful control throughout the experiment, circumstances were such that it was accidentally discovered part-way through the first testing session that one stimulus item possessed a different surface finish than the other 76 items (Munsell notation, 5Y 3/2). A substitute item of the appropriate matte finish arrived too late to be included in the testing.

After much deliberation it was decided that the investigation should continue with the one glossy item, and to begin to explore its possible effect upon preference judgments. Although 25 subjects were contacted upon short notice to re-evaluate their selections (without awareness that the proper matte finish item was substituted for the glossy one), only 15 subjects ultimately cooperated by returning for the testing.

All but two of the subjects that did return completely reversed earlier decisions regarding this one item. In fact, the reversals were so dramatic (moving the item from a most preferred category to a least preferred one, for example) that visual inspection of the results for each of the other 76 items was made. No other item changed so completely for these individuals. The additional two persons, meanwhile, were too inconsistent in their preferences overall to speculate about what effect surface finish may have had for them.

The accident in control, therefore, is worthy of mentioning for two reasons. The deviation in balance in terms of item selection (due 
to the one glossy item) could have had unmeasurable effects upon the stability of results as a whole; for the Q-sort method assumes that each item has an equal probability of being placed into one of the initial three categories. Second, it may be that surface finish (a physical aspect of every color stimulus) may play a more significant role in the expression of color preference than previously hypothesized by Beck (1975); or indeed, that finish may take precedence over other attributes of color perception, such as hue and/or lightness. It would appear extremely important that any future work with color preference be directed toward careful evaluation of surface finish, for its possibly powerful effects upon color preference have never been systematically studied. In a final effort to extract as much information as possible from the data, a cluster analysis of cases on both the raw scores and the scale scores was performed (Engleman, 1977). It was hoped that grouping together subjects that performed in a similar manner, and then looking to see what features might be shared in common (such as sex), would be helpful in discerning responsibility for similar response tendencies. Grouping of subjects was not possible, however, in that the analysis yielded but one single cluster. Results suggested, therefore, that "types" of individuals could not be identified by the data. 
VIII. SUMMARY, CONCLUSIONS, AND THEORETICAL IMPLICATIONS

The purpose of the investigation was to attempt to uncover the psychological meaning of color preference. The effects of hue and lightness (two psychological dimensions of surface color perception) were studied, particularly as they relate to an important dimension of personality--manifest needs. Its final emphasis was on how hue and lightness relate to needs for achievement, order, harm avoidance, social recognition, and exhibition, while a third dimension of color perception (saturation) was kept constant.

The specific objectives of the study were as follows:

1. To assess the relative stability of color preference judgment, within subjects, over a five-week interval.

2. To describe the underlying structural components of color preference judgment.

3. To relate color preference to five manifest needs purported to reflect personality characteristics of the person.

Interindividual differences in color preference have been studied extensively, and have generated findings which conflict greatly among studies. Intraindividual differences have not been paid much attention to by previous researchers. Reliability in this context (that is, how stable an individual is in his judgments over time) is basic to the understanding of cultural and/or biological determinants of aesthetic value-as it pertains to color preference. Further, evidence for intraindividual 
reliability over time is essential to the construction of instruments which aim to describe, explain, and predict individuals' color preference behavior: instruments which treat error variance as consisting of differences within persons.

The weight of the evidence for color preference as a stable entity (prior to this investigation) had rested with but three small studies done by Guilford (1939; 1940; 1959); studies which did not adequately control for the possible effects of illumination, color blindness, and/ or uncertain color stimulus specification. In addition, his method of presenting color items for only five seconds (to be passively observed and judged) did not afford the opportunity to study the active selection of colors judged pleasant or unpleasant, which may have more ecological validity. The present study had been designed and undertaken, therefore, in an effort to overcome the deficits that existed in the extremely limited color preference--within subject reliability literature.

The hypotheses posed for testing in the present investigation are relisted below:

1. that color preference can be reliably measured, within subjects, and represents a stable characteristic of the person.

2. that the underlying component structure responsible for color preference judgements, within subjects, can be described.

3. that color preference can be related to specific manifest needs; hence, that in a general sense, color preference and personality are associated.

The subjects used in the study were 90-101 junior college students, recruited primarily from introductory psychology courses. They had a 
median age of 19 years, were Caucasian, and represented both sexes. Subjects suggested no evidence of drug usage during the testing, and demonstrated at least a minimum adequacy of color vision.

Subjects were screened for color blindness using the FarnworthMunsel1 100-Hue Test for Color Discrimination (Farnworth, 1949; 1957), an individually administered and highly reliable technique. The color Preference Test, a new approach to the measurement of color preference using a Q-sort technique (Stephenson, 1953), was especially designed for the purposes of this investigation. Its psychometric soundness was evaluated as major aspect of the first two phases of this study. The Color Preference Test was administered on two occassions, approximately five weeks apart, in an effort to establish the degree to which subjects were stable in their color preference judgments. The Personality Research Form (Jackson, 1968; 1974) served as the criterion measure, in that five scales of interest (whose reliability and validity were most apparent) were thought to hold promise for relating color preference to personality. Except for the Personality Research Form, which was administered in a group setting, all testing was conducted in a self-contained laboratory. Control for proper illumination, uneven surface reflection, and certain color stimulus specification (using Munsell standard color papers) were important to the method, as was a standard background (also Munse11) and standardized viewing conditions (Judd \& Wyszecki, 1975). Color stimulus items were chosen to represent one level of satutation (Munsel1 Chroma 2, of low saturation), and balanced for hue and lightness. In a11, 77 items were chosen to represent the ten major hues, in addition to neutral, across 7 levels of lightness. (The asymetrical 
nature of the Munsell color space (Munsel1, 1946) does not allow for the simultaneous stratification of hue, lightness, and saturation levels.

The analysis of the data, relative to the principal objectives of the study, indicate that rejection of the first research hypothesis was technically indicated, but insufficient in providing definitive explanations for what was observed. Acceptance of the second and third hypotheses, although encouraging, are likewise insufficient in drawing final conclusions about the psychological meaning of color preference. Hypothesis 1: that color preference can be reliably measured, within subjects, and represents a stable characteristic of the person, is rejected.

The Q-sort technique, by design, renders information about the stability of judgments, within persons, over time. In addition, strong evidence for internal consistency of measurement (among persons), together with a reasonable degree of stability in measurement are apparent. It would appear legitimate to assume, therefore, that the Color Preference Test, as presently constructed, is a fairly useful method for the measurement of color preference. Full psychometric accredidation of this new instrument, however, for purposes other than for continued improvement is not possible at the present time, in that supporting data needs to be cross-validated and replicated.

As a consequence, the primary finding of this research, that there were vast differences in stability of color preference judgments over the five-week interval, is both interesting and important. Previous work in the area has been directed towards establishing a commumality of preferences (and, as a result, may be responsible for the dozens of 
contradictory statements about the psychological significance of regarding one color more highly than another), while knowledge of the stability of those judgments within persons has been uncertain.

The additional finding, that there were significant sex differences in stability of preference judgments within persons, is particularly important for future investigation; for although previous researchers have hinted that sex may be pertinent to the establishment of preferences for specific colors among subjects, none have alluded to a relationship between sex and within-subject reliability.

Hypothesis 2: that the underlying component structure responsible for color preference judgments, within subjects, can be described, is accepted.

The observation that color preference is reflective of attention to both hue and to lightness information (when saturation, finish, background, and illumination are kept constant) is theoretically consistent with Land's "Retinex Model" of color vision (1959; 1977); where both wavelength and reflectance data are believed to be simultaneously coded. Further, evidence for an interaction between hue and lightness in each of the components extracted attests to the futility of attempting to relate hue (alone) to any psychological variable. The serendipidous indication that finish may be as important to color preference behavior as both hue and lightness (and, may indeed take precedence over them) could take on extensive significance with further study and verification.

Hypothesis 3: that color preference can be related to specific manifest needs; hence, that in a general sense, color preference and personality are associated, is rejected. 
The negative outcome in this final phase of the investigation, although disappointing, may not be conclusive; for such a relationship cannot be rule out in an unusual population, or given another set of color stimuli (of higher saturation, for example), or given another criterion measure.

In summary, therefore, one may only conclude that the initial steps have been taken in the psychometric development of a potentially valuable instrument for the measurement of color preference behavior, and that:

1. there were vast differences among the 90 subjects studied, with respect to the stability of their color preferences. Sex differences were most apparent, with females observed to be more stable than males in their selections.

2. A hue and lightness interaction appeared to underlie the color preference judgments, which is theoretically consistent with Land's model of color vision (1959; 1977); where both wavelength and reflectance data are hypothesized to be simultaneously coded. An unexpected breakdown in control for surface finish pointed toward its possibly powerful effect in determining color preference, a finding which could take on substantial significance with further study.

3. A relationship between color preference and the five manifest needs of interest (purported to measure important aspects of personality) was not found, but cannot be entirely ruled out.

No effort was made to generalize results beyond the subjects studied (given the sampling method), or to situations other than those described. Hence, final and extemally valid statements with regard to explanations for what was observed cannot be supported at the present 
time.

What then do different colors mean to different people? Are different people influenced differently by various colors? Is color preference stable enough over time to suggest a systematic process underlying its occurrence? Can color preference be related to personality? What might the underlying structural components of color preference be? Questions which provided stimulation for undertaking the research in the first place are still not fully answerable, of course, while new and equally interesting questions (not previously ascertainable) have arisen.

It would appear important as a consequence of this study, for example, that future research concern itself with possible sex differences. A future study is needed to attempt to discover why males and females may be influenced (or interested) differently by/in color. Are there parallel differences in other sensory systems as well? Are culture and/or experience with color important determinants?

Other directions might include exploring sex differences in the context of color processing. Where is "solid color" processed in the brain? Might additive color (light) be processed differently than subtractive (pigment) color? Does consistency of color preference relate to consistency in preference for other tastes; in sounds, for example. Does consistency of color preference relate to other psychological variables, such as intelligence? What potentially important role does finish play in the expression of color preference; or perhaps more basic, what specific part does finish have in the overall perception of color? 
[One clue to the consequences of finish has emerged from informal discussion with several artists, where it was intuitively felt that a glossy finish (compared with a matte finish) has the effect of intensifying hue, particularly at edges. This phenomenon has not been formally studied, and suggests to the interested reader that a fairly simple experiment may be appropriate.]

There were a number of problems and/or limitations that were encountered in the process of implementing this research which should be considered when interpreting these data, and which also may have practical implications for others involved with color preference research.

1. Although all subjects had intially consented to be participants in the study, several had to be gently encouraged to return for the second testing session. It is not known what effects this situation may have had upon the motivation of such subjects; nor indeed, how any subject was motivated.

It was observed that subjects varied somewhat in their relative consideration of each color stimulus item; some making quite rapid choices, and others taking much longer time to make a decision. Except for outside limits of about ten minutes, the Q-sort method used in this study did not (and cannot) control for equal exposure time to each item. The future researcher might carefully consider whether this is desirable or a problem for him.

2. The forced-choice procedure, inherent in the Q-sort method, appeared difficult for several subjects, who insisted that they did not particularly like any of the colors. It is not known what effects this may have had upon their motivation to make decisions. It could have been 
that choices made be these individuals (or any others, for that matter) were made at random; which could have contributed to the low stability measures observed for some subjects.

3. One had no way of knowing what cognitive set each subject possesed in making preference decisions. Some subjects asked if the colors were to be thought of in the context of wall paint, or in reference to items of clothing. (Subjects were instructed to use whatever they wished.) It might be important to incoporate such issues in the design of future work.

4. There was the practical problem of keeping the color stimulus cards clean. Latex gloves worn by the researcher and the subjects seemed to provide a fairly effective way to reduce unwanted soil. Several subjects complained, however, that the gloves caused their hands to perspire under the light source. One subject commented that she thought she was allergic to rubber. The future researcher would obviously have to weigh the need for such measures, against possible undesirable effects of soil and umeven surface reflection (caused by different jewelry or skin tone, for example).

5. The difference in height among subjects made it physically impossible to insure that subjects were equally positioned from the viewing table. This was particularly a problem for several handicapped students. An adjustable stool might serve to correct for this potentially extraneous variable.

6. Careful attention should be given to the possibility that some subjects may be wearing tinted lenses, with or without awareness.

7. A voltage regulator for the light source was an afterthought. 
8. A future researcher might want to consider that subjects who are to be recalled for a second session are tested during the same hour of the day. Subsequent discussion with an optometrist alerted this researcher to the possibility that vision may not be similar at the beginning and end of a day; when fatigue, pollution, or any number of things (including diet) may affect vision, in general.

9. Instructions might be put on tape, with the researcher's availability for further questions. It might also be desirable to construct a practice exercise, in that it was observed that several subjects had difficulty understanding the instructions which were read to the subject.

10. Although $3^{\prime \prime} \times 5^{\prime \prime}$ color stimulus items appeared adequate for making choices, even larger representations of color would have been desirable. Some subjects had to be frequently reminded to work with the items at the table level; the temptation for these subjects was to bring the stimulus card to eye level, hence not comply with the standardized viewing conditions.

11. The necessity for seven levels of lightness is not apparent, for it called upon many subjects to make subtle decisions among small differences in value. Although one is confident that a minimum amount of color discrimination ability was insured, subjects differed widely in their abilities upon color vision screening. Larger intervals in the choice of lightness levels could have the effect of increasing within subject stability.

The substantial effort put forth in the present investigation has accordingly presented the opportunity to continue the search for the psychological meaning of color preference in a more theoretically sup- 
ported and emperically sound manner; one which places an emphasis upon the unique quality of our human responses to a colorfully perceived world. It is expected that with continued work in the area, particularly along the suggested lines, that psychology will serve the interests of science well: by furthering its own contribution to the newly integrative, interdisciplinary approach to the problem of color. 
APPENDIX A

MUNSELL NOTATIONS FOR

77 COLOR STIMULUS ITEMS

COMPRISING

THE COLOR PREFERENCE TEST 
TABLE 1

COLORIMETRIC DATA SHEET

FOR CIE ILLUMINANT C

MUNSELL STANDARD PAPERS

\begin{tabular}{|c|c|c|c|}
\hline Nominal & Measured & Nominal & Measured \\
\hline $\mathrm{N} 3 /$ & $\mathrm{N} 3.01 / 0$ & $5 G \quad 6 / 2$ & $5.3 G \quad 5.98 / 2.05$ \\
\hline $\mathrm{N} 4 /$ & $N 4.01 /(\mathrm{PB}, 0.1-)$ & $5 G \quad 7 / 2$ & $5.3 G 6.99 / 2.0$ \\
\hline $\mathrm{N} 5 /$ & $\mathrm{N} 4.99 / 0$ & $5 G \quad 8 / 2$ & $5 G 8.00 / 1.9$ \\
\hline $\mathrm{N} 6 /$ & $\mathrm{N} 6.00 /(2.5 \mathrm{~PB}, 0.06)$ & $5 G 9 / 2$ & $4.4 \mathrm{G} 9.01 / 1.95+$ \\
\hline N $7 /$ & $\mathrm{N} 6.99 /(\mathrm{GY}, 0.01)$ & $5 B G \quad 3 / 2$ & 5BG $2.99 / 1.85$ \\
\hline $\mathrm{N} 8 /$ & $\mathrm{N} 8.02 /(10 \mathrm{Y}, 0.03)$ & $5 B G 4 / 2$ & 5BG $4.04 / 1.9$ \\
\hline N $9 /$ & $\mathrm{N} 8.96 / 0$ & $5 B G \quad 5 / 2$ & $4.8 \mathrm{BG} 5.02 / 1.95$ \\
\hline $5 \mathrm{R} 3 / 2$ & $5.05 \mathrm{R} \quad 3.01 / 2.05$ & $5 B G \quad 6 / 2$ & $5.2 \mathrm{BG} 6.00 / 2.1-$ \\
\hline $5 R \quad 4 / 2$ & $4.9 \mathrm{R} 4.01 / 2.1+$ & $5 B G \quad 7 / 2$ & $4.5 \mathrm{BG} 7.00 / 2.0$ \\
\hline $5 R \quad 5 / 2$ & $4.3 R \quad 4.95 / 2.05$ & $5 B G \quad 8 / 2$ & $5.2 \mathrm{BG} 7.99 / 2.0$ \\
\hline $5 R \quad 6 / 2$ & SR $5.96 / 2.0$ & $5 B G 9 / 2$ & 5.6 BG $9.00 / 1.9$ \\
\hline $5 R 7 / 2$ & $4.8 \mathrm{R} \quad 6.99 / 2.0$ & $5 B \quad 3 / 2$ & $5 B \quad 3.01 / 2.05$ \\
\hline $5 \mathrm{R} 8 / 2$ & $5.5 R \quad 7.96 / 2.05$ & $5 B \quad 4 / 2$ & $5 B \quad 3.99 / 2.0$ \\
\hline $5 \mathrm{R} 9 / 2$ & $4.6 \mathrm{R} \quad 8.95 / 2.0$ & $5 B \quad 5 / 2$ & $5.1 \mathrm{~B} 5.03 / 1.95$ \\
\hline $5 Y R \quad 3 / 2$ & $5.3 Y R \quad 2.99 / 1.85$ & $5 B \quad 6 / 2$ & $5 \mathrm{~B} 6.00 / 2.1$ \\
\hline $5 Y R \quad 4 / 2$ & $4.8 Y R \quad 3.99 / 2.0+$ & $5 B \quad 7 / 2$ & $5 \mathrm{~B} 7.00 / 2.0$ \\
\hline $5 Y R 5 / 2$ & 5.3YR $5.01 / 2.0+$ & $5 B \quad 8 / 2$ & $5.2 \mathrm{~B} 7.96 / 2.0+$ \\
\hline $5 Y R \quad 6 / 2$ & $5.4 Y R \quad 6.02 / 2.1$ & $5 B \quad 9 / 2$ & $4.8 \mathrm{~B} 9.03 / 2.1$ \\
\hline SYR $7 / 2$ & $5 \mathrm{YR} 7.00 / 2.0$ & $5 \mathrm{~PB} \quad 3 / 2$ & $5 \mathrm{~PB} 3.00 / 2.0+$ \\
\hline 5YR $8 / 2$ & $4.8 \mathrm{YR} 7.98 / 2.0$ & $5 \mathrm{~PB} \quad 4 / 2$ & $4.9 \mathrm{~PB} \quad 3.90 / 2.05$ \\
\hline $5 Y R \quad 9 / 2$ & 5YR $8.98 / 2.0+$ & $5 \mathrm{~PB} 5 / 2$ & $5.1 P B \quad 5.00 / 2.0$ \\
\hline $5 Y \quad 3 / 2$ & $4.0 Y \quad 3.04 / 1.95$ & $5 P B \quad 6 / 2$ & $4.9 \mathrm{~PB} \quad 6.01 / 1.95$ \\
\hline $5 Y 4 / 2$ & $4.9 \mathrm{Y} \quad 3.98 / 1.95+$ & $5 \mathrm{~PB} \quad 7 / 2$ & $5.2 \mathrm{~PB} \quad 7.00 / 2.0$ \\
\hline $5 Y 5 / 2$ & $5.1 Y 5.01 / 2.0-$ & $5 \mathrm{~PB} 8 / 2$ & 4.9 В $7.99 / 2.0+$ \\
\hline $5 Y 6 / 2$ & $5 Y 6.03 / 2.0$ & $5 P B \quad 9 / 2$ & $5.1 \mathrm{~PB} 8.95 / 1.9$ \\
\hline $5 Y 7 / 2$ & $4.8 \mathrm{Y} 7.03 / 2.0$ & $5 \mathrm{P} 3 / 2$ & $5.3 \mathrm{P} 3.03 / 1.8-$ \\
\hline $5 Y 8 / 2$ & $4.4 Y \quad 7.99 / 2.0$ & $5 P 4 / 2$ & $4.8 \mathrm{P} \quad 4.02 / 1.95$ \\
\hline $5 Y 9 / 2$ & $4.5 Y 9.02 / 2.35+$ & $5 P \quad 5 / 2$ & $5.8 \mathrm{P} \quad 5.03 / 2.1-$ \\
\hline $5 G Y \quad 3 / 2$ & $5 G Y 2.98 / 2.2$ & $5 P \quad 6 / 2$ & $5 \mathrm{P} \quad 6.02 / 1.95$ \\
\hline $5 \mathrm{GY} 4 / 2$ & $5 G Y 4.03 / 1.95+$ & $5 P \quad 7 / 2$ & $4.9 \mathrm{P} 6.98 / 1.9$ \\
\hline $5 \mathrm{GY} 5 / 2$ & $5 G Y \quad 5.02 / 1.95+$ & $5 \mathrm{P} 8 / 2$ & $5.2 \mathrm{P} 7.98 / 2.05$ \\
\hline $5 G Y 6 / 2$ & $4.8 \mathrm{GY} 5.98 / 1.95+$ & $5 P \quad 9 / 2$ & $5.5 \mathrm{P} \quad 8.97 / 2.0$ \\
\hline $5 \mathrm{GY} \quad 7 / 2$ & $5.2 \mathrm{GY} 6.93 / 1.95$ & $5 R P \quad 3 / 2$ & $5.2 \mathrm{RP} \quad 2.97 / 2.0+$ \\
\hline $5 G Y 8 / 2$ & $4.8 \mathrm{GY} 7.93 / 2.0$ & $5 R P \quad 4 / 2$ & $5.9 R P \quad 3.96 / 2.0$ \\
\hline $5 G Y \quad 9 / 2$ & $4.9 \mathrm{GY} 9.00 / 2.1$ & $5 R P \quad 5 / 2$ & 5. $2 \mathrm{RP} \quad 4.99 / 1.95$ \\
\hline $5 G \quad 3 / 2$ & $5.1 \mathrm{G} 3.02 / 2.1+$ & $5 \mathrm{RP} \quad 6 / 2$ & $4.7 \mathrm{RP} 5.93 / 2.2$ \\
\hline $5 G \quad 4 / 2$ & $5.4 \mathrm{G} 3.96 / 2.05$ & $5 R P \quad 7 / 2$ & $4.95 \mathrm{RP} \quad 6.98 / 2.05$ \\
\hline \multirow[t]{2}{*}{$5 G \quad 5 / 2$} & $4.8 G 5.00 / 2.0$ & $5 R P \quad 8 / 2$ & $5.2 \mathrm{RP} 7.97 / 2.1$ \\
\hline & & $5 R P \quad 9 / 2$ & $5.4 R P \quad 8.99 / 2.0$ \\
\hline
\end{tabular}


APPENDIX B

SAMPLE PROFILE SHEETS FOR

THE FARNSWORTH-MUNSELL 100-HUE TEST

FOR COLOR DISCRIMINATION 
Figure 1

Speciman Profile Sheet

of Subject with

Probable Normal Color Vision

FARNSWORTH-MUNSELL 1OO-HUE TEST FOR COLOR DISCRIMINATION
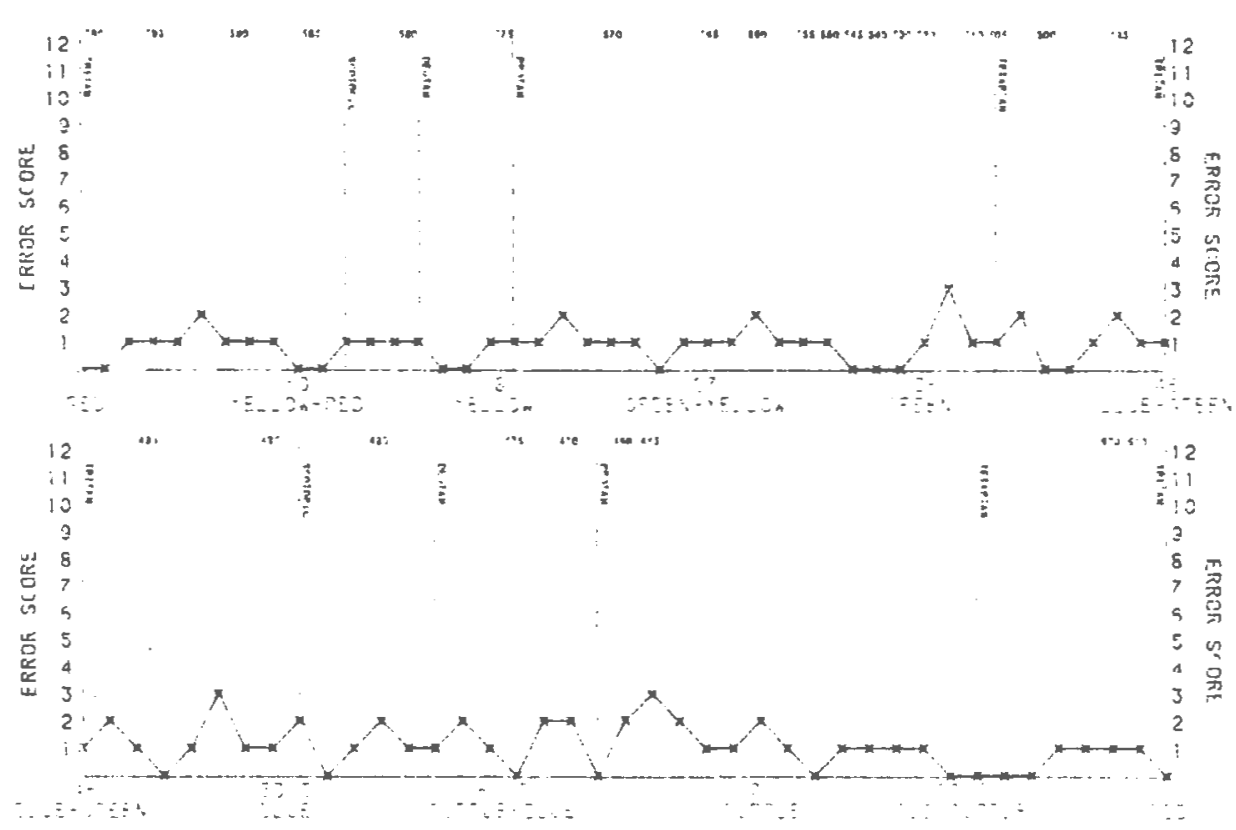

SUE!ECT HUMERQ = 4

TCTAL 3COEE - OA

MIPEOIYT OE ERRAZS - 42 AT I:EM 47 
Figure 2

Speciman Profile Sheet of Subject with

Probable Poor Color Discrimination Ability

(Color Weakness)

FARNSWORTH-MUNSELL 1OO-HUE TEST FOR COLOR DISCRIMINATION
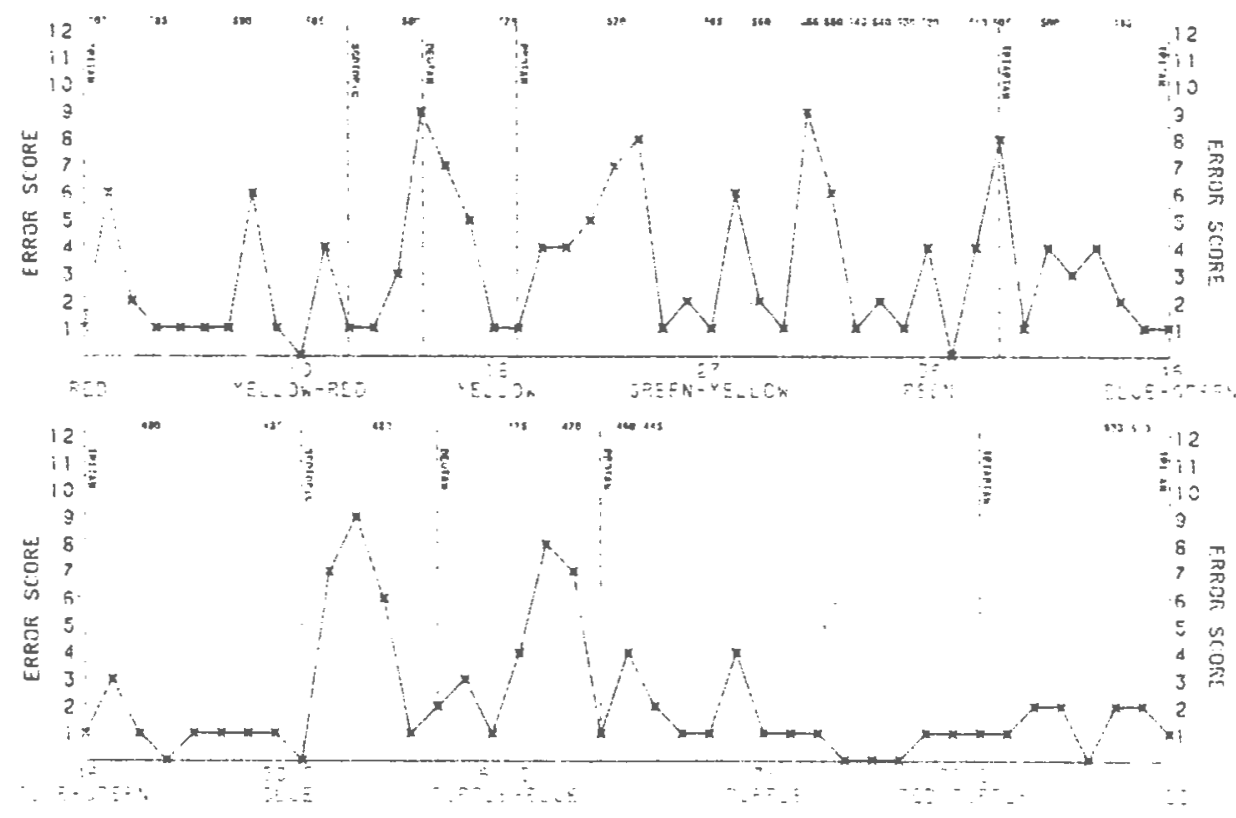

SUEJECT NUMSER = 14

TCTAL STOEE = 226

MIDPCENT OF EROARS - IIL AT ITEM JS 
Figure 3

Speciman Profile Sheet

of Subject with

Probable Color Vision Dysfunction

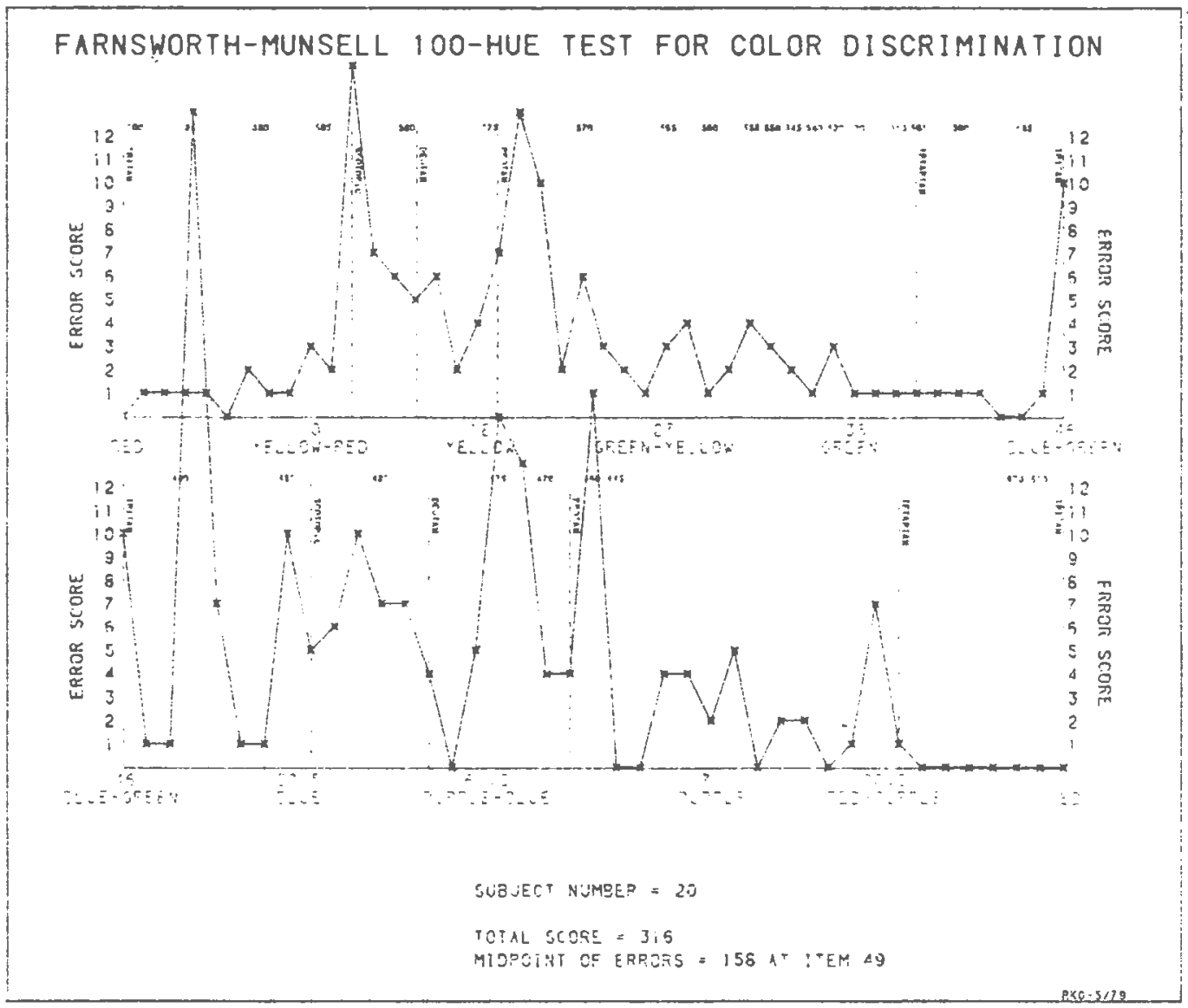


APPENDIX C

SCHEMATIC FIGURES

REPRESENTING TEN PRINCIPAL COMPONENTS

EXTRACTED FROM TWO ADMINISTRATIONS OF

THE COLOR PREFERENCE TEST

(MATCHED FOR SIMILARITY) 

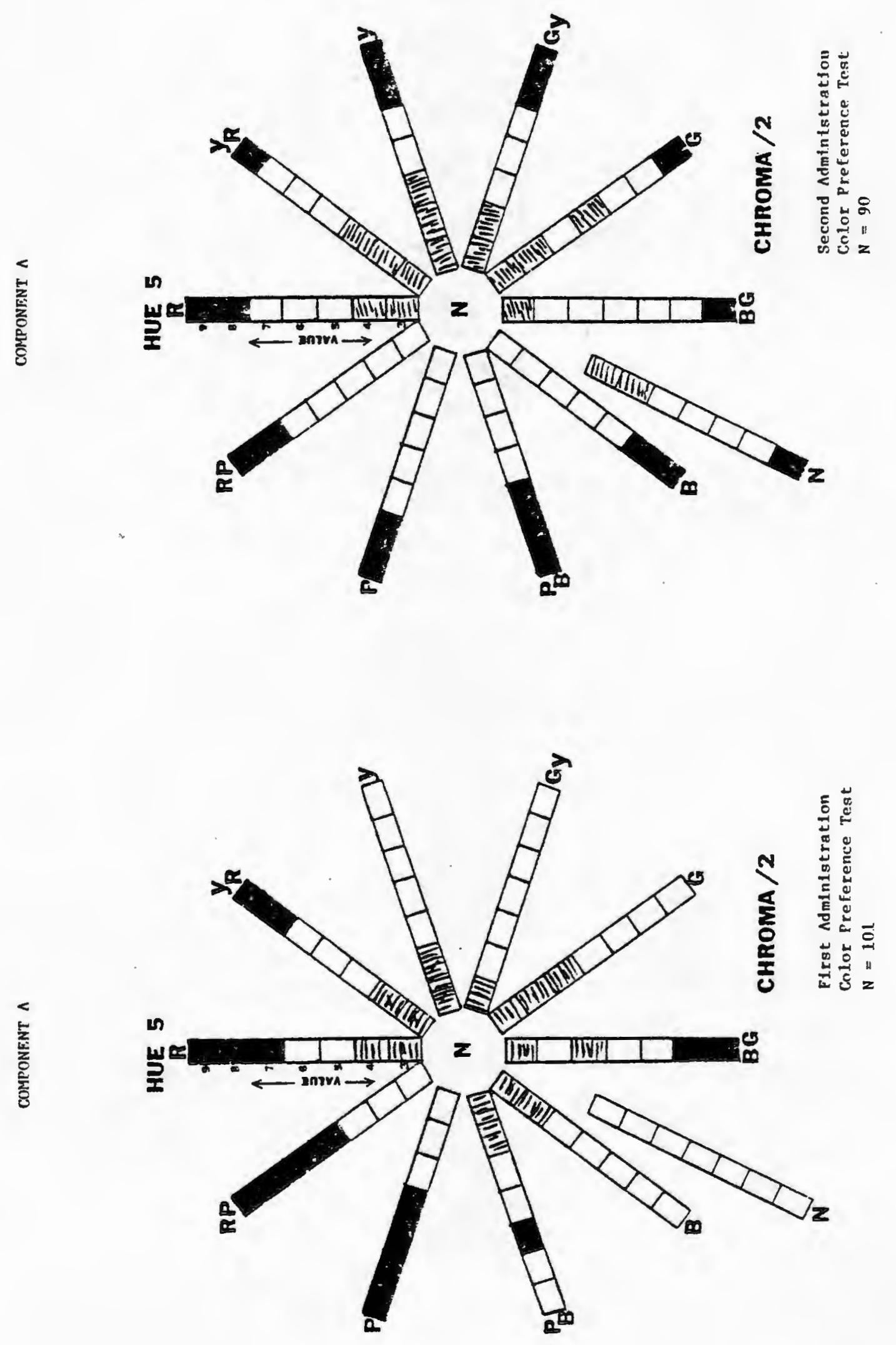

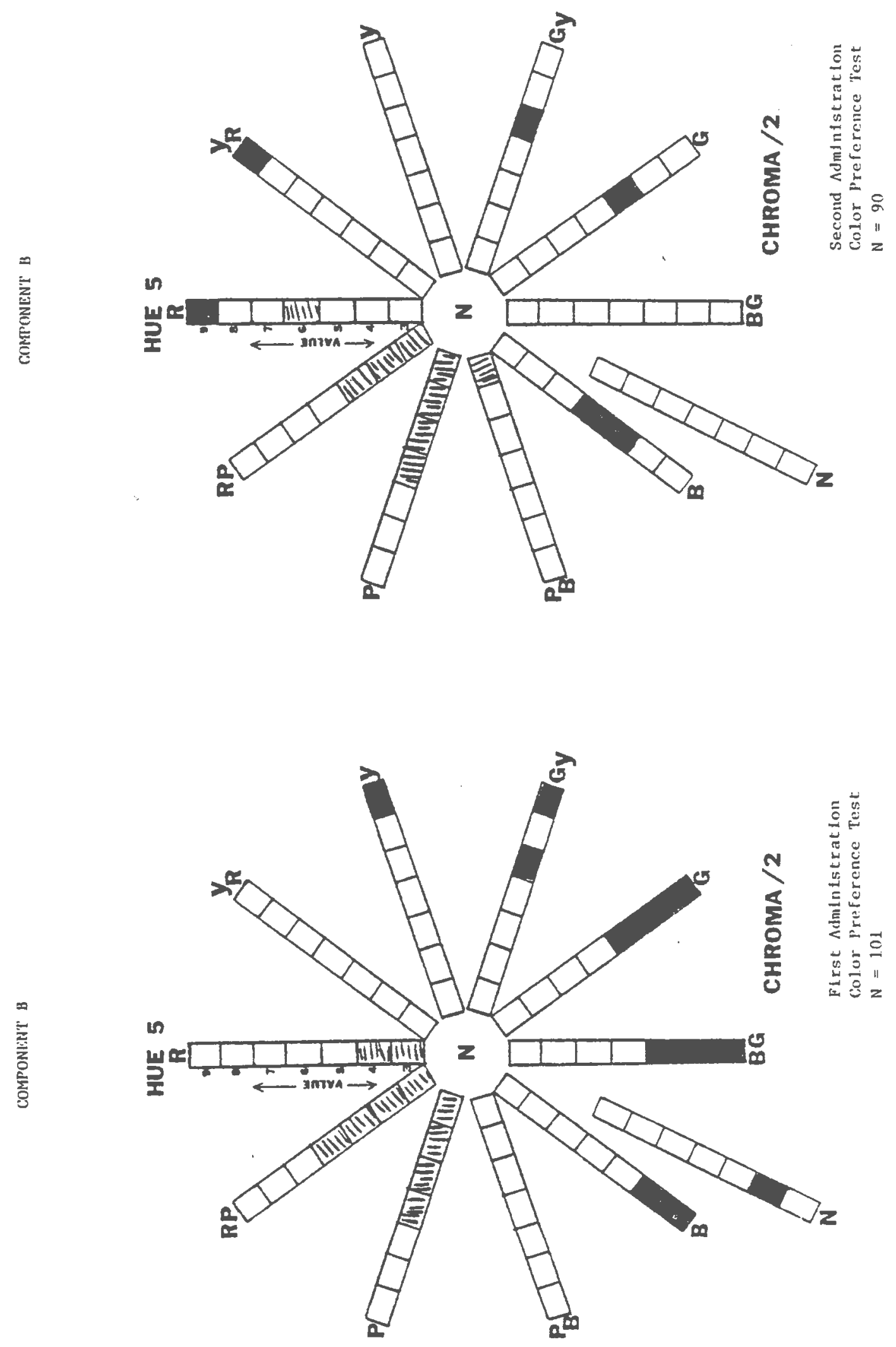
146
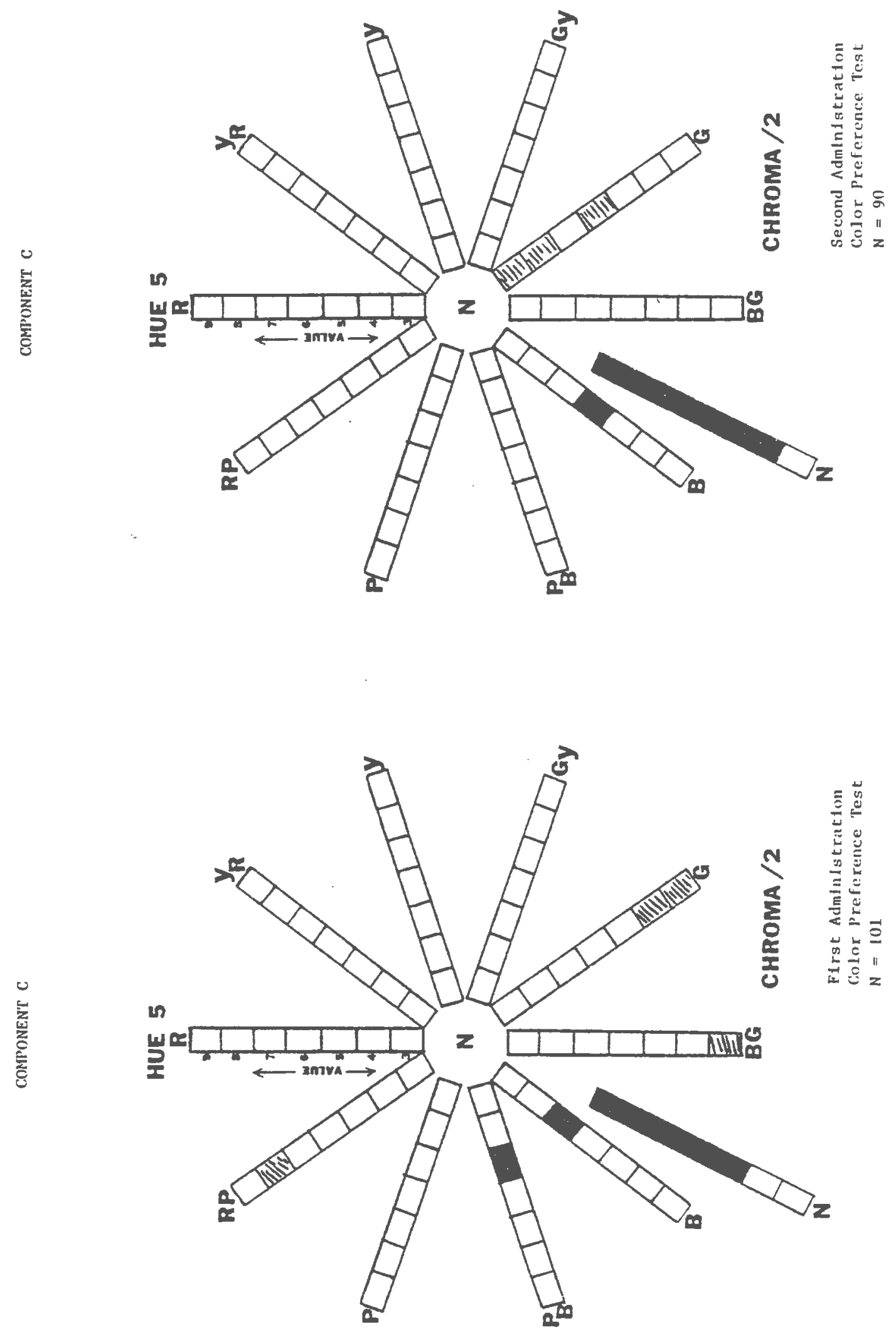


\section{7}
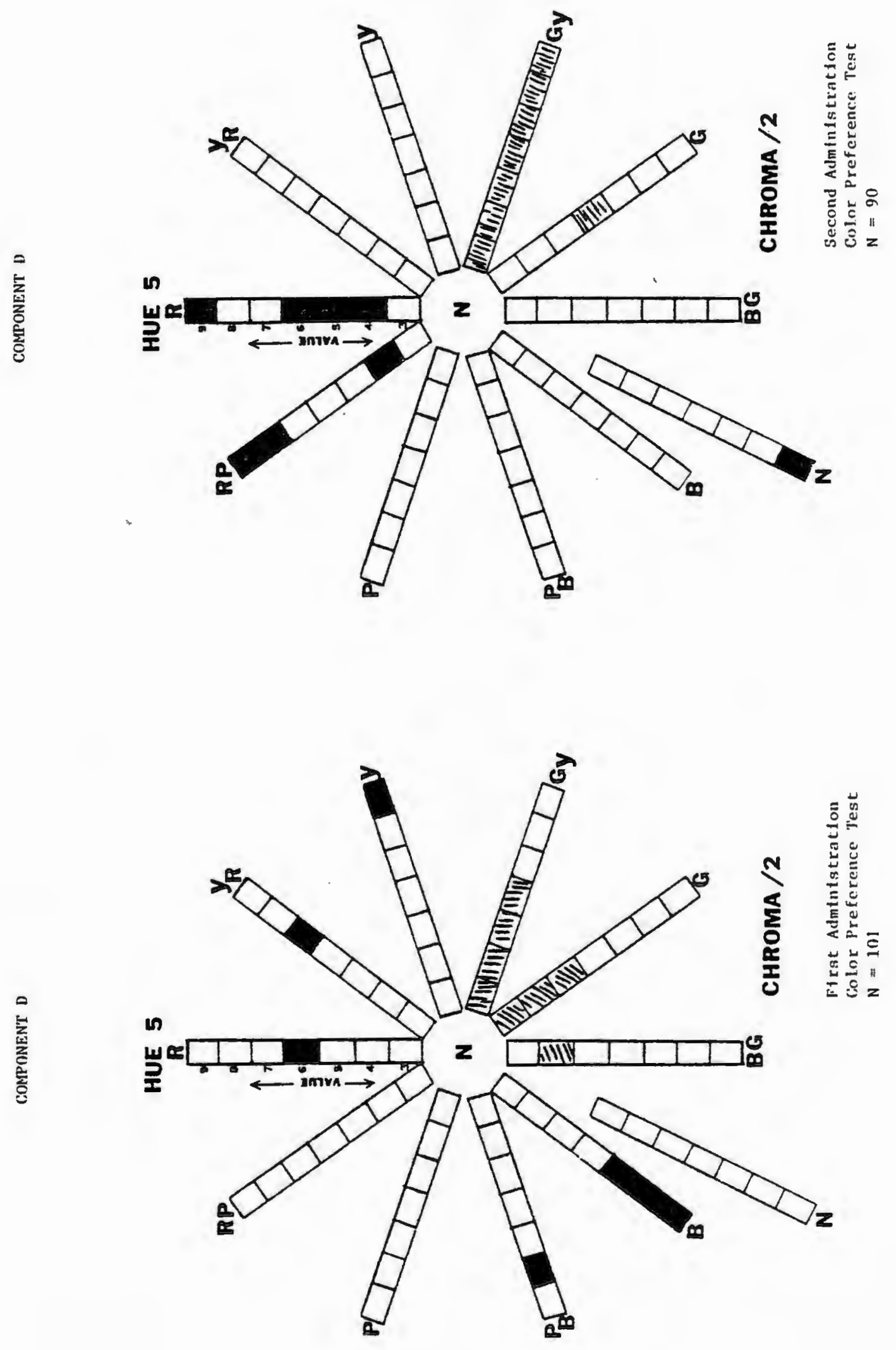
这

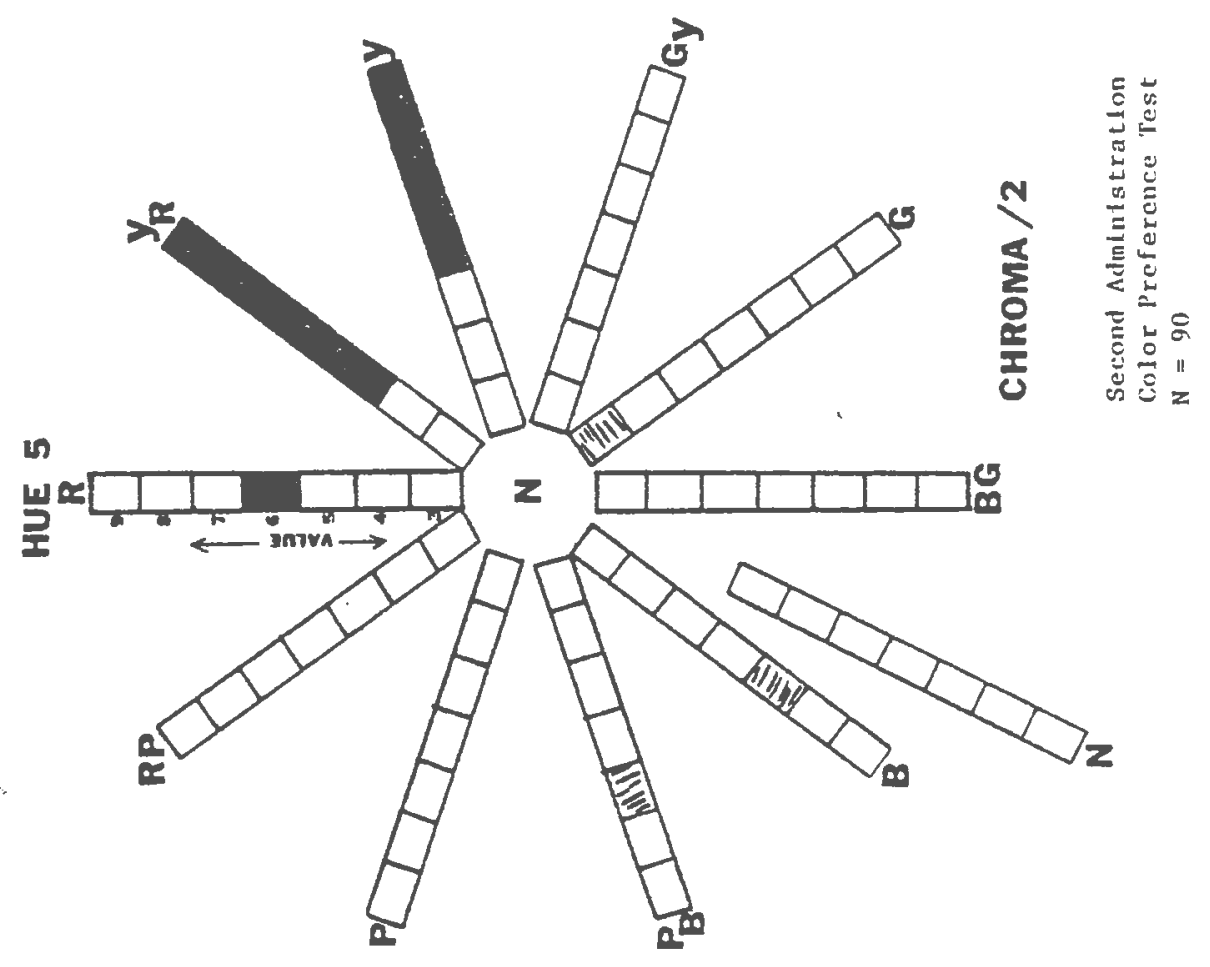

突

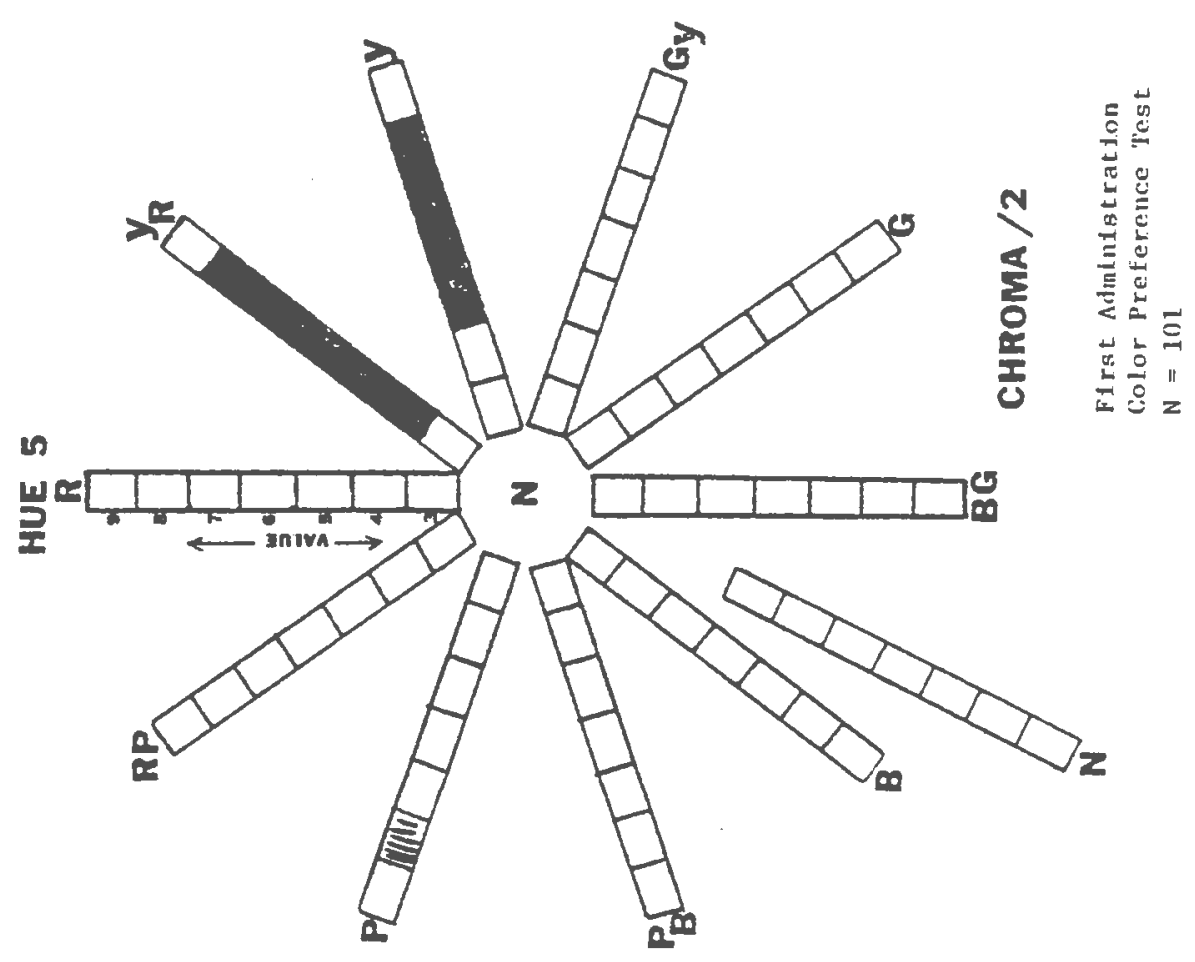


ż

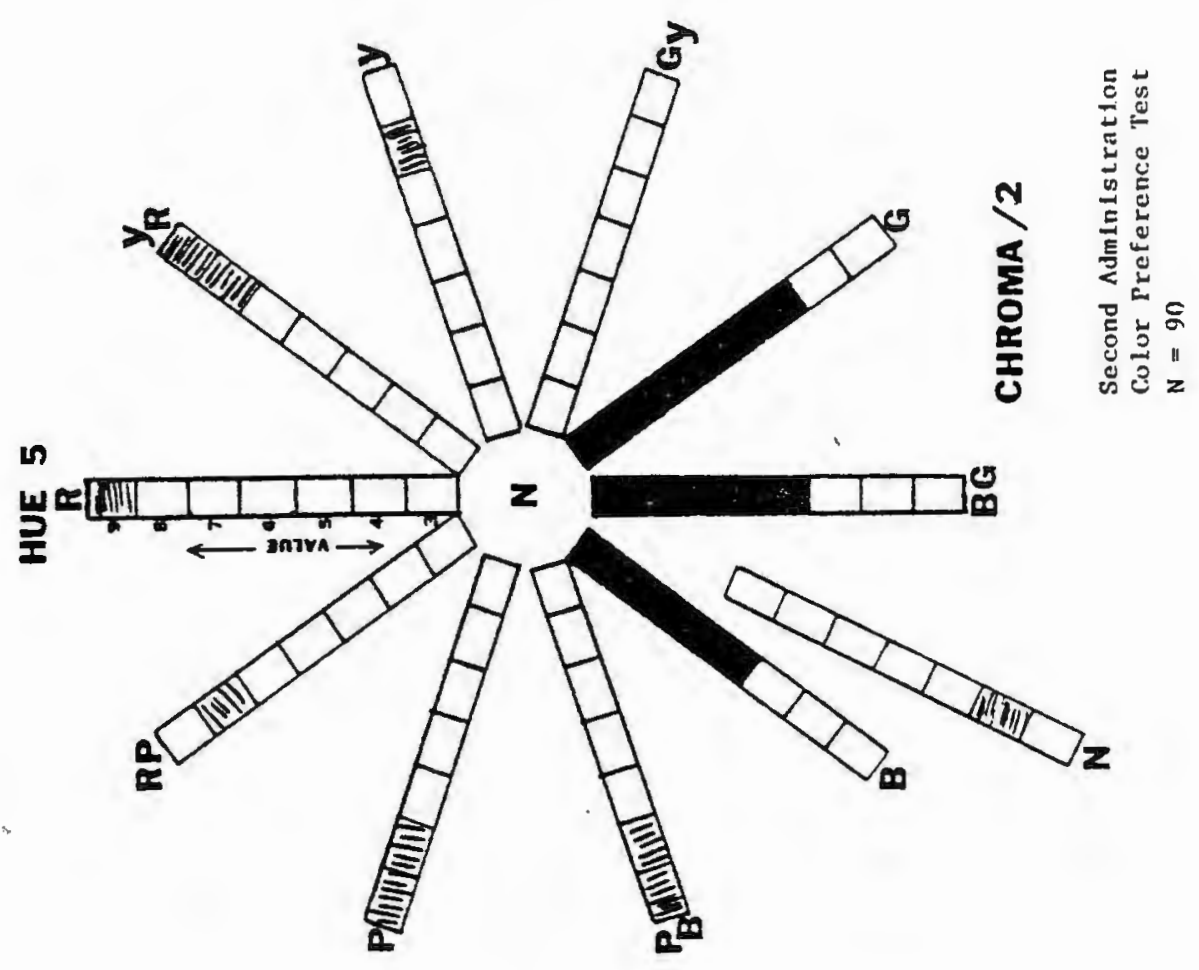

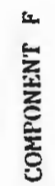

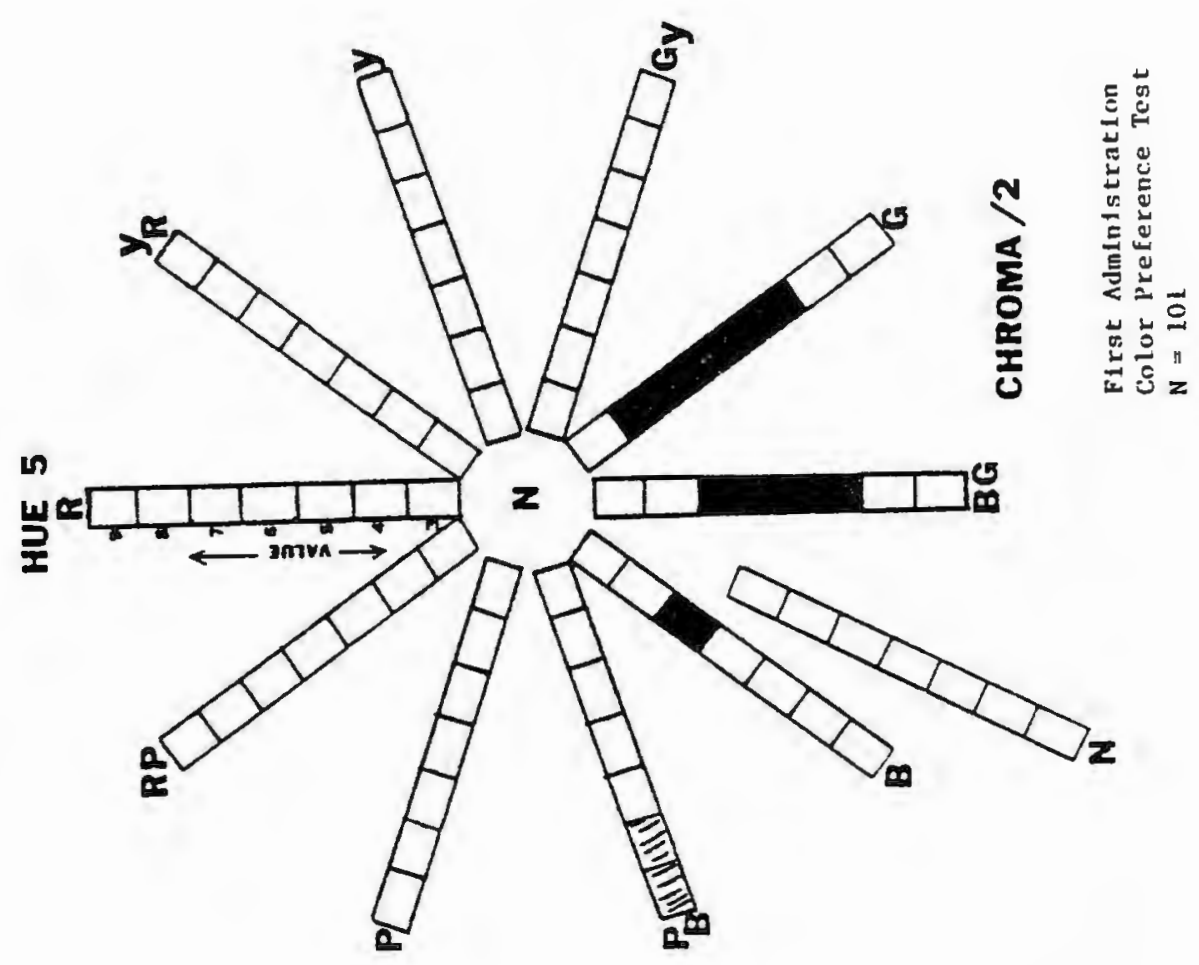


늘

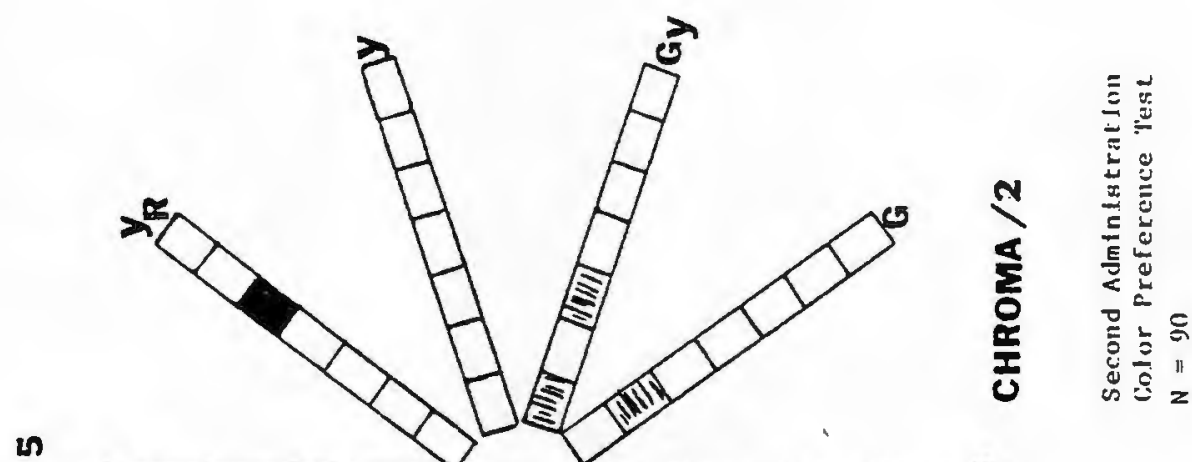
닌

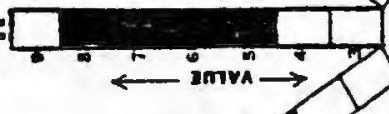

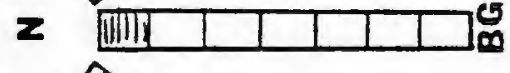

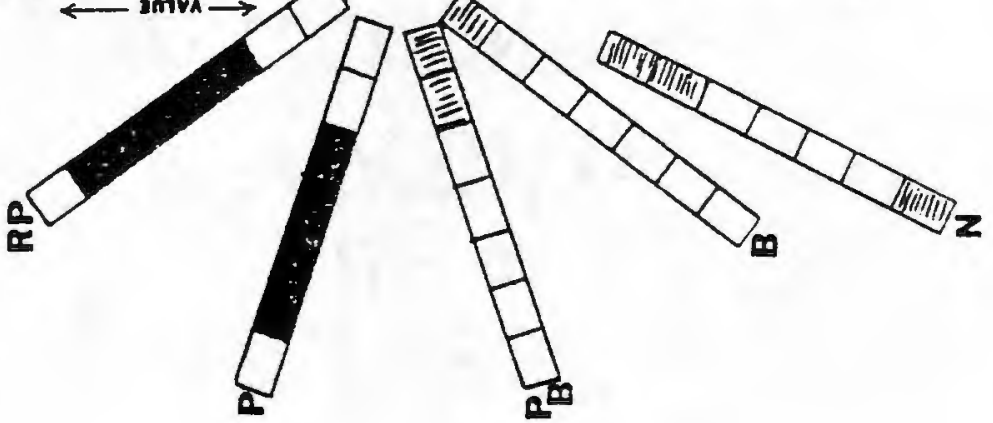

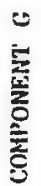

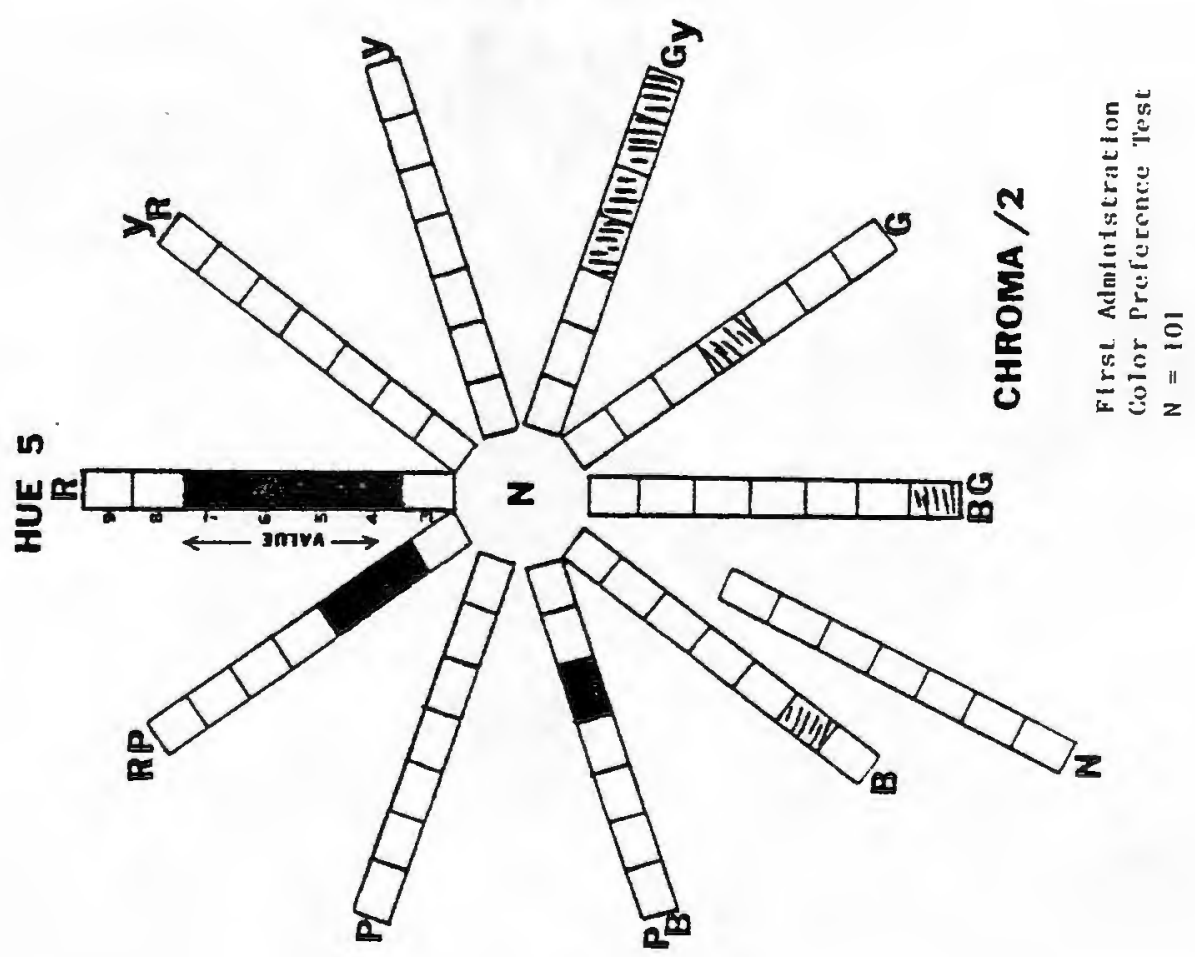



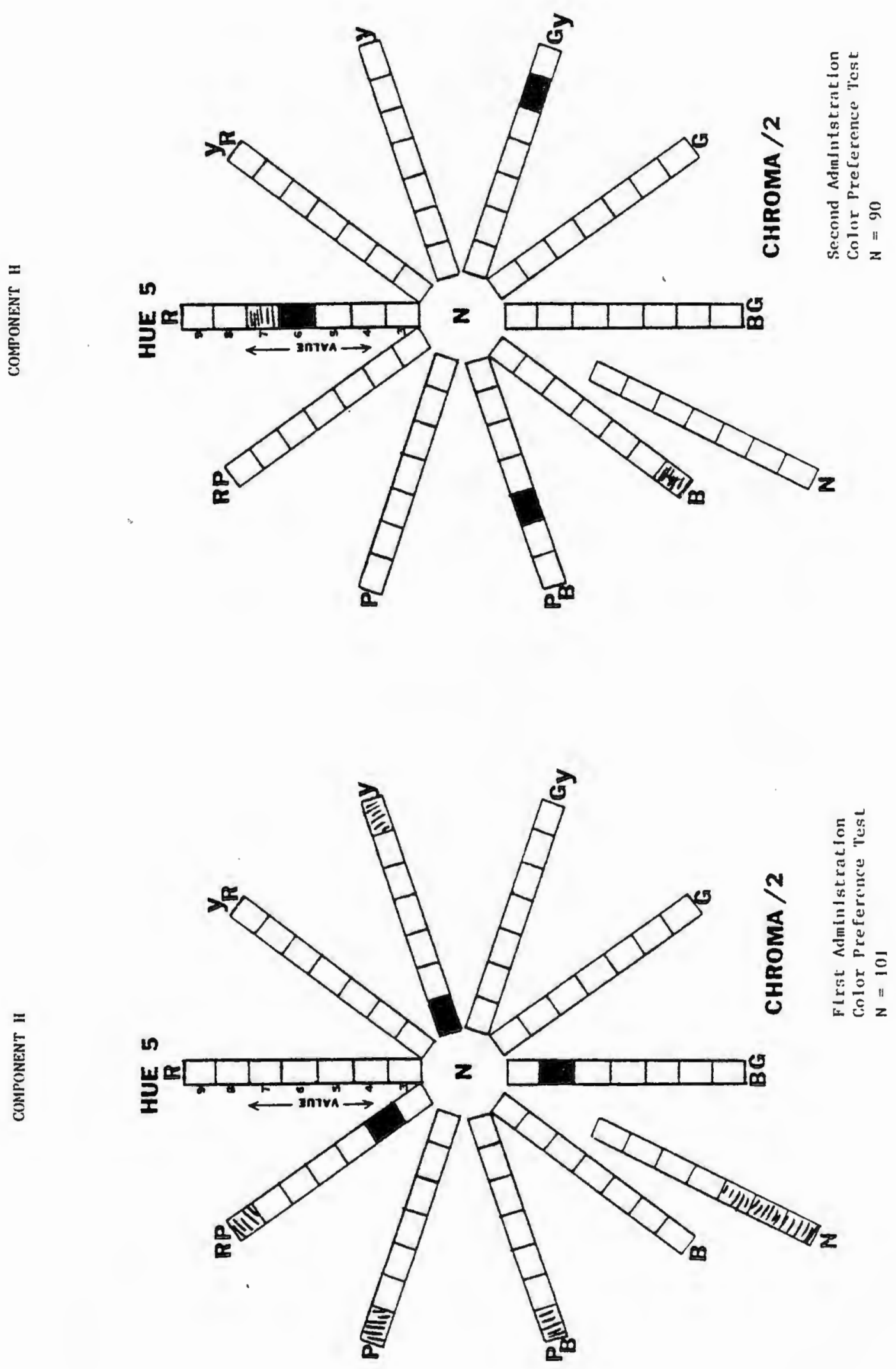
告
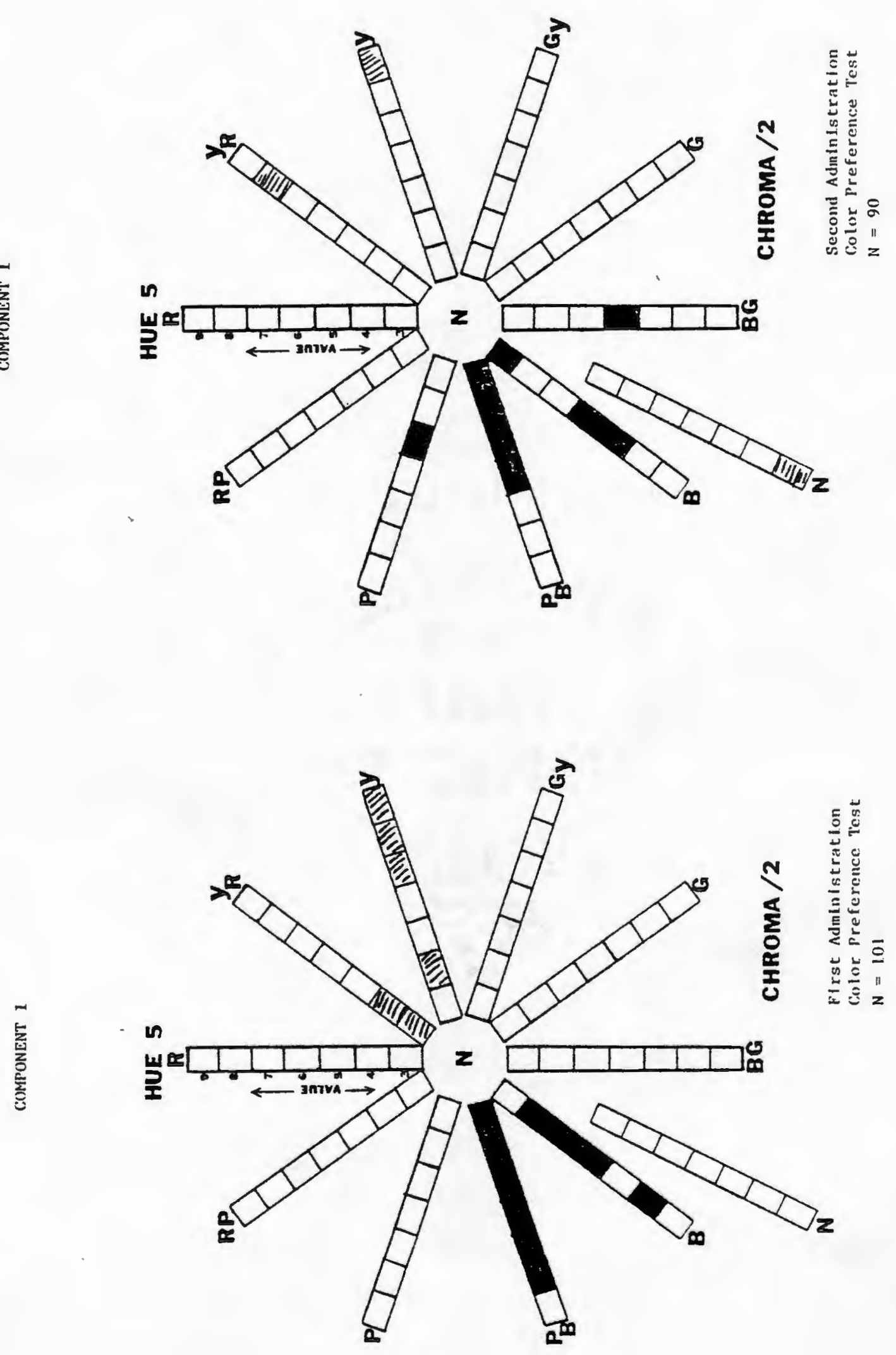
153
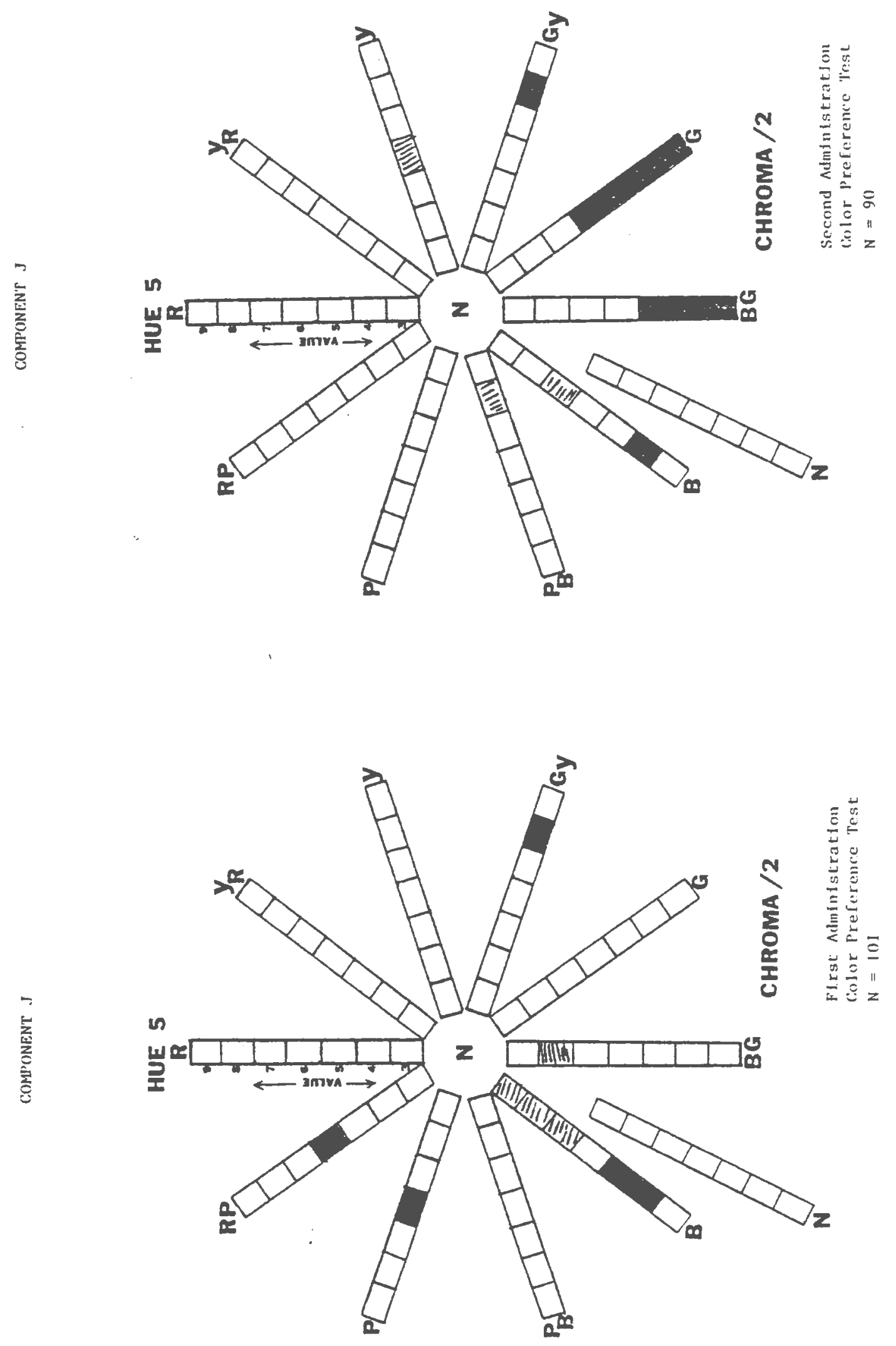
APPENDIX D

COMPUTATION OF Q 


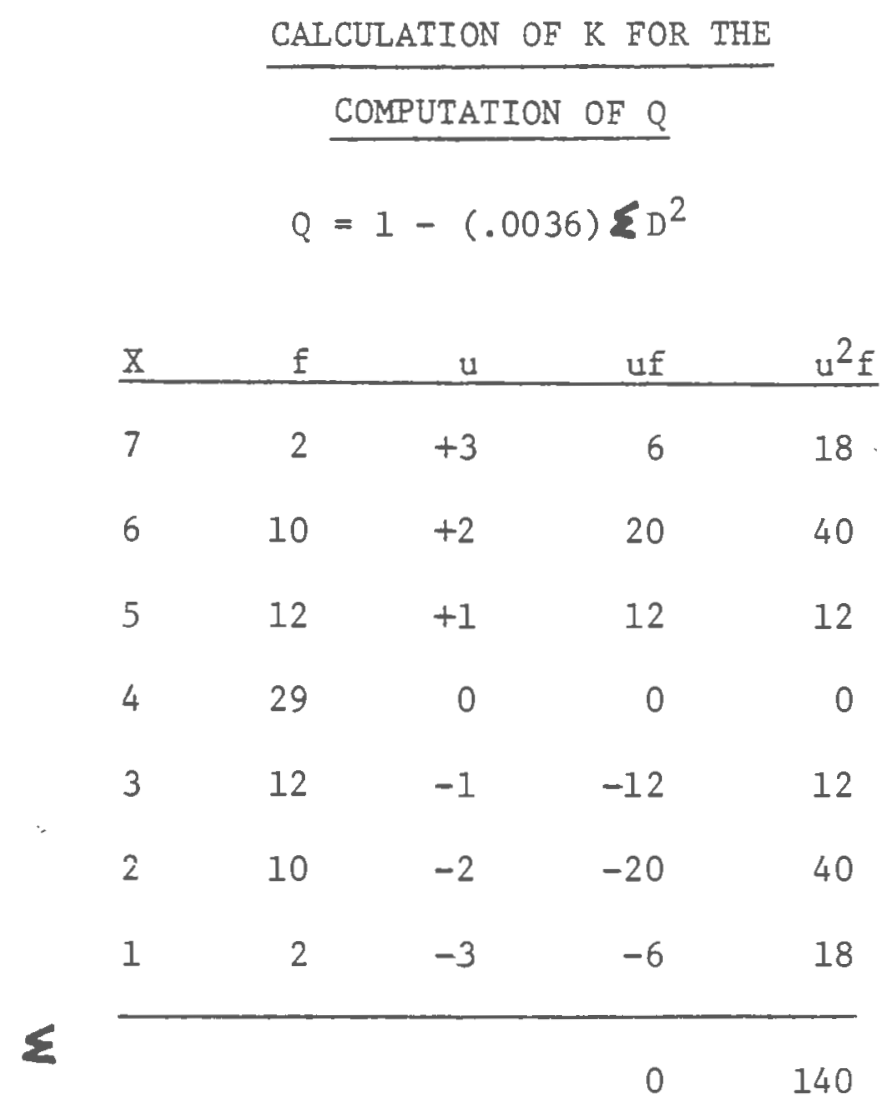

$N=77$

$$
\begin{aligned}
& Q=1-K \leqslant D^{2} \quad=\quad Q=\left[1-\frac{D^{2}}{2 N \sigma^{2}}\right] \quad \sigma^{2}=\frac{\sum u^{2} f}{N} \\
& K=\frac{1}{2 N \sigma^{2}} \\
& =\left[1-\frac{\sum D^{2}}{2(77)(1.82)}\right] \\
& =\frac{140}{77} \\
& =\frac{1}{2(77)(1.82)} \\
& =\left[1-\frac{\varepsilon D^{2}}{.0036}\right] \\
& =1.82 \\
& =\frac{1}{(154)(1.82)} \\
& =.0036
\end{aligned}
$$


APPENDIX E

CRITERION MEASURE 


\author{
Description of Scales \\ Personality Research Form
}

Description of High Scorer (with Defining Adjectives)

Achievement

Exhibition

Harmavoidance

Order
Aspires to accomplish difficult tasks; maintains high standards and is willing to work toward distant goals; responds positively to competition; willing to put forth effort to attain excellence.

striving, accomplishing, capable, purposeful, attaining, industrious, achieving, aspiring, enterprising, self-impoving, productive, driving, ambitious, resourcefu1, competitive

Wants to be the center of attention; enjoys having an audience; engages in behavior which wins the notice of others; may enjoy being dramatic or witty.

colorful, entertaining, unusual, spellbinding, exhibitionistic, conspicuous, noticeable, expressive, ostentatious, immodest, demonstrative, flashy, dramatic, pretentious, showy

Does not enjoy exciting activities; especially if danger is involved; avoids risk of bodily harm; seeks to maximize personal safety.

fearful, withdraws from danger, self-protecting, pain-avoidant, careful, cautious, seeks safety, timorous, apprehensive, precautionary, unadventurous, avoids risks, attentive to danger, stays out of harm's way, vigilant

Concerned with keeping personal effects and surroundings neat and organized; dislikes clutter, confusion, lack of organization; interested in developing methods for keeping materials methodically organized.

neat, organized, tidy, systematic, we11-ordered, disciplined, prompt, consistent, orderly, clean, methodical, scheduled, planful, unvarying, deliberate 
Social Recognition Desires to be held in high esteem by acquaintances; concerned about reputation and what other people think of him; works for the approval and recognition of others.

approval seeking, proper, well-behaved, seeks recognition, courteous, makes good impression, seeks respectability, accommodating, socially proper, seeks admiration, obliging, agreeable, socially sensitive, desirous of credit, behaves appropriately

(Jackson, 1968; 1974) 
American Psychological Association, Inc. Standards for Educational and Psychological Tests. Washington, D. C., 1974.

American Society for Testing Materials. Standard Method of Specifying Color by the Munsell System. Philadelphia, 1974. (Designation D153568)

Anastasi, A. Psychological Testing. (4th ed.) New York: Macmillan Publishing Co., Inc., 1976.

Atkinson, J. W. (Ed.) Motives in Fantasy, Action, and Society. Princeton, New Jersey: Van Nostrand, 1958.

Atkinson, J. W. and Feather, N. T., et al. A Theory of Achievement Motivation. New York: Wiley, 1966.

Baker, K. H. "Item validity by analyses of variance: an outline of method." Psychological Record, 1939, 3, 242-248.

Baker, K. H. and Guilford, J. P. Psychometric Methods. (2nd ed.) New York: McGraw-Hill Book Company, 1954.

Baron, M. "Linkage between an $\mathrm{x}$-chromosome marker (deutan color blindness) and bipolar affective illness." Archives of General Psychiatry, 1977, 34, 721-725.

Barrett, D. M. and Eaton, E. B. "Preference for color or tint and some related test data." Journal of Personality, 1947, 15, 222-232.

Beck, J. "The perception of surface color." Scientific American, 1975 $\underline{233}, 62-75$.

Birren, F. Color: A Survey in Words and Pictures. New York: University Books, Inc., 1963.

Borislow, B. "The Edwards Personal Preference Schedule and fakability." Journal of Applied Psychology, 1958, 42, 22-27.

Bradford, E. J. "Note on relation and aesthetic value of the perception types in color appreciation." American Journal of Psychology, $1913, \underline{24}, 544$.

Brehmer, I. "A study of the reliability of the Color Pyramid Test." Psychological Research, 1960, 109-118.

Cerbus, G. and Nichols, R. C. "Personality variables and response to color." Psychological Bulletin, 1963, 60, 566-575. 
Chandler, A. R. "Recent experiments on visual aesthetics." Psychological Bulletin, 1928, 24, 720-732.

Cohen, J. "Experimentelle untersuchungen uber die gefuhlsbetonung der farben, helligkeiten, und ihrer combinationen." cited in Major, B. S. "On the affective tone of simple sense impressions":" American Journal of Psychology, 1895, 7, 57-77.

Cook, B. F. "An approach to use of color on the Rorschach through individual color preferences." Journal of Projective Techniques and Personality Assessment, $1967,31,48-53$.

Cooley W. W. and Lohnes, P. R. Multivariate Data Analysis. New York: Wiley, 1971.

Corah, M. L., et al. "Social desirability as a variable in the Edwards Personal Preference Schedule." Journal of Consulting Psychology, $1958, \underline{22}, 70-72$.

DiCaprio, N. S. Personality Theories, Guides to Living. Philadelphia: W. B. Saunders Co., 1974 .

DIN-Farbenkarte DIN 6164. (Beuth-Vertrieb, Berlin, 1962)

Donnelly, F. A. "The Luscher Color Test: reliability and selection preferences by college students." Psychological Reports, 1974, 34, 635-638.

Donnelly, F. A. "The Luscher Color Test: a validity study." Perceptual and Motor Skills, 1977, 44, 17-18.

Dorcus, R. M. "Color preferences and color associations." Ped. Sem., 1926, 399-434.

Dubrovner, R. J., VonLackum, W. J., and Jost, H. "A study of the effect of color on productivity and reaction time in the Rorschach test." Journal of Clinical Psychology, 1950, 6, 331-336.

Dvorine, I. Manual: Dvorine Pseudo-Isochromatic Plates. New York: Scientific Publishers Company, 1944; 1955.

Edwards, A. L. Manual: Edwards Personal Preference Schedule. New York: The Psychological Corporation, 1954.

Ellis, H. "The psychology of red." Popular Science Monthly, AugustSeptember $1900,365,375$.

Ellis H. "The psychology of yellow." Popular Science Monthly, 1906, 68, 456-463.

Engleman, L. "P2M, Cluster Analysis of Cases" BMDP Biomedical Computer Programs. Los Angeles, Calif.: University of California Press, 1977. 
Eysenck, H. J. "A critical and experimental study of color preferences." American Journal of Psychology, 1941, 54, 385-394.

Eysenck, H. J. "Personality factors and preference judgments." Nature, $1941,148,346$.

Eysenck, H. J. "Type factors in aesthetic judgments." British Journal of Psychology, 1941, 31, 262-270.

Farnsworth, D. "The Farnworth-Munsel1 100-hue and Dichotomous Test for color vision." Journal of the Optical Society of America, 1943, 46, 389-393.

Farnsworth, D. Manual: The Farnsworth Dichotomous Test for Color Blindness: Panel D-15. New York: The Psychological Corp., 1947.

Farnsworth, D. Manual: The Farnworth-Munsel1 100-Hue Test for the Examination of Color Discrimination. Baltimore, Maryland: Munsel1 Color Company, 1945; 1957.

Farnsworth, P. R. and Chichizola, T. L. "Color preferences in terms of sigma units." American Journal of Psychology, 1930, 43, 631.

Fiske, D. W. "Can a personality construct be validated emperically?" Psychological Bulletin, 1973, 80, 89-92.

Frank, G. "On the validity of hypotheses derived from the Rorschach: I. The relationship between color and affect." Perceptual and Motor Skills, 1976, $\underline{43}$, 411-427.

Franklin, C. L. Color and Color Theories. New York: Harcourt Brace, 1929.

Gardner, E. Fundamentals of Neurology: A Psychophysiological Approach. (6th ed.) Philadelphia: W. B. Saunders Co., 1975.

Gerard, R. "Differential effects of colored lights on psychophysiological functions." Unpublished dissertation. cited in Jacobs, K. W. and Suess, J. F. "Effects of four psychological primary colors on anxiety state." Perceptual and Motor Skills, 1975, 41, 207-210.

Gilchrist, A. L. "The perception of surface blacks and whites." Scientific American, 1979, 240,

Goldfried, M. R., Stricker, G., and Weiner, I. R. Rorschach Handbook of Clinical and Research Applications. Englewood Cliffs, New Jersey: Prentice-Hall, 1971.

Goldman, L. Applications of the Laser. Ohio: CRC Press, 1973. 
Goldstein, K. "Some experimental observations concerning the influence of colors on the function of the organism." Occupational Therapy, $1942,21,147-151$.

Goodman, H. W. "An experimental investigation of the affective value of color in the Rorschach test." American Psychologist, 1950, 5, 321-322.

Gotz, K. 0. and Gotz, K. "Introversion-extraversion and neuroticism in gifted and ungiften art students." Perceptual and Motor Skills, $1973,36,675-678$.

Gotz, K. O. and Gotz, K. "Color preferences of art students: surface colors I." Perceptual and Motor Skills, 1974, 39, 1103-1109.

Gotz, K. 0. and Gotz, K. "Color preferences of art students: surface colors II." Perceptual and Motor Skills, 1975, 41, 271-278.

Gotz, K. O. and Gotz, K. "Color preferences, extraversion and neuroticism of art students." Perceptua1 and Motor Skills, 1975, 41, 919-930.

Gough, H. G. "The Adjective Check List as a personality assessment research technique." Psychological Reports, 1960, 6, 107-122.

Gough, H. G. and Heilbrun, A. B. Manual: The Adjective Check List. Palo Alto, Calif.: Consulting Psychologists Press, 1972.

Guilford, J. P. "A study in psychodynamics." Psychometrika, 1939, 4, $1-21$.

Guilford, J. P. "There is a system in color preferences." Journal of the Optical Society of America, 1940, 30, 355-359.

Guilford, J. P. and Smith, P. C. "A system of color preferences." American Journal of Psychology, 1959, 72, 487-502.

Haber, A. and Runyon, R. P. General Statistics. (2nd ed.) Reading, Mass.: Addison-Wesley Publishing Co., 1974.

Hardy, L. H., Rand, G. and Rittler, M. C. "Tests for the detection and analysis of color blindness. I. The Ishihara Test: an evaluation." Journal of the Optical Society of America, 35, 268275.

Hardy, L. H., Rand, G. and Rittler, M. C. Manual: AO-HRR PseudoIsochromatic Plates for Detecting, Classifying, and Estimating the Degree of Defective Color Vision. Sourthbridge, Mass.: American Optical Co., 1957.

Heiss, R. and Hiltmann, H. The Color Pyramid Test. Bern, Switzerland: Hans Huber Publishers, 1951. 
Hevner, K. "Experimental studies of the affective value of colors and lines." Journal of Applied Psychology, 1935, 19, 385-398.

Hilgard, C. R, Atkinson, R. C. and Atkinson, R. L. Introduction to Psychology. (6th ed.) New York: Harcourt, Brace, Jovanovich, 1975.

Hill, E. F. "Affect aroused by color, a function of stimulus strength." Journal of Projective Techniques and Personality Assessment, 1966, 30, 23-30.

Hotelling, H. "Aralysis of a complex of statistical variables into principal components." Journal of Educational Psychology, $1933,24,417-441,498-520$.

Hube1, D. H. and Wiesel, T. N. "Receptive fields and functional architecture in two non-striate visual areas (18 and 19) of the cat." Journal of Neurophysiology, 1965, 28, 229-289.

Hurvich, L. M. Color Vision Deficiencies. (Color vision symposium conducted at the Spring meeting, 1971) Washington, D. C.: National Academy of Sciences, 1973.

Ishihara, S. Tests for Colour-blindness. (10th ed.) Japan: Nippon Isho Suppan Co., 1951.

Jackson, D. N. "Multi-method factor analysis in the analysis of convergent and discriminant validity." (Society for Multivariate Experimental Psychology) Atlanta, Georgia: paper read in 1966. cited in Jackson, D. N. Manual: Personality Research Form. Goshen, New York: Research Psychologists Press, 1968; 1974.

Jackson, D. N. Manual: Personality Research Form. Goshen, N. Y.: Research Psychologists Press, 1968; 1974.

Jackson, D. N. "A sequential system for personality scale development." in Spielberged, C. D. (Ed.). Current Topics in Clinical and Community Psychology. New York: Academic Press, 1970, 2, 61-96.

Jackson, D. N. and Guthrie, G. M. "A multitrait-multimethod evaluation of the Personality Research Form." Proceedings of the 76th Annual Convention of the American Psychological Association, 1968, 177-178.

Jacobs, K. W. and Hustmyer, F. E. "Effects of four psychological primary colors on GSR, heart rate, and respiration rate." Perceptual and Motor Skills, 1974, 38, 763-766.

Jacobs, K. W. and Suess, J. F. "Effects of four psychological primary colors on anxiety state." Perceptual and Motor Skills, 1975, 41, 207-210. 
Jolas, G. "Test-retest experiments with the Color Pyramid Test." cited in Schaie, K. W. "The Color Pyramid Test." Psychological Bulletin, 1963, 60, 530-547.

Judd, D. B. "A Maxwell triangle yielding uniform chromaticity scales." Journal of the Optical Society of America, 1935, 25, 24.

Judd, D. B. and Wyszecki, G. Color in Business, Science, and Industry. (3rd ed.) New York: John Wiley and Sons, 1975.

Kaiser, H. F. "The varimax criterion for analytic rotation in factor analysis." Psychometrika, 1958, 23, 187.

Kaiser, H. F. "A second generation little jiggy." Psychometrika, 1970, 35, 401 .

Keehn, J. D. "A re-interpretation of the role played by colour in the Rorschach test." British Journal of Medical Psychology, 1954, 27, 89-93.

Keehn, J. D. "The response to color and ego functions: a critique in light of recent experimental evidence." Psychological Bulletin, 1954, 51, 65-67.

Kries, V., cited in Helmholtz, H. L. (J.P.C. Southall, translation). Treatise on Physiological Optics. New York: Optical Society of America, 1924.

Kuppers, H. Color: Origin, Systems, Uses. New York: Van Nostrand, 1973.

Kusyszyn, I. A. "A comparison of judgmental methods with endorsements in the assessment of personality traits." Journal of Applied Psychology, 1968, 52, 227-233.

Lakowski, R. "The Farnsworth-Munse11 100-hue Test." Ohtha1. Optician, 1968, ㅇ, 862-872.

Lakowski, R. "Theory and practice of colour vision testing: a review. Part I" British Journal of Industrial Medicine, 1969, 26, 173-189.

Lakowski, R. "Theory and practice of colour vision testing: a review. Part II" British Journal of Industrial Medicine, 1969, 26, $265 f f$.

Lakowski, R. "The Pickford-Nicolson anomaloscope as a test for acquired dyschromatopsias." International symposium on acquired colour vision deficiencies, Ghent 1971, in Modern Problems Ophthal., 11, 25-33. (Basel: Karger, 1972) 
Land, E. H. "Color vision and the natural image." (Part I) Proceedings of the National Academy of Sciences, 1959, 45, 115-129.

Land, E. H. "Color vision and the natural image." (Part II) Proceedings of the National Academy of Sciences, 1959, 45, 636-644.

Land, E. H. "The retinex theory of color vision." Scientific American, $1977,237,108-128$.

Land, E. H. and McCann, J. J. "Lightness and retinex theory." Journal of the Optical Society of America, $1971,61,1-11$.

Land, M. "Animal eyes with mirror optics." Scientific American, 1978, 239, $126-134$.

Lanyon, R. I. and Goodstein, L. D. Personality Assessment. New York: John Wiley and Sons, Inc., 1971.

Lee, S. G. "The Luscher Color Test." in Buros, 0. K. (Ed.) The Seventh Mental.Measurements Yearbook. Highland Park, New Jersey: Gryphon Press, 1970.

Levy, J. R. "Changes in the galvanic skin response accompanying the Rorschach test." Journal of Consulting Psychology, 1950, 14, 128-133.

Lewinski, R. J. "An investigation of individual responses to chromatic illumination." Journa1 of Psychology, 1938, 6, 155-166.

Luscher, M. The Luscher Color Test. New York: Pocket Book, 1971.

Luscher, M. and Scott, I. A. The Luscher Color Test. New York: Random House, 1969.

Major, D. R. "On the affective tone of simple sense impressions." American Journal of Psychology, 1895, 7, 57-77.

Malone, D. R. and Hannay, H. J. "The Farnsworth-Munsell 100-Hue Test: a question of norms." Perceptual and Motor Skills, 1977, 44, 1249-1250.

Marre, M., Neubauer, O. and Nemetz, A. "Colour vision and the pill." Colour Vision Deficiencies II. International symposium in Edinburgh. Verriest, G. (Ed.) Modern Problems Ophthal, 1973, $13,345-348$.

McCann, J. J. and Benton, J. L. "Interaction of the long-wave cones and the rods to produce color sensations." Journal of the Optical Society of America, 1969, 59, 103-107.

McClelland, D. C., Atkinson, J. W., Clark, R. A., and Lowell, E. L. The Achievement Motive. New York: Appleton-Century Crofts, 1953. 
Megargee, E. I. and Parker, G. V. "An exploration of the equivalence of Murrayan needs as assessed by the Adjective Check List, the TAT, and the Edwards Personal Preference Schedule." Journal of Clinical Psychology, 1968, 24, 47-51.

Mendlewicz, J. and Fleiss, J. L. "Linkage studies with $\mathrm{x}$-chromosome markers in bipolar and unipolar illness." Biological Psychiatry, $1974, \underline{9}, 261-294$.

Mische1, W. Personality and Assessment. New York: Wiley, 1968.

Munse11, A. H. A Color Notation. (12th ed.) Baltimore, Maryland: Munsell Color Company, Inc., 1946.

Munsell Color Company, Inc. Munsell Color Book. Baltimore, Maryland: Munsel1 Color Company (Kollmorgen Corp.), 1978.

Murray, H. A. Explorations in Personality. New York: Oxford Univ. Press, 1938 .

Murray, H. A. "Some basic psychological assumptions and conceptions." Dialectia, 1951, 5, 266-292.

Murray, H. A. Toward a Classification of Interaction. Philadelphia: W. B. Saunders Co., 1974 .

Murray, H. A. Preparations for the Scaffold of a Comprehensive System. Philadelphia: W. B. Saunders Co., 1974.

Murray, H. A. and Kluckhohn, C. Outline of a Conception of Personality. Philadelphia: W. B. Saunders Co., 1974.

Newhal1, R., Nickerson, D., and Judd, D. "Final report of the OSA subcommittee on the spacing of Munsell colors." Journal of the Optical Society of America, 1943, 33, 385.

Nickerson, D. "History of the Munsell color system and its scientific application." Journal of the Optical Society of America, 1940, 30, 575 .

Norris. C., Twiss, R., and Washburn, W. "An effect of fatigue on judgments of the affective value of colors." American Journal of Psychology, 1911, 22, 112-114.

Optical Society of America. (Committee on Colorimetry) The Science of Color. (3rd ed.) Washington, D. C.: Optical Society of America, 1963.

Padgham, C. A. and Saunders, J. E. The Perception of Light and Colour. New York: Academic Press, 1975. 
Pickford, R. W. and Lakowski, R. "The Pickford-Nicolson anomaloscope." British Journal of Physiological Optics, 1960, 17, 131 .

Pflanz, M. "On pharmacological methodology." cited in Schaie, K. W. "The Color Pyramid Test." Psychological Bulletin, 1963, 60, $530-547$.

Poulsen, A. D. "Acquired dyschromatopsias." Modern Problems Ophthal., G. Verriest (Ed.), 1971, 11, 84-93.

Pribram, K. cited in Goldman, D. "Holographic memory." Psychology Today, $1979,12,70 f f$.

Rainwater, C. Light and Color. Racine, Wisconsin: Western Publishing Co., Inc., 1971.

Reich, T., Clayton, P., and Winokur, G. "Family history studies: V. the genetics of mania." American Journal of Psychiatry, 1969, $125,1358-1369$.

Rorschach, H. Psychodiagnostics. New York: Grune and Stratton, 1942 .

Rothima, A. "Le test 28 hue selon Farnsworth." Bulletin Soc. Ophtha1., France, 1966, 66, 231-238. cited in Poulsen, A. "Acquired dyschromatopsias." Modern Problems Ophthal., G. Verriest (Ed.), 11 , 84-93.

Rushton, W. A. "Chemical basis of human color vision." Research, 1958, 11, 478-483.

Rushton, W. A. "A cone pigment in the protanope." Journal of Physiology, 1965, 168, 345-359.

Rushton, W. A. "A foveal pigment in the deuteranope." Journal of Physiology, 1965, 176, 24-27.

Rushton, W. H., Powel1, D. S., and White, K. D. "Anomalous pigments in the eyes of the red-green colour blind." Nature, 1973, 243, 167-168.

Schaie, K. W. "A Q-sort study of color-mood association." Journal of Projective Techniques and Personality Assessment, 1960,25 , 341-347.

Schaie, K. W. "The Color Pyramid Test: a nonverbal technique for personality assessment." Psychological Bulletin, 1963, 60, 530-547. 
Schaie, K. W. "On the relation of color and personality." Journal of Projective Techniques and Personality Assessment, 1966, 30, 512-524.

Schaie, K. W. and Heiss, R. Color and Personality: A Manual for the Color Pyramid Test. Berne, Switzerland: Hans Huber Publishers, 1964.

Schiffman, H. R. Sensation and Perception: An Integrated Approach. New York: John Wiley and Sons, Inc., 1976.

Schmidt, F. L. "The relative efficiency of regression and simple unit predictor weights in applied differential psychology." Educational and Psychological Measurements, 1971, 31, 699ff.

Schultz, D. Theories of Personality. Monterey, California: Wadsworth Publishing Co., 1976.

Siess, T. F. and Jackson, D. N. "A personological approach to the interpretation of vocational interests." Proceedings for the 75th Annual Convention of the American Psychological Association, $1967,353-354$.

Sivik, L. "Measuring the meaning of colors: reliability and stability." Sweeden: Goteborg Psychological Reports, 1974, 4, 14.

Spielberger, C. D., Gorsuch, R. L., and Lushene, R. E. Manual: The State-Trait Anxiety Inventory. Palo Alto, California: Consulting Psychologists Press, 1970.

Stephenson, W. "Correlating persons instead of tests." Character and Personality, 1935, 4, 17-24.

Stephenson, W. A Study of Behavior. Chicago: University of Chicago Press, 1953.

Stewart, K. and Love, W. A. "A general canonical correlation index." Psychological Bulletin, 1968, 70, 160-168.

Sundberg, N. D. Assessment of Persons. New Jersey: Prentice-Hall, 1977.

Time, Inc., C. G. Mueller (Ed.). Light and Vision. New York: Time, Inc., 1966.

Tokyo Medical College. Tokyo Medical College Color Vision Test. Tokyo, Japan: Murakami Color Research Laboratory, 1957.

Umazume, K. and Harutake, M. "Tokyo Medical College Color Vision Test." Farbe, 1962, 11, 45-47. 
Valentine, C. W. "The color perception and color preferences of an infant during its 4 th and 8th months." British Journal of Psychology, 1914, 6, 363.

Velicer, W. F. "Determining the number of components from the matrix of partial correlations." Psychometrika, 1976, 41, 321-327.

Veroff, J., Atkinson, J.W., Feld, S. C., and Gurin, G. "The use of thematic apperception to assess motivation in a nationwide interview study." cited in J. W. Atkinson and J. 0. Raynor et al. Motivation and Achievement. Washington, D. C.: Wiley, 1974.

Verriest, G., Vandevyvere, R., and Vanderdonck, R. "Nouvelle recherches se rapportant a I'influence du sexe et de I'age sur la discrimination chromatique aninsi qu'a la significahon pratique des resultats du test 100 hue de Farnsworth-Munsell." Rev. Opt., 1962, 41, 499-509. cited in Poulsen, A. D. "Acquired dischromatopsias." Modern Problems Ophthal., G. Verriest (Ed.), 1971, 11, 84-93.

Verriest, G. "Les deficences acquises de la discrimination chromatique." Mem. Acad. Roy. Med. Belg., 1964, 4, 35-327. cited in Lakowski, R. "Theory and practice of colour vision testing: a review. Part II" British Journal of Industrial Medicine, $1969,27,265 f f$.

Verriest, G. (Ed.) "Colour vision deficiencies II" Modern Problems Ophtha1., 1974, 13, Basel: S. Karger, 1974.

Wackwitz, J. H. and Horn, J. L. "On obtaining the best estimates of factor scores within an ideal simple structure." Multivariate Behavioral Research, 1971, 6, 389.

Warner, S. J. "The color preferences of psychiatric groups." Psychological Monographs, 1949, 63, 1-25.

Weale, R. A. cited in LeGrand, Y. "About the photopigments of colour vision." G. Verriest (Ed.). Modern Problems Ophtal., 1971, 11, 186-192.

Wilson, G. D. "Arousal properties of red vs. green." Perceptual and Motor Skills, 1966, 23, 947-949.

Wright, W. D. "A survey of methods used in examining macular colour vision." G. Verries (Ed.) Modern Problems Ophtal., 1971, 11, 2-11.

Yariv, A. "Guided-wave optics." Scientific American, 1979, 240, 64-72.

Young, J. Z. Programs of the Brain. London: Oxford Union Press, 1978. 